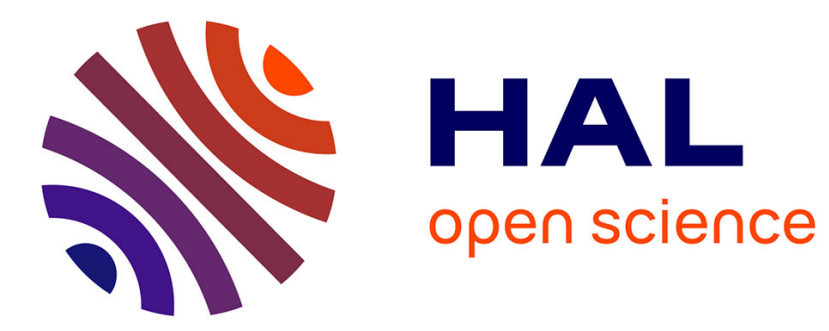

\title{
Is Modeling the PSD in Emulsion Polymerization a Finished Problem? An Overview
}

Nida Sheibat-Othman, Hugo M. Vale, Jordan M. Pohn, Timothy F. L. Mckenna

\section{- To cite this version:}

Nida Sheibat-Othman, Hugo M. Vale, Jordan M. Pohn, Timothy F. L. Mckenna. Is Modeling the PSD in Emulsion Polymerization a Finished Problem? An Overview. Macromolecular Reaction Engineering, 2017, 11 (5), pp.1600059. 10.1002/mren.201600059 . hal-01872869

\section{HAL Id: hal-01872869 https://hal.science/hal-01872869}

Submitted on 6 Dec 2020

HAL is a multi-disciplinary open access archive for the deposit and dissemination of scientific research documents, whether they are published or not. The documents may come from teaching and research institutions in France or abroad, or from public or private research centers.
L'archive ouverte pluridisciplinaire HAL, est destinée au dépôt et à la diffusion de documents scientifiques de niveau recherche, publiés ou non, émanant des établissements d'enseignement et de recherche français ou étrangers, des laboratoires publics ou privés. 


\title{
Is Modeling the PSD in Emulsion Polymerization a
}

\section{Finished Problem? An Overview}

\author{
Nida Sheibat-Othman ${ }^{1}$, Hugo M. Vale ${ }^{2,4}$, Jordan M. Pohn ${ }^{3,4}$, and Timothy F.L. McKenna ${ }^{3,4}$ \\ ${ }^{1}$ Univ Lyon, Université Claude Bernard Lyon 1, CNRS, LAGEP UMR 5007, F-69100, Villeurbanne, \\ France, \\ ${ }^{2}$ BASF SE, Carl-Bosch-Str. 38, 67056 Ludwigshafen, Germany, \\ ${ }^{3}$ Department of Chemical Engineering, Queen's University, Kingston, ON, Canada, \\ ${ }^{4}$ Univ Lyon, Université Claude Bernard Lyon 1, CPE Lyon, CNRS, UMR 5265, Laboratoire de \\ Chimie, Catalyse, Polymères et Procédés (C2P2) - LCPP group, Villeurbanne, France \\ E-mail: timothy.mckenna@univ-lyon1.fr, nida.othman@lagep.univ-lyon1.fr
}

\begin{abstract}
Significant progress has been made over the past twenty to thirty years in terms of our ability to develop and solve mechanistic models of emulsion polymerization processes, and in particular models for prediction of the particle size distribution (PSD). However, this does not imply that modeling of these economically important processes is by any means a 'solved problem', nor that it is no longer necessary to perform fundamental research in this area. There are a number of areas where strong scientific work would increase our understanding of the process, including events in the aqueous phase, radical entry into growing particles, monomer partitioning, and especially the mechanisms and modeling of particle coagulation.
\end{abstract}

Keywords: emulsion polymerization; modeling; particle size distribution.

\section{Introduction}

\subsection{The importance of the particle size distribution}

The development of mathematical models to describe the dynamics of emulsion polymerization (EP) systems, and in particular the evolution of the particle size distribution (PSD) is a subject of great interest. Practically speaking, the PSD is a key characteristic of an emulsion latex, as much as the composition and structure of the polymer chains. Indeed, the PSD has a strong impact on several key properties of the final product: viscosity, maximum solid content, adhesion, drying time, etc. For instance, the production of high solid content (HSC) latexes [1] usually requires a very well-defined 
PSD in order to maintain acceptable levels of viscosity. Tools to predict the influence of the polymerization conditions on the product PSD are therefore very useful.

In addition to the practical benefits of PSD modeling, there are fundamental justifications as well. Indeed, a distribution of particle sizes always develops in EP systems and certain key phenomena are notably affected by this distribution. Particle formation, in particular, is an excellent example of such class of phenomena: the dynamics of particle formation significantly depends on the full size distribution of the particles (typically broad during the initial stages of the reaction). Consequently, any coherent model of emulsion polymerization (and certainly those claiming to describe particle formation) should take the PSD into account. In other terms, one should not be constrained by the notion that PSD models are only required when the PSD is complex (i.e., not monomodal) and/or when information other than the average particle diameter and particle number is sought.

The current paper will place more emphasis on modeling the particle size distribution than other quality-related properties (e.g., MWD) in order to present the argument that this is not a 'finished' topic (despite the extensive and impressive work already done in this area). This primary focus on the PSD should not be taken to mean that other aspects, in particular the fundamentals of reaction kinetics (e.g., how/why do transfer reactions occur, an a priori description of chain termination in multicomponent systems, etc.), thermodynamics (e.g., precipitation of oligoradicals, particle swelling, again more complex in multicomponent systems, polymerization induced self-assembly, etc.), physical chemistry (e.g., mobility of surfactants on particle surface), and macromolecular architecture, that are closely related to the evolution of the PSD, are all topics that are finalized. Furthermore, we are consciously limiting ourselves to discussions of commercially important 'direct' emulsion polymerization for the specific case of conventional free radical chemistry. We should not forget that more complex emulsion polymerizations, such as inverse water-in-oil systems will exhibit different characteristics.

\subsection{Population balance models}

In order to describe the evolution of the PSD in an emulsion polymerization system mathematically, it is necessary to account for the various phenomena capable of effecting the number and diameter of the latex particles: nucleation, growth by polymerization, coagulation, monomer and surfactant partitioning, and radical kinetics. As shown by Min \& Ray[2] more than four decades ago, this can, in principle, be done with the help of population balances. Models of this kind are thus called population balance models (PBM). Particle dynamics may also be investigated from the point of view of molecular dynamics and their hydrodynamic interactions, using Stokesian dynamics or the Discrete 
Element Method.[3] However, these much more time consuming and case-specific methods are out of the scope of the present paper.

The typical structure of a detailed PBM of emulsion polymerization is illustrated in Figure 1. The particle population balance, where all the information about the PSD is contained, and the aqueousphase balances are the keystones of the model. These balances interact with all processes taking place in the reaction medium: phase-transfer events, nucleation, partitioning, coagulation, etc. This deep interdependence between phenomena is one of the main reasons why it is such a challenge to accurately describe PSD dynamics.

Some interesting reviews on the development of EP models accounting for the distributed nature of the particle phase have already been published. We can cite, for instance, the comprehensive works of Min \& Ray[2] and Saldívar et al.[4]. More recently, the use and limitations of population balance equations in the modeling of emulsion polymerization and PSD has been reviewed by Vale \& McKenna.[5]

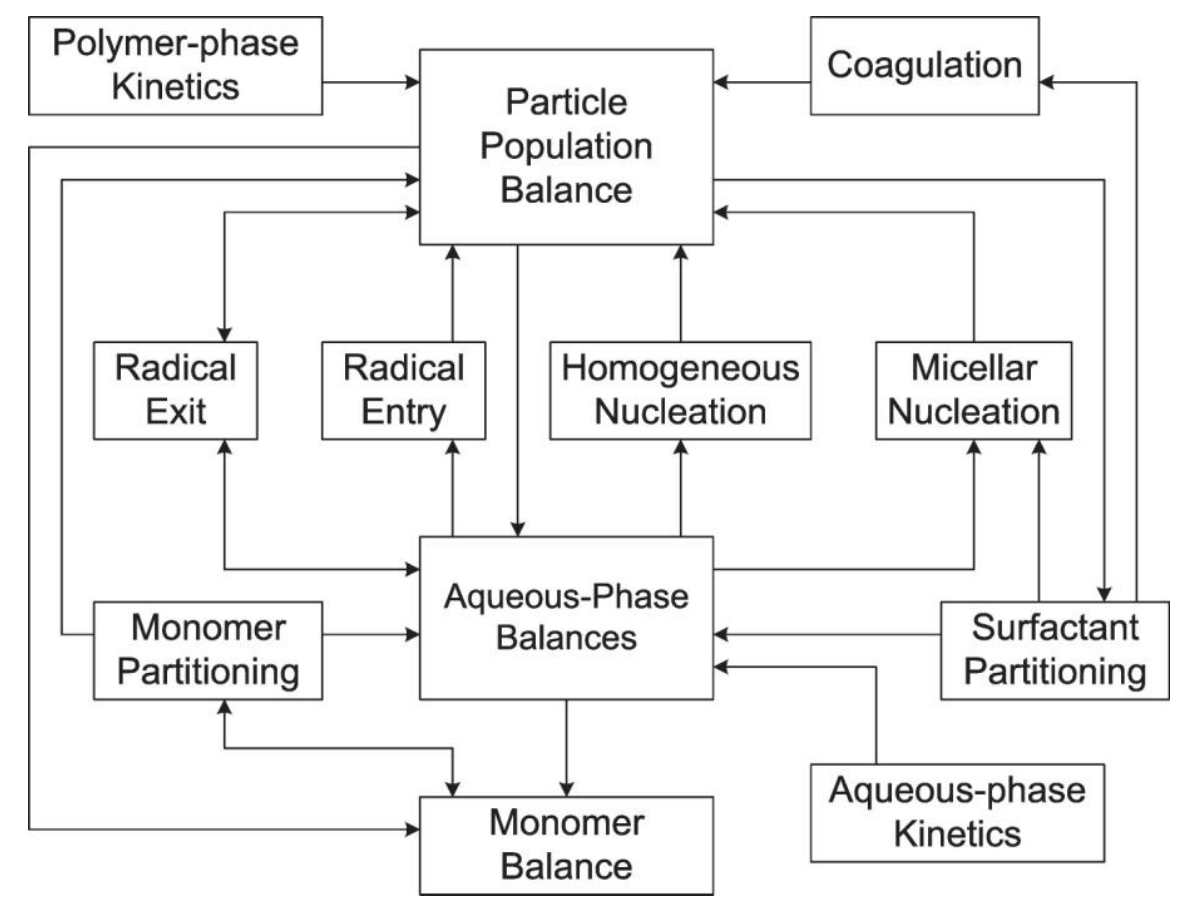

Figure 1. Typical structure of a detailed PBM of emulsion polymerization. The direction of the arrows indicates the dominant flow of information.

\subsection{PSD characterization}

Note also that the related domain of particle characterisation (important for model validation) is also important for the development of PSD models.

It is fair to say that until accurate, inexpensive devices for the measurement of the PSD that can be used in real time in situ are available, we will in fact be missing vital information required to construct 
and validate models for the evolution of the PSD. Indeed, measuring the full PSD of a polymeric dispersion is not a simple task off-line, and even more challenging on-line. Over the course of the past decade or so, several studies on the evaluation of different off-line approaches to measuring the PSD have been published. These include a study by Elizalde et al.[6] that compared capillary hydrodynamic fractionation (CHDF), disc photosedimentometry, dynamic light scattering (DLS) and TEM; and another by Schneider \& McKenna[7] who set-up a round-robin evaluation of monomodal and bimodal latexes using different DLS and static-light scattering (SLS) devices in addition to scanning electron microscopy, CHDF and field flow fractionation. A different roundrobin analysis of particle characterization, including the measurement of particle size was also carried out by Stubbs \& Sundberg.[8]

The conclusions of these studies can be summarized as follows. For monomodal (reasonably monodispersed) latexes, the average particle size of a sample measured off-line can be correctly determined by various methods (e.g., DLS), although there is some variability either from laboratory to laboratory when using the same equipment, or in a given lab when using equipment employing slightly different methods or from different manufacturers. In contrast, the analysis of multimodal latexes is far more complicated, as most techniques frequently fail in determining the average size and relative amount of each population (e.g., a small mass fraction of small particles may not be detected). In such cases, absolute measurements can only be assured by microscopic methods (e.g., TEM, cryoTEM), but these have the inconvenience of being quite expensive and time-consuming. Recently, other more immediate techniques were developed such as nanoparticle tracking analysis[9] that relies on both light scattering and Brownian motion in order to obtain the particle size distribution.

Manufacturers are of course improving the technology, and off-line measurement of the PSD is certainly more reliable at the current time than at the time the devices used in the studies reported above were carried out. Nevertheless, off-line techniques still suffer from the need to take samples from the reactor, which are then diluted and analyzed over a period of several minutes. The disadvantage of this is that when one needs to understand precisely the evolution of the PSD during steps such as the nucleation phase, where particles are highly unstable, and their number and size distribution are changing rapidly, techniques which can take at best several minutes or tens of minutes will not provide the user with a picture of what is actually in the reactor (see, e.g., Fortuny et al.[10]). Even most so-called on-line techniques are often an SLS or DLS that are connected to a reactor with automated sampling and dilution steps that help to reduce the time for analysis. 


\section{$1.4 \mathrm{Goal}$}

In the current work, we focus on issues that still need to be addressed in order to be able to model the PSD with confidence. Nevertheless, the topics discussed briefly above show the importance of understanding the fundamental mechanisms of EP including aqueous phase reactions and transfer between the phases (of radicals, monomer and surfactant) as well as particle formation (nucleation and coagulation) in order to develop the equations that need to be solved. For each of these subjects, we will present a rapid overview of the state of the art and summarize the proposed models, highlighting the areas where progress needs to be made, either to arrive at a consensus of conflicting viewpoints or simply to deepen our current knowledge of the system. The reader is assumed to have already basic knowledge of the mechanism of EP.

\section{The (Right) Particle Population Balances}

As depicted in Figure 1, the particle population balance equation (PBE) is the central element of a PSD model. It is thus natural to start by taking a brief look at the formulation of PBEs for EP systems and, especially, at the associated applicability conditions.

In an emulsion polymerization, the latex particles can be described using a set of states or internal coordinates: particle size, number of radicals per particle and chain length of the radicals (in order to account for chain-length-dependent termination).

In practice, however, the use of three internal coordinates yields an intractable multidimensional PBE. To reduce the dimensionality of the PBE to particle size only, one of two approximations (to the corresponding kinetic limits) will commonly be employed: the zero-one (0-1) model or the pseudobulk (PB) model (cf. Table 1; the meaning of all symbols is explained in Notation). Unfortunately, the conditions under which these approximations are valid are not always met. This problem is addressed in the following sections. Mathematical details on the various PBEs and associated numerical resolution methods can be found in Vale \& McKenna[5], [11] and references cited therein. 
Table 1. Overview of alternative population balance model formulations

General equation of the PBM, by volume

$\frac{\partial}{\partial t} \mathbf{f}(v, t)=-\frac{\partial}{\partial v}[\dot{\boldsymbol{v}}(t) \boldsymbol{f}(v, t)]+\mathbf{s}(\boldsymbol{f}, v, t)$

with: $\mathbf{s}(\boldsymbol{f}, v, t)=\mathbf{R}(v, t) \boldsymbol{f}(v, t)+\mathbf{a}(\boldsymbol{f}, v, t)+\frac{1}{\theta^{\text {in }}} \boldsymbol{f}^{\text {in }}(v, t)-\left(\frac{1}{\theta^{\text {out }}}+\frac{\dot{V}^{\mathrm{w}}}{V^{\mathrm{w}}}\right) \boldsymbol{f}(v, t)+\mathbf{n} \delta\left(v-v_{\text {nuc }}\right) R_{\text {nuc }}(t)$

$K=\frac{k_{\mathrm{p}}[\mathrm{M}]_{\mathrm{p}} M_{\mathrm{M}}}{N_{\mathrm{A}} \rho_{\mathrm{p}}}, f=\sum \boldsymbol{f}$

$\underline{0-1 \text { Model }}$

$\mathbf{f}=\left[\begin{array}{lll}f_{0} & f_{1 \mathrm{p}} & f_{1 \mathrm{~m}}\end{array}\right]^{\mathrm{T}}, f_{1}=f_{1 \mathrm{p}}+f_{1 \mathrm{~m}}$

$\dot{\boldsymbol{v}}=K\left[\begin{array}{lll}0 & 1 & 0\end{array}\right]$

$\mathbf{R}=\left[\begin{array}{ccc}-\rho & \rho & \rho+k_{0} \\ \rho_{\mathrm{I}} & -\rho-k_{\mathrm{fM}}[\mathrm{M}]_{\mathrm{P}} & k_{\mathrm{p}}^{\prime}[\mathrm{M}]_{\mathrm{P}} \\ \rho_{\mathrm{E}} & k_{\mathrm{fM}}[\mathrm{M}]_{\mathrm{P}} & -\rho-k_{0}-k_{\mathrm{p}}^{\prime}[\mathrm{M}]_{\mathrm{P}}\end{array}\right]$

$\mathbf{a}=\left[\begin{array}{cc}\frac{1}{2} \int_{v_{\text {nuc }}}^{v-v_{\text {nuc }}} & \beta\left(v-v^{\prime}, v^{\prime}\right)\left[f_{0}\left(v-v^{\prime}\right) f_{0}\left(v^{\prime}\right)+f_{1}\left(v-v^{\prime}\right) f_{1}\left(v^{\prime}\right)\right] d v^{\prime}-f_{0}(v) \int_{v_{\text {nuc }}}^{\infty} \beta\left(v, v^{\prime}\right) f\left(v^{\prime}\right) d v^{\prime} \\ & \int_{v_{\text {nuc }}}^{v-v_{\text {nuc }}} \beta\left(v-v^{\prime}, v^{\prime}\right) f_{0}\left(v-v^{\prime}\right) f_{1 \mathrm{p}}\left(v^{\prime}\right) d v^{\prime}-f_{1 \mathrm{p}}(v) \int_{v_{\text {nuc }}}^{\infty} \beta\left(v, v^{\prime}\right) f\left(v^{\prime}\right) d v^{\prime} \\ & \int_{v_{\text {nuc }}}^{v-v_{\text {nuc }}} \beta\left(v-v^{\prime}, v^{\prime}\right) f_{0}\left(v-v^{\prime}\right) f_{1 \mathrm{~m}}\left(v^{\prime}\right) d v^{\prime}-f_{1 \mathrm{~m}}(v) \int_{v_{\text {nuc }}}^{\infty} \beta\left(v, v^{\prime}\right) f\left(v^{\prime}\right) d v^{\prime}\end{array}\right]$

$\mathbf{n}=\left[\begin{array}{lll}0 & 1 & 0\end{array}\right]^{\mathrm{T}}$

$\bar{n}(r, t)=\left(f_{1 \mathrm{p}}+f_{1 \mathrm{~m}}\right) / f$

0-1-2 Model

$\begin{aligned} \mathbf{f} & =\left[\begin{array}{lll}f_{0} & f_{1} & f_{2}\end{array}\right]^{\mathrm{T}} \\ \boldsymbol{v} & =K\left[\begin{array}{lll}0 & 1 & 2\end{array}\right] \\ \mathbf{R} & =\left[\begin{array}{ccc}-\rho & k_{\mathrm{des}} & 2 c \\ \rho & -\rho-k_{\mathrm{des}} & \rho+2 k_{\mathrm{des}} \\ 0 & \rho & -\rho-2 k_{\mathrm{des}}-2 c\end{array}\right]\end{aligned}$

a

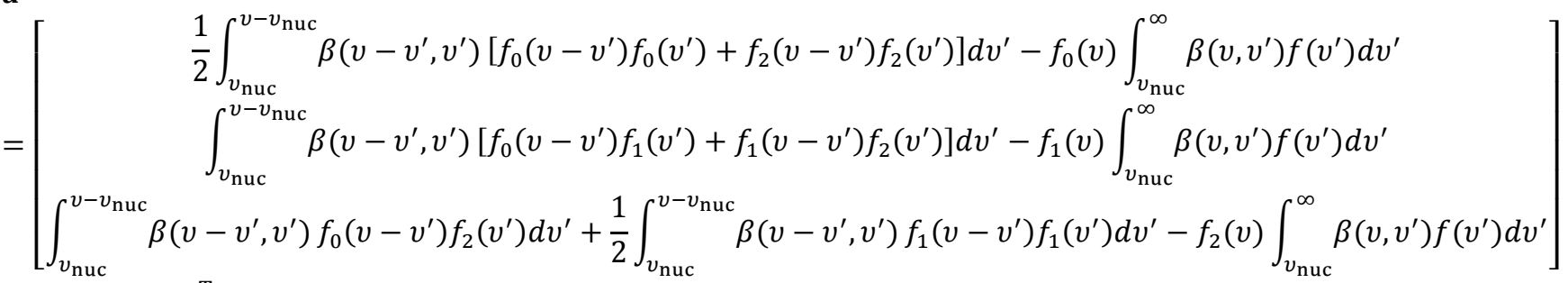

$\mathbf{n}=\left[\begin{array}{lll}0 & 1 & 0\end{array}\right]^{\mathrm{T}}$

$\bar{n}(v, t)=\left(f_{1}+2 f_{2}\right) / f$

\section{PB Model}

$\mathbf{f}=f$

$\dot{\boldsymbol{v}}=K \bar{n}$

$\mathbf{R}=0$

$\mathbf{a}=\frac{1}{2} \int_{v_{\text {nuc }}}^{v-v_{\text {nuc }}} \beta\left(v-v^{\prime}, v^{\prime}\right) f\left(v-v^{\prime}\right) f\left(v^{\prime}\right) d v^{\prime}-f(v) \int_{v_{\text {nuc }}}^{\infty} \beta\left(v, v^{\prime}\right) f\left(v^{\prime}\right) d v^{\prime}$

$\mathbf{n}=1$

$\bar{n}(v, t)=$ cf. Section 2.2

0-1-S model

$\mathbf{f}=\left[\begin{array}{ll}f_{0} & f_{1}\end{array}\right]^{\mathrm{T}}, f_{1}=f_{1 \mathrm{p}}+f_{1 \mathrm{~m}}$

$\dot{\boldsymbol{v}}=K\left[\begin{array}{ll}0 & 1\end{array}\right]$

$\mathbf{R}=\left[\begin{array}{cc}-\rho & \rho+k_{\mathrm{des}} \\ \rho & -\rho-k_{\mathrm{des}}\end{array}\right]$

$\mathbf{a}=\left[\begin{array}{c}\frac{1}{2} \int_{v_{\text {nuc }}}^{v-v_{\text {nuc }}} \beta\left(v-v^{\prime}, v^{\prime}\right)\left[f_{0}\left(v-v^{\prime}\right) f_{0}\left(v^{\prime}\right)+f_{1}\left(v-v^{\prime}\right) f_{1}\left(v^{\prime}\right)\right] d v^{\prime}-f_{0}(v) \int_{v_{\text {nuc }}}^{\infty} \beta\left(v, v^{\prime}\right) f\left(v^{\prime}\right) d v^{\prime} \\ \int_{v_{\text {nuc }}}^{v-v_{\text {nuc }}} \beta\left(v-v^{\prime}, v^{\prime}\right) f_{0}\left(v-v^{\prime}\right) f_{1}\left(v^{\prime}\right) d v^{\prime}-f_{1}(v) \int_{v_{\text {nuc }}}^{\infty} \beta\left(v, v^{\prime}\right) f\left(v^{\prime}\right) d v^{\prime}\end{array}\right]$

$\mathbf{n}=\left[\begin{array}{ll}0 & 1\end{array}\right]^{\mathrm{T}}$

$\bar{n}(v, t)=f_{1} / f$ 


\subsection{Zero-One Model}

In the 0-1 approach (cf. Figure 2), particles with two or more radicals are neglected by assuming that termination is pseudo-instantaneous. Therefore, the use of such approach is typically restricted to small particles and low conversions. Note that this hypothesis automatically eliminates the issues related to chain-length-dependent termination.

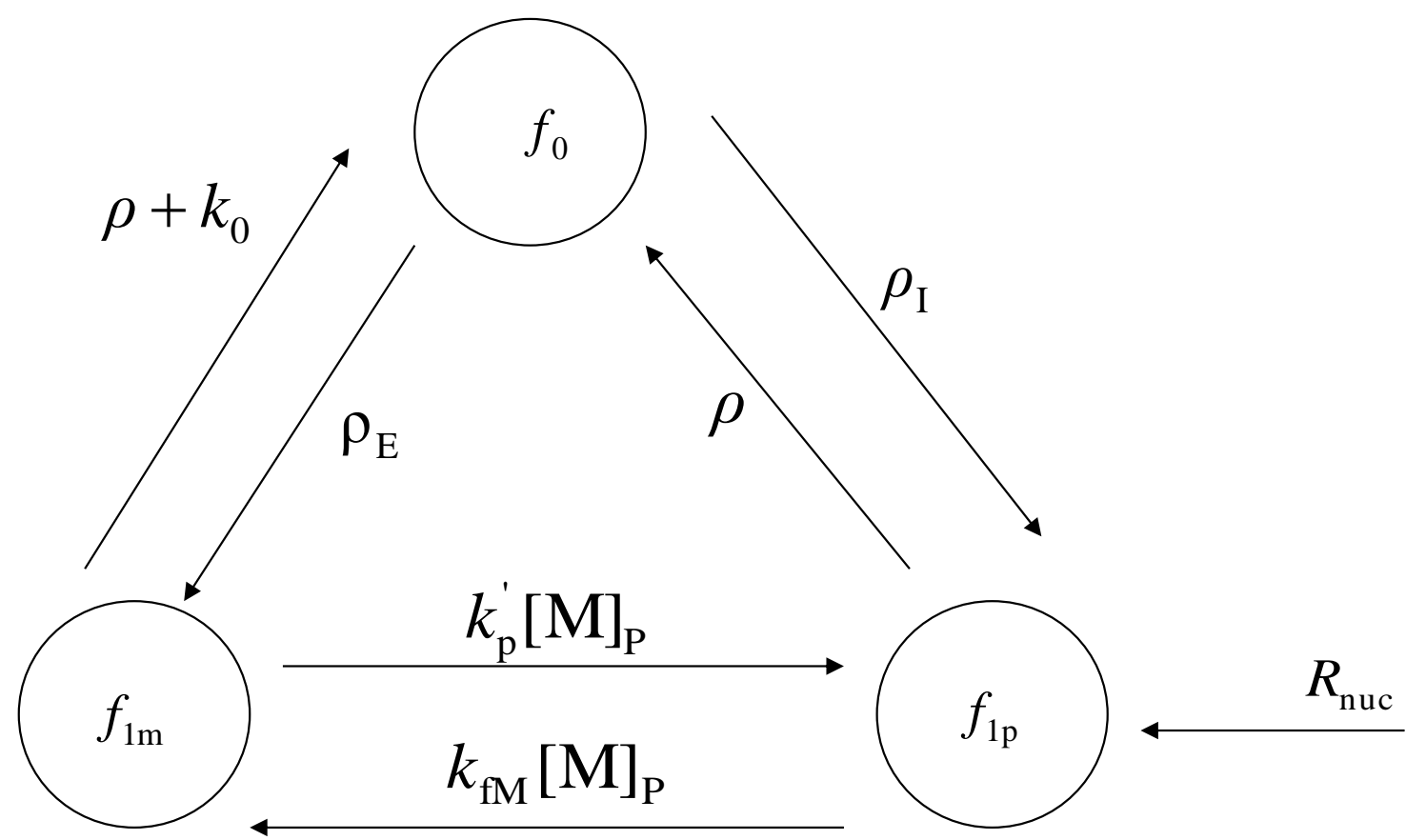

Figure 2. Kinetic fluxes between particles according to the 0-1 model.

Gilbert and co-workers[12]-[15] developed a series of theoretical and experimental tests to check if a given system obeys 0-1 kinetics. For example, a necessary but not sufficient condition is that the average number of radicals per particle obeys $\bar{n}<1$. Nevertheless, it is necessary to make a clear distinction between the applicability of the 0-1 model for the prediction of the macroscopic kinetic behavior of the system (i.e., $\bar{n}$ and/or rate of polymerization) and the prediction of the PSD, an issue that has been discussed in detail by Giannetti.[16] According to this author, even if the contribution of particles with more than one radical is negligible with respect to the kinetic behavior of the system when $\bar{n} \ll 0.5$, the same is not true for the PSD. The presence of particles with more than one radical increases the broadness of the PSD with respect to that predicted by the 0-1 model. This is a shortcoming to bear in mind when using this approach to compute the PSD.

Despite its inherent limitations, the 0-1 model can be of great value in interpreting mechanistic studies. In particular, it has been used by Gilbert's workgroup (see Section 3.4) to investigate the mechanisms of particle formation in the emulsion polymerization of styrene.[13], [17], [18] Edouard et al.[19] presented the 0-1 model under a slightly different form and used it to develop an observer of the PSD. 


\subsection{Pseudo-Bulk Model}

In the pseudo-bulk approach, all particles of the same size are assumed to have the same average number of radicals, $\bar{n}(r, t)$. One may or may not account for chain-length-dependent termination, but the radical chain length is no longer an internal coordinate of the PBE.

This hypothesis has the great advantage of reducing the computation of the PSD to the resolution of a single PBE. However, in exchange for this simplicity, an independent and necessarily approximate expression for $\bar{n}(r, t)$ must be supplied. Most often, the Stockmayer-O'Toole[20] solution, or an equivalent formula, is employed for this purpose. Such mathematical expressions are quite convenient, but they all rely on the assumption that the rates of nucleation, coagulation, growth and inflow/outflow are negligible with respect to the rates of radical entry, desorption and termination. Although this hypothesis works well in certain conditions, it can lead to severe errors when simulating particle formation processes (see Section 3.4).

The validity of the PB model is also conditioned by the assumption of uniform growth. In general, this hypothesis only holds true for high values of $\bar{n}$ (the radical distribution among particles is then sufficiently uniform to validate the averaging procedure) or for high radical entry rates. If the condition of uniform growth is not satisfied, then particles with a number of radicals $n<\bar{n}$ will lag behind and particles with $n>\bar{n}$ will grow more quickly, which will give rise to stochastic broadening, a phenomena not taken into account by the PB approach. Accordingly, the accuracy of the results obtained with the PB model depends on the relative importance of stochastic broadening. For example, stochastic broadening will not be of importance in CSTRs, since in that case the PSD is inherently broad.[21], [22]

Despite its shortcomings, the compromise between simplicity and predictability appears to have favored the generalized use of the PB approach for modeling PSD in EP reactors, as seen in Section 4. The PB model may be favored over the 0-1 model as it does not place restrictions with regards to the maximum number of radicals per particle or particle size, thus allowing one to simulate the entire conversion range. A modified form of the pseudo-bulk model was recently considered by Hosseini et al. [23].

\subsection{0-1-2 Model}

In addition to the 0-1 and PB kinetic limits, other kinetic limits have been used for modeling EP under conditions where the commonly-employed kinetic limits do not apply.

For example, in vinyl chloride EP, the hypothesis of pseudo-instantaneous termination is invalid for particles with a swollen radius greater than $5-10 \mathrm{~nm}$ in diameter due to the relatively fast rate of 
monomeric radical desorption. As such, the 0-1 model is of little practical interest. While the PB limit can be used to model seeded vinyl chloride polymerizations, the expressions used to compute $\bar{n}$ do not account for important considerations in systems with extensive particle formation. The simplest alternative, the zero-one-two limit (0-1-2) has been used efficiently to model the kinetics and PSD dynamics of vinyl chloride EP,[5], [24] where $\bar{n}$ is small, but termination is rate-determining.

The 0-1-2 model is similar in structure to the 0-1 model, the main difference being the additional set of equations to describe the dynamics of particles containing two radicals. The 0-1-2 model is formulated in such a way that that the $0-1$ model is recovered if the relative rate of intraparticle termination approaches infinity.

\subsection{Hybrid Model}

The hybrid 0-1/PB approach, first proposed by Coen et al.[25] and later employed by Jung et al.[26] uses a cross-over radius to divide the particle size domain into two regions: particles smaller than the cross-over radius are treated with 0-1 kinetics, while particles larger than the cross-over radius are treated with PB kinetics. The hybrid 0-1/PB approach may be useful in systems where particle nucleation occurs in the presence of larger particles obeying PB kinetics. The numerical challenge that arises under the hybrid approach is linking the two sets of PBEs; care must be taken to ensure that particle coagulation events between large and small particles, or two small particles, where the radius of the resulting particle exceeds the cross-over radius, are accounted for correctly.

\subsection{Numerical solutions of the PBM}

As can be seen from Table 1, an important challenge in using PBMs is realted to the resolution of the integro-hyperbolic partial differential equations, as there are no analytical solutions when nucleation and realistic growth and coagulation kernels are involved (N.B. we can generally neglect breakage which is usually inexistent in emulsion polymerization). The numerical methods used to solve the PBM can be classified as follows: moment methods[27], stochastic methods (such as Monte Carlo simulations[28]), and discretization methods (such as finite element methods[29], finite volumes and sectional methods[30]). Other varieties of discretization methods were developed, but making a comprehensive review of numerical techniques is out of the scope of this work. It can be generalized, however, that each of these numerical methods has a limited range of validity. The lowest calculation time is obtained using the moment methods, but they only give certain integral properties of the distribution. This method is appreciated for instance when coupling the population balance equations with fluid dynamics, where the computation time increases exponentially. Stochastic methods are based on the assumption that random dynamics of a population (e.g., nucleation and aggregation) can be simulated with a representative population of smaller number of particles. They were found to be 
less computationally expensive for multi-dimensional PBE than discretization methods[31]. Discretization methods allow one to calculate the full distribution, using linear, or geometric grids to reduce the computational burden while ensuring accuracy[32]. Among these methods, the finite element methods (such as the method of weighted residuals, orthogonal collocation and Galerkin's method) are considered relatively difficult to implement (unless using specific commercial software). They can however represent complex distributions as the solution is approximated by linear combinations of piecewise basis functions. The finite volumes (FV) method is more practical and was adapted to solve breakage and aggregation problems.[33] In this method, the number density of the PBM is transformed to a mass conservation law which makes the solution consistent with respect to the first moment but does not ensure good predictions of the zeroth moment. The fixed pivot (FP) technique is simple to implement and is computationally attractive [34]. It was found to be consistent with the first two moments of the distribution in aggregation and breakage problems (without growth or nucleation terms). The moving pivot technique (which is a little more difficult to implement and to solve) is aimed to improve the FP technique in terms of predicting the particle number in the large size range which fails in the FP technique due to sharp variations in the density function.[35]

\section{Fundamental Mechanisms of Emulsion Polymerization}

\subsection{Aqueous-Phase and Phase-Transfer Events}

Despite a certain consensus on the general lines, there is no universal agreement on the mechanistic details of the aqueous-phase and phase-transfer events (see, e.g., Tauer et al.[36]). Essentially, this is due to a limited knowledge of the chemistry (structure, reactions, etc.) and properties of the radical species, and also of the phenomena that govern radical entry/exit rates.

A simplified scheme of the processes generally assumed to occur in an emulsion homopolymerization initiated by a water-soluble free radical initiator such as a persulphate is shown in Figure 3. Most authors consider schemes that are particular cases of this one, as illustrated in Table 2. To facilitate the discussion of this subject, aspects pertaining to initiator-derived and exited radicals will be presented separately. Note that when copolymers are involved, the determination of the fate of the oligomers becomes even more difficult, [37] but this topic is not discussed in this paper. 


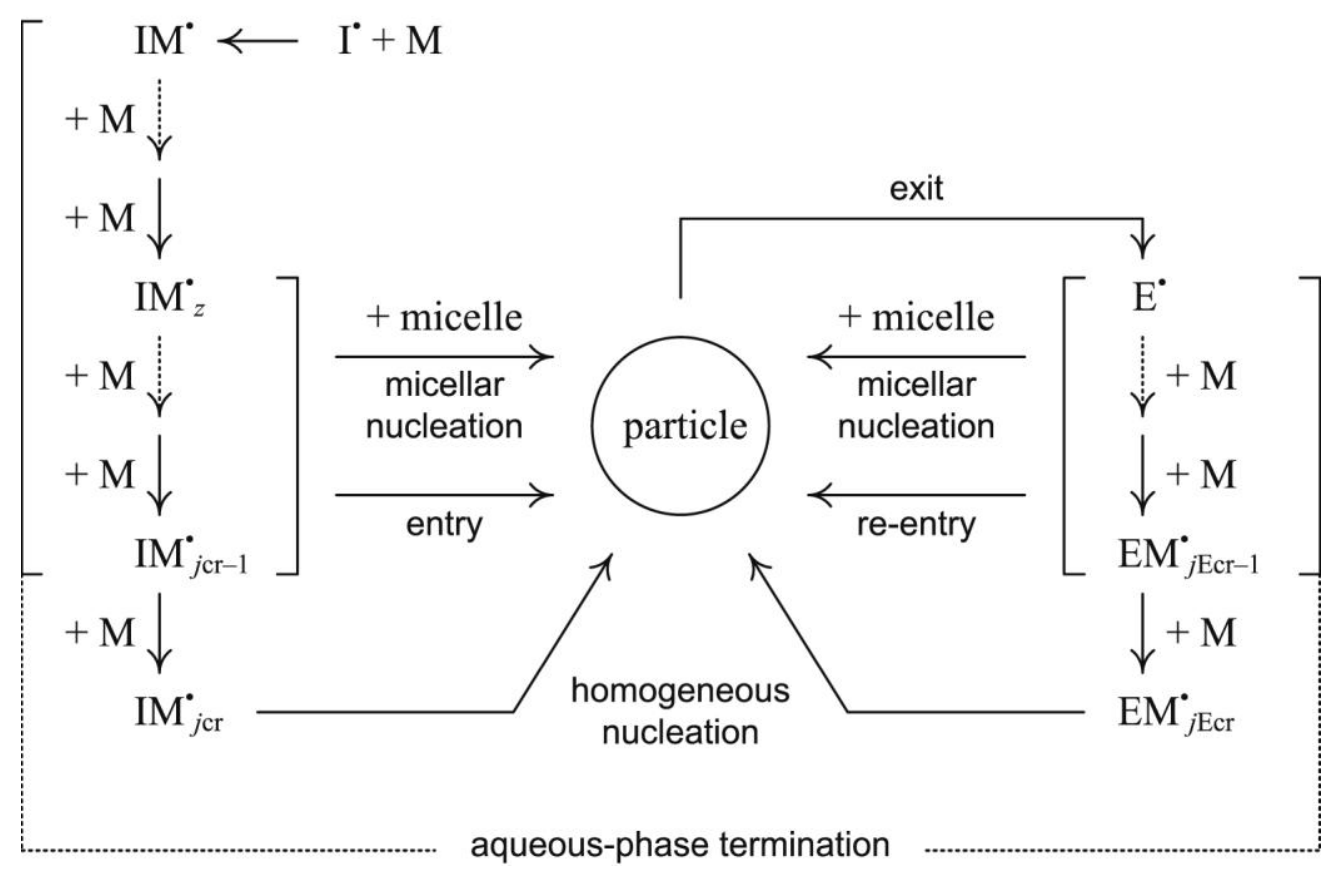

Figure 3. Scheme of the aqueous-phase and phase-transfer events assumed to occur in an emulsion homopolymerization initiated by persulfate $\left(\mathrm{I} \equiv \mathrm{OSO}_{3}\right)$. Reprinted with permission from Vale \& McKenna.[38] Copyright 2009 American Chemical Society.

Table 2. Details of the aqueous phase reaction schemes assumed by some authors (involving persulfate as initiator, cf. Figure 3)

\begin{tabular}{|c|c|c|}
\hline \multirow{2}{*}{ 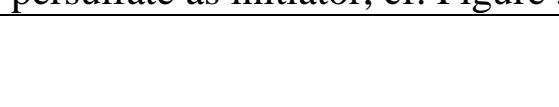 } & \multicolumn{2}{|c|}{ Type of radical } \\
\hline & initiator derived $\left(\mathrm{IM}_{i}^{\bullet}\right)$ & desorbed $\left(\mathrm{EM}_{i}^{\bullet}\right)$ \\
\hline \multicolumn{3}{|l|}{ Ugelstad et al.[24] } \\
\hline propagation & $0 \leq i \leq j_{\mathrm{cr}}-1$ & $0 \leq i \leq j_{\mathrm{Ecr}}-1$ \\
\hline termination & $0 \leq i \leq j_{\mathrm{cr}}-1$ & $0 \leq i \leq j_{\mathrm{Ecr}}-1$ \\
\hline entry particle & $0 \leq i \leq j_{\mathrm{cr}}-1$ & $0 \leq i \leq j_{\mathrm{Ecr}}-1$ \\
\hline micellar nucleation & - & - \\
\hline homogeneous nucleation & $i=j_{\mathrm{cr}}$ & $i=j_{\mathrm{Ecr}}$ \\
\hline \multicolumn{3}{|l|}{ Dubé et al.[39] } \\
\hline propagation & $0 \leq i \leq j_{\mathrm{cr}}-1$ & - \\
\hline termination & $1 \leq i \leq j_{\mathrm{cr}}-1$ & - \\
\hline entry particle & $j_{\mathrm{cr}} / 2+1 \leq i \leq j_{\mathrm{cr}}$ & $i=0$ \\
\hline micellar nucleation & $j_{\mathrm{cr}} / 2+1 \leq i \leq j_{\mathrm{cr}}$ & - \\
\hline homogeneous nucleation & $i=j_{\mathrm{cr}}$ & - \\
\hline \multicolumn{3}{|l|}{ Coen et al.[25], [40] } \\
\hline propagation & $0 \leq i \leq j_{\mathrm{cr}}-1$ & - \\
\hline termination & $1 \leq i \leq j_{\mathrm{cr}}-1$ & $i=0$ \\
\hline entry particle & $z \leq i \leq j_{\mathrm{cr}}-1$ & $i=0$ \\
\hline micellar nucleation & $z \leq i \leq j_{\mathrm{cr}}-1$ & - \\
\hline homogeneous nucleation & $i=j_{\mathrm{cr}}$ & - \\
\hline \multicolumn{3}{|l|}{ Gao \& Penlidis[41] } \\
\hline propagation & $0 \leq i \leq j_{\mathrm{cr}}-1$ & $0 \leq i \leq j_{\mathrm{Ecr}}-1$ \\
\hline termination & $0 \leq i \leq j_{\mathrm{cr}}-1$ & $0 \leq i \leq j_{\mathrm{Ecr}}-1$ \\
\hline entry particle & $1 \leq i \leq j_{\mathrm{cr}}-1$ & $1 \leq i \leq j_{\mathrm{Ecr}}-1$ \\
\hline micellar nucleation & $1 \leq i \leq j_{\mathrm{cr}}-1$ & $1 \leq i \leq j_{\mathrm{Ecr}}-1$ \\
\hline homogeneous nucleation & $i=j_{\mathrm{cr}}$ & $i=j_{\mathrm{Ecr}}$ \\
\hline
\end{tabular}




\subsubsection{Initiator-Derived Radicals}

In general, the reaction schemes are quite idealized with respect to the possible reactions between aqueous-phase species. For instance, in persulfate-initiated polymerizations (see Figure 3), it is generally assumed that the persulfate anion $\left(\mathrm{S}_{2} \mathrm{O}_{8}^{2-}\right)$ thermally decomposes into $\mathrm{SO}_{4}^{-\bullet}$ radicals, which then propagate with monomer dissolved in the aqueous phase to form charged oligomers of the type $\left(\mathrm{SO}_{4}^{-\bullet}\right) \mathrm{M}_{i}^{\bullet}$. These species can terminate with other radicals present in the aqueous phase to form dead polymer chains. Additionally, reaction with water-soluble impurities,[39],[41]-[43] and/or chain transfer to monomer or chain transfer agent [41], [44], [45] are sometimes considered. Chain transfer to the surfactant has also been suggested to explain the presence of surfactant fragments in the polymeric chain.[46]

The supposition that initiator-derived radicals have the formula $\left(\mathrm{SO}_{4}^{-\bullet}\right) \mathrm{M}_{i}^{\bullet}$ is intuitive and convenient, but questioned by some authors. Tauer \& Deckwer[47] used MALDI-TOF-MS to investigate the polymer inside the particles at the end of a styrene emulsion polymerization initiated with potassium persulfate and carried out in the absence of emulsifier. The analysis revealed end groups other than the obvious $\mathrm{RSO}_{4}^{-}$, namely: $\mathrm{RH}, \mathrm{ROH}$, and $\mathrm{ROO}^{-}$. Regrettably, information on the relative concentrations of these species were not given in order to estimate their contribution to the overall entry process. According to the same authors, all products except the chains with carboxyl groups are initiated by the respective radicals. The entering radicals could either be the primary radicals $\left(\mathrm{H}^{\bullet}\right.$, $\mathrm{OH}^{\bullet}$, or $\mathrm{SO}^{-\bullet}$ ) or the corresponding oligomeric radicals. Goicoechea et al. [48] indicated that direct primary radical entry may be due to the generation of hydrophobic hydroxyl radical during persulfate ions decomposition and that this effect can be suppressed if hydroxyl radical generation is avoided. Hydroxyl and hydrogen end groups were also found in polymerizations conducted with V-50 as initiator.[49] These articles draw our attention for the potential importance of the side reactions of the initiator in the aqueous phase,[50], [51] and their influence upon the entry and nucleation mechanisms. Indeed, if these findings are correct, surface activity might not be a necessary condition for the entry of radicals (see next section). Moreover, as the solubility of the oligomers is affected by their chemical structure, this has also an impact on particle nucleation (cf. Section 3.4).

In order to be able to connect the aqueous phase reactions, the material balances of initiator and primary and oligomeric radicals in the aqueous phase for a very frequent case study are shown in Table 3. In this scheme, it is assumed that primary radicals are produced by initiator decomposition in the aqueous phase and propagate with monomer or terminate with other radicals, but reactions with impurities, side reactions and transfer to monomer, chain transfer to chain transfer agent or surfactant are excluded. Radicals with a sufficient length $z \leq i \leq j_{\mathrm{cr}}-1$ may enter micelles or polymer particles (where $z$ represents the minimal degree polymerization DP for entry, and $j_{\text {cr }}$ is the critical DP for 
particle formation by homogeneous nucleation). Instantaneous reaction of primary radicals, $\left[\mathrm{I}^{\bullet}\right]_{\mathrm{w}}$, is also considered. Exited radicals are distinguished from initiator derived radicals in terms of the radical entry rate coefficient into micelles and particles, and in terms of critical chain length before precipitation in the aqueous phase, $j_{\mathrm{Ecr}}$. Note that the quasi-stationary state hypothesis can be applied to all types of radicals. The neglected terms should be added to these balances if their contribution is found significant.

Table 3. Material balances of initiator-derived radicals in the aqueous phase[13], [52], [53]

\begin{tabular}{|c|c|}
\hline Component & Material balance \\
\hline Initiator & $\frac{\mathrm{d}[\mathrm{I}]}{\mathrm{d} t}=-k_{\mathrm{d}}[\mathrm{I}]$ \\
\hline $\begin{array}{l}\text { Oligomeric radicals in aqueous phase } \\
\text { with } 1 \text { monomer unit }\end{array}$ & $\frac{\mathrm{d}\left[\mathrm{IM}_{\mathrm{i}}^{\mathrm{i}}\right]_{\mathrm{w}}}{\mathrm{d} t}=2 f_{\mathrm{I}} k_{\mathrm{d}}[\mathrm{I}]-\left[\mathrm{IM}_{1}^{\bullet}\right]_{\mathrm{w}}\left(k_{\mathrm{pw}}[\mathrm{M}]_{\mathrm{w}}+k_{\mathrm{tw}}\left[\mathrm{T}^{\bullet}\right]_{\mathrm{w}}\right)$ \\
\hline $\begin{array}{l}\text { Oligomeric radicals in aqueous phase } \\
\text { with } i \text { monomer units }(2 \leq i \leq z-1)\end{array}$ & $\frac{\mathrm{d}\left[\mathrm{IM}_{i}^{*}\right]_{\mathrm{w}}}{\mathrm{d} t}=k_{\mathrm{pw}}[\mathrm{M}]_{\mathrm{w}}\left(\left[\mathrm{IM}_{i-1}^{\cdot}\right]_{\mathrm{w}}-\left[\operatorname{IM}_{i}^{*}\right]_{\mathrm{w}}\right)-k_{\mathrm{tw}}\left[\mathrm{IM}_{i}^{*}\right]_{\mathrm{w}}\left[\mathrm{T}^{\bullet}\right]_{\mathrm{w}}$ \\
\hline $\begin{array}{l}\text { Oligomeric radicals in aqueous phase } \\
\text { with } i \text { monomer units }\left(z \leq i \leq j_{\mathrm{cr}}-1\right)\end{array}$ & $\begin{aligned} \frac{\mathrm{d}\left[\mathrm{IM}_{i}^{*}\right]_{\mathrm{w}}}{\mathrm{d} t}= & k_{\mathrm{pw}}[\mathrm{M}]_{\mathrm{w}}\left(\left[\mathrm{IM}_{i-1}^{\bullet}\right]_{\mathrm{w}}-\left[\mathrm{IM}_{i}^{*}\right]_{\mathrm{W}}\right)-k_{\mathrm{tw}}\left[\mathrm{IM}_{i}^{*}\right]_{\mathrm{w}}\left[\mathrm{T}^{\bullet}\right]_{\mathrm{w}}- \\
& \frac{\left[\mathrm{IM}_{i}^{*}\right]_{\mathrm{w}}}{N_{A}} \int_{0}^{\infty} k_{\mathrm{e}(i)}(r) f(r, t) \mathrm{d} r-k_{\mathrm{em}(i)}\left[\mathrm{IM}_{i}^{*}\right]_{\mathrm{w}}[\mathrm{MIC}]\end{aligned}$ \\
\hline $\begin{array}{l}\text { Total oligomeric radicals in aqueous } \\
\text { phase }\end{array}$ & {$\left[\mathrm{T}^{\bullet}\right]_{\mathrm{w}}=\sum_{i=1}^{j_{\mathrm{cr}}-1}\left[\mathrm{IM}_{i}^{\bullet}\right]_{\mathrm{w}}+\sum_{i=0}^{j_{\mathrm{Ecr}}-1}\left[\mathrm{EM}_{i}^{\bullet}\right]_{\mathrm{w}}$} \\
\hline Monomer reaction rate in water & $R_{\mathrm{p}}^{\mathrm{W}}=k_{\mathrm{pw}}[\mathrm{M}]_{\mathrm{w}}\left[\mathrm{T}^{\bullet}\right]_{\mathrm{W}}$ \\
\hline
\end{tabular}

\subsubsection{Radical entry}

A number of different mechanisms have been proposed to describe radical entry into particles, which should be due to the inherent differences between the considered systems: monomer solubility in water, type of radicals, type of stabilizer, particle size and temperature. The radical entry frequency can be written as a function of the total concentration of radicals in the aqueous phase, as follows $\rho=k_{\mathrm{e}}\left[\mathrm{T}^{\bullet}\right]_{\mathrm{w}}$ (where $k_{\mathrm{e}}$ is the entry rate coefficient and $\left[\mathrm{T}^{*}\right]_{\mathrm{w}}$ corresponds to the total concentration of oligomeric radicals in the aqueous phase). The controlling forces for radical entry might be radical diffusion, collision or propagation, or the particles surface properties. For example, in the model of Maxwell et al.[54] not all radicals can enter a particle (but only $\mathrm{IM}_{z}^{\bullet}$ ), $k_{\mathrm{e}}$ is thus expressed in Table 4 as a function of the ratio $\left[\mathrm{IM}_{z-1}^{\bullet}\right]_{\mathrm{w}} /\left[\mathrm{T}^{\bullet}\right]_{\mathrm{w}}$ (as also suggested by [55]). This allows easier comparison of $k_{\mathrm{e}}$ by the different models. The models for the rate of radical entry (allowing to describe the radical entry rate coefficient $k_{\mathrm{e}}$ ) can be classified as:

Particle size dependence
- The diffusion-controlled mechanism (limited by radical diffusion in the aqueous phase, Smith \& Ewart (1948)[56]).

- The collision-controlled mechanism (limited by collision between radicals and polymer particles, Gardon (1968)[57]).

- The colloidal-controlled mechanism (defined as the coagulation rate between a precursor and a latex particle, Penboss et al. (1986) [57]). 
Chain length $\mid$ - The propagation-controlled mechanism (controlled by aqueous phase dependence growth, Maxwell et al. (1991)[54]).

\begin{tabular}{l|l} 
Surface & - The surfactant displacement mechanism (in which radical entry might
\end{tabular} properties dependence depend on the surfactant layer, Yeliseyeva \& Zuikov (1977) [58]).

The surfactant displacement radical entry mechanism was discarded for conventional mobile surfactants, that undergo dynamic adsorption equilibrium, but may become dominant for polymeric surfactants. For instance, this was the case for the steric stabilizer poly(ethylene oxide) nonylphenol (with 30 EO units)[59], [60] the reactive surfactant sodium dodecyl allyl sulfosuccinate[61], polymeric surfactants (e.g., electrosteric copolymer of acrylic acid and styrene[62]), the copolymer of styrene and styrene sulfonate,[63] poly(acrylic acid)[64] or when the used entering radical charge was different from the charge of the polyelectrolyte surfactant.[65]

Table 4 summarizes the radical entry correlations proposed in the literature for systems with charged particles (by surfactant and/or initiator fragments). It can be seen that the coefficient of radical entry is proportional to the particle surface area in the collisional mechanism and to the particle size in the diffusion and colloidal mechanisms, and is independent of the particle diameter in the propagationcontrolled mechanism.

In the propagation-controlled radical entry mechanism, put forward by Gilbert's group[13], [66], the charged oligomers $\left(\mathrm{SO}_{4}^{-\bullet}\right) \mathrm{M}_{i}^{\bullet}$ must attain a minimum $\mathrm{DP}, i=z$, at which they become surface-active and, thus, capable of irreversibly entering a particle or a micelle (Figure 3). This model is thus independent of the particle size.

The parameter $z$ can be estimated using a semi-empirical expression suggested by Maxwell et al.[54] and is an increasing function of the monomer solubility in the aqueous phase. Of course, one should not forget that these authors' view is entirely based on the hypothesis that the initiator-derived radicals have the formula $\left(\mathrm{SO}_{4}^{-\bullet}\right) \mathrm{M}_{i}^{\bullet}$. Kshirsagar \& Poehlein[67] attempted to validate the idea of Gilbert and co-workers by experimentally determining the degree of polymerization of the oligomers that enter particles during the emulsion polymerization of vinyl acetate. Their results gave indirect support for the theory. An approach similar to Gilbert's, but perhaps more pragmatic, has been used by Dubé et al.[39]. They admitted that the capture of radicals by particles and micelles only occurs above a minimum DP that they defined in terms of the critical DP for particle formation by homogeneous nucleation, namely $z=1+0.5 j_{\mathrm{cr}}$. It is worth noting that, from a numerical perspective, this approach does not lead to results significantly different from those obtained with Maxwell's formulas, which can be shown to give $z=1+0.42\left(j_{\mathrm{cr}}-1\right)$.

The radical entry diffusion mechanism assumes the radical entry rate to be proportional to the particle diameter. Note that, in this framework, surface activity is not a condition for the entry of radicals. 
Associated to this mechanism, an absorption efficiency factor $\left(f_{\mathrm{e}}\right)$ was proposed,[68] then different forms of this factor were proposed (cf. Table 4). For instance, Coen et al.[17] assumed a dependence on the chain length $i$, making thus a combination of the diffusion and propagation mechanisms.

Table 4. Overview of models for the entry frequency of oligomeric radicals into particles (or micelles)

\begin{tabular}{|c|c|}
\hline \multicolumn{2}{|c|}{ Frequency of radical entry: $\rho=k_{\mathrm{e}}\left[\mathrm{T}^{*}\right]_{\mathrm{W}}$} \\
\hline Diffusion-controlled mechanism & $k_{\mathrm{e}}=2 \pi d N_{\mathrm{A}} D_{\mathrm{w}} f_{\mathrm{e}}$ \\
\hline Smith \& Ewart (1948) [56] & $f_{\mathrm{e}}=1$ \\
\hline Hansen \& Ugelstad (1978) [69] & $\begin{array}{c}f_{\mathrm{e}}=\frac{\frac{1}{\exp \left(z_{\alpha}\right) D_{\mathrm{W}}}+W}{\left(\tilde{X}_{\mathrm{p}} \cdot \operatorname{coth}\left(\widetilde{X}_{\mathrm{p}}\right)-1\right) D_{\mathrm{p}}}+W \\
\tilde{X}_{\mathrm{p}}=\frac{d}{2} \sqrt{\frac{k_{\mathrm{p}}[\mathrm{M}]_{\mathrm{p}}}{D_{\mathrm{p}}}+\frac{k_{\mathrm{tp}} n(r)}{N_{\mathrm{A}} v D_{\mathrm{p}}}}, z_{\alpha}=\frac{v V_{\mathrm{T}}}{k_{\mathrm{B}} T}, W=\frac{d}{2} \int_{0}^{\infty} \exp \left(\frac{V_{\mathrm{T}}}{k_{\mathrm{B}} T}\right) \frac{\mathrm{d} L}{\left(\frac{d}{2}+L\right)^{2}}\end{array}$ \\
\hline Coen et al (1998) [17] & $f_{\mathrm{e}}=\left\{\begin{array}{cr}\frac{1}{i^{1 / 2}}, & z \leq i<j_{\text {crit }} \\
0, & \text { else } \\
1, & \text { for exited radicals }\end{array}\right.$ \\
\hline Herrera et al. (2000) [70] & $f_{\mathrm{e}}=\frac{k_{\mathrm{p}}[\mathrm{M}]_{\mathrm{p}}+k_{\mathrm{tp}} n(r)(n(r)-1) /\left(v N_{\mathrm{A}}\right)}{k_{0}+k_{\mathrm{p}}[\mathrm{M}]_{\mathrm{p}}+k_{\mathrm{tp}} n(r)(n(r)-1) /\left(v N_{\mathrm{A}}\right)}$ \\
\hline Nomura et al (2005) [71] & $f_{\mathrm{e}}=\frac{k_{\mathrm{p}}[\mathrm{M}]_{\mathrm{p}}+k_{\mathrm{tp}} n(r) /\left(v N_{\mathrm{A}}\right)}{k_{0}+k_{\mathrm{p}}[\mathrm{M}]_{\mathrm{p}}+k_{\mathrm{tp}}\left(n(r) /\left(v N_{\mathrm{A}}\right)\right)}$ \\
\hline Hernandez \& Tauer (2007) [72] & $f_{\mathrm{e}}=p \frac{\pi}{6} d^{3} N+1$ \\
\hline Collision-controlled mechanism & \\
\hline Gardon (1968) [73] & $k_{\mathrm{e}}=\frac{1}{4} \sqrt{\frac{8 \pi k_{\mathrm{B}} T}{m_{i}}} N_{\mathrm{A}} d^{2}$ \\
\hline $\begin{array}{l}\text { Colloidal-controlled mechanism } \\
\text { Penboss et al. (1986) [57] }\end{array}$ & $k_{\mathrm{e}}=\frac{k_{\mathrm{B}} T N_{\mathrm{A}}\left(d+d_{i}\right)^{2}}{3 \mu W d_{i} d}, W=\frac{1}{\kappa} \exp \left(\frac{V_{\mathrm{T}, \max }}{k_{\mathrm{B}} T}\right)\left(\frac{d+d_{i}}{d d_{i}}\right)$ \\
\hline Propagation-controlled mechan & \\
\hline Maxwell \& Gilbert (1991) [54] & $k_{\mathrm{e}}=k_{\mathrm{p}}[\mathrm{M}]_{\mathrm{w}} \frac{N_{\mathrm{A}}}{N} \frac{\left[\mathrm{IM}_{\mathrm{Z}-1}\right]_{\mathrm{W}}}{\left[\mathrm{T}^{*}\right]_{\mathrm{w}}}$ \\
\hline
\end{tabular}

Hernandez \& Tauer[74],[75] used Monte Carlo to estimate the collision coefficient and revealed an importance of polymer volume fraction in the radical capture process when the diffusion of radicals in the aqueous phase is the rate-controlling step. Note that this leads however to an absorption efficiency factor that is higher than 1 . While the authors assume radical entry not to be conditioned by surface activity, they describe a mechanism where, upon entry, the radical is likely to undergo propagation near the surface of the particle as the radical will not have time to diffuse to the center of the particle. The energy released from the propagation reaction $\Delta H_{\mathrm{p}}$ may facilitate the radical escaping the particle, although the rate of success will depend on the energy barrier to desorption, $E_{\mathrm{des}}$. They defined the chain length for which half the radicals escape the particle as $z_{1 / 2}=-\Delta H_{\mathrm{p}} / E_{\mathrm{des}}$ and the chain length at which irreversible entry occurs can be approximated as $z=2 z_{1 / 2}$. This method leads to slightly different results from Maxwell's formulas. However, the requirement of estimating $E_{\mathrm{des}}$ values, for the particular used polymer, initiator and eventually stabilizing system, may limit its applicability. 
In the collision-controlled mechanism, the radical entry rate is proportional to the particle surface. Liotta et al.[76] found that this model is the most adapted for polystyrene particles of about 100-140 nm or 220-300 nm (unswollen diameter).

There are, still, different opinions regarding radical entry. For instance, Arbina et al.[77] compared three particle growth models with different levels of description of the radical events: (i) a simple model without any distinction between aqueous-phase radicals; (ii) a model accounting for radical chain length, distinguishing between initiator-derived and exited radicals, and assuming instantaneous entry of initiator-derived radicals with degree of polymerization $z$; and (iii) a model like the previous one, but without assuming instantaneous entry. As major conclusion, they found that all three models fitted styrene data in a similar way, and that they were statistically equivalent. Unfortunately, a direct comparison of the results of Arbina et al. [77] and Maxwell et al.[66] seems difficult. First, because the experimental data are reported in terms of different quantities (entry frequency in one case, and entry rate coefficient in the other). Second, because different values of key parameters have been used by the two groups, in particular, very distinct values of the aqueous-phase termination rate coefficient, which plays a central role in the outcome of the models.

These paragraphs make it clear that radical entry is not yet an entirely resolved issue. For some 'simple' applications (e.g., modeling monomer conversion) this lack of mechanistic information can often be circumvented by parameter fitting and, thus, is not perceived as a real obstacle. Indeed, a certain degree of parameter averaging and adjustment is permitted when modeling macroscopic variables (integral variables) like monomer conversion. On the other hand, a detailed knowledge of the radical entry mechanism is indispensable when attempting to quantify more complex phenomena like the nucleation of latex particles or the time evolution of the PSD, given their great sensitivity on the nature, length, concentration and entry rate of the various aqueous-phase radicals. The surface activity condition (propagation-controlled mechanism) appears to be logical, but it should probably be combined with the diffusional-controlled mechanism to allow handling both phenomena: particle sizeand radical size-dependence.

\subsubsection{Radical desorption and fate of exited radicals}

Radical exit (or desorption) corresponds to the transfer of small, mobile species $\left(\mathrm{E}^{\bullet}\right)$, formed by chain transfer to monomer or CTA, from the interior of the particle to the aqueous phase.[71] As for radical entry, modeling radical desorption remains an open challenge again due to differences in the considered systems (e.g., monomer solubility, type of initiator, type of stabilizer, temperature) in which all phenomenon are not necessarily significant, and are thus not identifiable (e.g. at high temperature, the propagation rate increases and may lead to th desorption rate to become negligible). In addition, there are myriad factors that must be considered. First, from the interior of the particle 
side, a number of factors play a role before the exit event. Are mobile species generated randomly throughout the particle or is radical generation focused within a monomer-rich zone inside the particle? How much resistance to radical desorption will the stabilization layer present? For heterogeneous particles, how does the morphology of the particle influence the flux of mobile species out of the particle? While the desorption kinetic rate coefficient can be inferred from indirect measurements combined with kinetics involving some assumptions (refer to Thickett \& Gilbert[78] for an overview), the experimental validation of theoretical radical desorption models is challenging, particularly for complex systems where it is difficult to estimate key kinetic parameters. Hernandez \& Tauer[79], [80] convincingly argue that Brownian dynamics simulations can be used to estimate desorption rate coefficients in increasingly-complex systems and to validate existing theoretical desorption models.

Second, from the aqueous phase side, determining the fate of exited radicals in water after the exit event is essential. Will they simply re-enter particles? Propagate in the aqueous phase? Terminate with other exited or initiator-derived radicals? Contribute to particle formation? Do they even have the same reactivity as initiator-derived radicals? Answering these questions is absolutely essential to accurately model polymerization kinetics, particle nucleation and PSD evolution. Unfortunately, the literature is not of much help in providing definite responses to these interrogations (cf. Table 2). For instance, Gao \& Penlidis[41] consider that desorbed radicals undergo the exact same path as the initiator-derived radicals, including participation in particle formation via micellar and homogeneous nucleation. The same is assumed in some models developed by Asua and co-workers.[81], [82] On the other hand, Gilbert and co-workers[13], [83] claim, on the basis of time-scale arguments, that aqueous-phase propagation and termination are very unlikely with respect to re-entry. Despite that, Coen et al.[17], [25] did account for the possibility of termination in the aqueous phase. Dubé et al.[39] argue that the desorbed radicals do not move far beyond the particle from which they desorbed, which would mean that the radicals could only re-enter the same particle. Finally, recent evidence put forward suggests that the exited species may chemically interact with the stabilization layer surrounding the particle before having a chance to exit into the aqueous phase.[84]-[86] Fragmented stabilizer chains could form and subsequently migrate to the aqueous phase, thereby explaining the significant amount of secondary nucleation observed in systems employing electrosteric stabilizers.[64]

Exited radicals are chemically distinct (less hydrophilic) from initiator-derived radicals, as the latter supposedly have an ionic (or at least a water soluble) fragment attached. Thus, it may be assumed that exited radicals can freely re-enter particles and that their critical DP for precipitating is smaller than that of initiator-derived radicals $\left(j_{\mathrm{Ecr}}<j_{\mathrm{cr}}\right)$. It is worth noting however that the nature of the exited 
species $\mathrm{E}^{\bullet}$ may, in certain cases, be difficult to establish, for example, when the chain transfer mechanisms are not well known. Table 5 shows the material balances of radicals that may desorb from the polymer particles and those of exited radicals. It is assumed in this scheme that only hydrophilic monomeric radicals, $\left[\mathrm{M}_{1}^{*}\right]_{\mathrm{p}}$, formed by transfer to monomer reaction may desorb. For monomers with high water solubility, it might be assumed that chains with two monomer units $\left(\left[\mathrm{M}_{2}^{*}\right]_{\mathrm{p}}\right)$ can also desorb. It is worth mentioning that the radical entry and exit rate coefficients can be size dependent in the proposed scheme.

Table 5. Material balances of monomeric radicals that may exit and exited radicals in the aqueous phase[52], [53], [87], [88]

\begin{tabular}{|c|c|}
\hline Component & Material balance \\
\hline Exited monomeric radical & $\begin{array}{l}\frac{\mathrm{d}\left[\mathrm{E}^{*}\right]_{\mathrm{w}}}{\mathrm{d} t}=\frac{1}{N_{\mathrm{A}}} \int_{0}^{\infty} k_{\mathrm{des}} \bar{n}(r, t) f(r, t) \mathrm{d} r-\left[\mathrm{E}^{\bullet}\right]_{\mathrm{w}}\left(k_{\mathrm{pw}}[\mathrm{M}]_{\mathrm{w}}+k_{\mathrm{tw}}\left[\mathrm{T}^{\bullet}\right]_{\mathrm{w}}+\right. \\
\left.\left\langle k_{\mathrm{e}, \mathrm{E}(0)}\right\rangle \frac{N}{N_{\mathrm{A}}}+k_{\mathrm{em}, \mathrm{E}(0)}[\mathrm{MIC}]\right)\end{array}$ \\
\hline $\begin{array}{l}\text { Exited radical reacted with one } \\
\text { monomer unit in water }\end{array}$ & $\begin{array}{l}\frac{\mathrm{d}\left[\mathrm{EM}_{\mathrm{i}}^{*}\right]_{\mathrm{w}}}{\mathrm{d} t}=k_{\mathrm{pw}}\left[\mathrm{E}^{\bullet}\right]_{\mathrm{w}}[\mathrm{M}]_{\mathrm{w}}-\left[\mathrm{EM}_{1}^{*}\right]_{w}\left(k_{\mathrm{pw}}[\mathrm{M}]_{\mathrm{w}}+k_{\mathrm{tw}}\left[\mathrm{T}^{\bullet}\right]_{\mathrm{w}}+\right. \\
\left.\left\langle k_{\mathrm{e}, \mathrm{E}(1)}\right\rangle \frac{N}{N_{\mathrm{A}}}+k_{\mathrm{em}, \mathrm{E}(1)}[\mathrm{MIC}]\right)\end{array}$ \\
\hline $\begin{array}{l}\text { Exited radical with } i \text { monomer } \\
\text { units } 2 \leq i \leq j_{\mathrm{Ecr}}-1\end{array}$ & $\begin{array}{l}\frac{\mathrm{d}\left[\mathrm{EM}_{i}^{*}\right]_{\mathrm{W}}}{\mathrm{d} t}=k_{\mathrm{pw}}\left[\mathrm{EM}_{i-1}^{\cdot}\right]_{\mathrm{w}}[\mathrm{M}]_{\mathrm{W}}-\left[\mathrm{EM}_{i}^{\cdot}\right]_{\mathrm{w}}\left(k_{\mathrm{pw}}[\mathrm{M}]_{\mathrm{W}}+k_{\mathrm{tw}}\left[\mathrm{T}^{\bullet}\right]_{\mathrm{W}}+\right. \\
\left.\left\langle k_{\mathrm{e}, \mathrm{E}(i)}\right\rangle \frac{N}{N_{\mathrm{A}}}+k_{\mathrm{em}, \mathrm{E}(i)}[\mathrm{MIC}]\right)\end{array}$ \\
\hline $\begin{array}{l}\text { Radical desorption rate per } \\
\text { particle }\end{array}$ & $\rho_{\mathrm{des}}=k_{\mathrm{des}}(r, t) \bar{n}(r, t)$ \\
\hline
\end{tabular}

In order to estimate the desorption rate coefficient $k_{\text {des }}$ (cf. Table 1 and 5), different approaches have been described in the literature. As can be seen in Table 6, the mechanistic picture of the desorption process increased in complexity with time, going from a simple diffusion-based mechanism, to a mechanism taking into account competitive reactions inside the particles, and finally to a mechanism accounting for competitive reactions in the aqueous phase (fate of exited radicals). A general consensus exists regarding the dependency on the particle surface (except for the original model of Smith \& Ewart [56]). The effect of partitioning of small radicals (that are able to desorb) between the polymer particles and the aqueous phase is accounted for through its ratio, $m$, that is however usually replaced by the corresponding monomer partition coefficient, $m=[\mathrm{M}]_{\mathrm{p}} /[\mathrm{M}]_{\mathrm{W}}$.

Models accounting for the competing reactions in the polymer particles and in the aqueous phase are the most comprehensive nowadays, and are therefore recommended here. Among these models, the model by Hernandez \& Tauer 2008 [89] can easily be used within the 0-1 or pseudo-bulk PBE (cf. Table 1). As described in the previous section, the requirement of estimating $E_{\text {des }}$ values may limit the applicability of the calculation of $k_{0}$. The probability terms of this model can therefore be combined to another form of $k_{0}$ available in the table. The model by Asua et al. [90] depends on the number density of particles containing $i$ radicals, $N_{i}$, and is thus to be used with the Smith \& Ewart recursion equation.[56] A very similar approach to that of Asua et al. [90] was also recently proposed by 
Ghielmi et al. (2014), in which the propagation and re-entry rate coefficients of exited radicals are distinguished from primary radicals. [91]. 


\section{Diffusion-controlled radical desorption mechanism}

\begin{tabular}{|c|c|}
\hline & $\boldsymbol{k}_{\mathrm{des}}$ \\
\hline Smith \& Ewart (1948) [56] & $k_{\mathrm{des}}=\frac{a p^{\prime}}{v}=\frac{6 p}{d}$ \\
\hline Ugelstad et al. (1969) [24] & $k_{\mathrm{des}}=\frac{p^{\prime} N^{2 / 3}}{v^{2 / 3}}=\frac{p(6 / \pi)^{2 / 3}}{d^{2}}$ \\
\hline Chang et al. (1981) [92] & $k_{\mathrm{des}}=\frac{2 D_{\mathrm{p}}}{d^{2}}, \frac{4 D_{\mathrm{p}}}{d^{2}}, \frac{5 D_{\mathrm{p}}}{d^{2}}, \quad$ radicals generated at the centre, edge or anywhere in the particle, respectively. \\
\hline Asua \& de la Cal. (1991) [55] & $k_{\mathrm{des}}=\frac{p}{d^{\alpha}}, \quad 0 \leq \alpha \leq 2$ \\
\hline
\end{tabular}

Radical desorption mechanism accounting for polymer phase reactions: $k_{\mathrm{des}}=P \cdot f_{\mathrm{M}}, \quad f_{\mathrm{M}}=k_{\mathrm{fM}}[\mathrm{M}]_{\mathrm{p}}$

$\boldsymbol{P}$ : Probability of the radical escaping the particle before undergoing other reactions in the particle

$k_{0}$

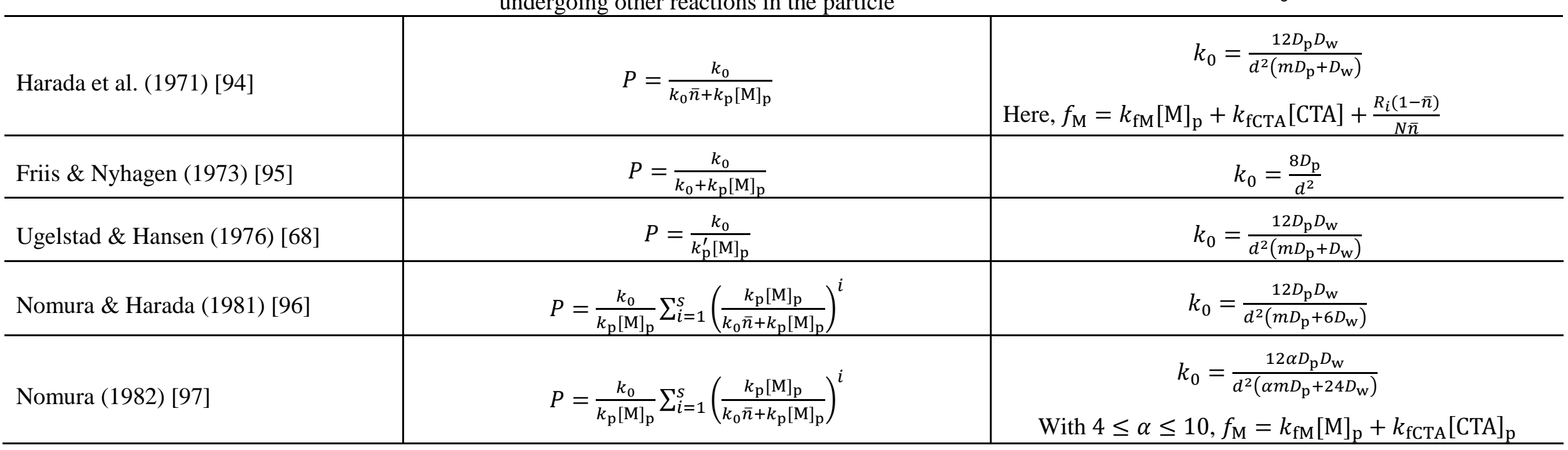




\begin{tabular}{|c|c|c|}
\hline Mead \& Poelhein (1989) [98] & $P=\frac{k_{0}}{k_{0}+k_{\mathrm{p}}[\mathrm{M}]_{\mathrm{p}}}$ & $\begin{array}{c}k_{0}=\frac{A 12 D_{\mathrm{p}} D_{\mathrm{w}}}{d^{2}\left(m D_{\mathrm{p}}+\epsilon D_{\mathrm{w}}\right)} \\
\text { With } \epsilon=\frac{k^{2}-3(k \operatorname{coth}(k)-1)}{k^{2}(k \operatorname{coth}(k)-1)}, k=\frac{d}{2} \sqrt{\frac{k_{\mathrm{p}}[\mathrm{M}]_{\mathrm{p}}}{D_{\mathrm{p}}}}\end{array}$ \\
\hline Lacik et al. (1992) [99] & $P=\frac{k_{0}}{k_{0}+k_{\mathrm{p}}[\mathrm{M}]_{\mathrm{p}}}$ & $k_{0}=\frac{12 D_{\mathrm{w}}}{m d^{2}}$ \\
\hline Grady (1996) [100] & $P=\frac{k_{0}(s-1)}{k_{0}(s-1)+k_{\mathrm{p}}[\mathrm{M}]_{\mathrm{p}}} \sum_{i=1}^{s} \frac{1}{1+m(i)}$ & $k_{0}=\frac{20 D_{\mathrm{p}} D_{\mathrm{w}}}{3 d^{2}\left(3 D_{\mathrm{p}}+D_{\mathrm{w}}\right)}$ \\
\hline Asua (2003) [101] & $\begin{array}{c}P=\frac{k_{0}}{k_{\mathrm{p}}[\mathrm{M}]_{p}+\frac{2 k_{\mathrm{tp}}(\bar{n}-1)}{N_{A} v}} P_{\mathrm{w}} \\
P_{w}=\frac{k_{\mathrm{pw}}[\mathrm{M}]_{\mathrm{W}}+2 k_{\mathrm{tw}}\left[\mathrm{T}^{*}\right]}{k_{0} m v N+k_{\mathrm{pw}}[\mathrm{M}]_{\mathrm{W}}+2 k_{\mathrm{tw}}\left[\mathrm{T}^{*}\right]}\end{array}$ & $\begin{array}{c}k_{0}=\frac{D_{\mathrm{w}} D_{p}}{d^{2}\left(m D_{\mathrm{p}}+m D_{\mathrm{w}} \frac{2 \delta_{1}}{D_{\mathrm{h}} d}+\epsilon D_{\mathrm{w}}\right)} \\
\text { With } \epsilon=\frac{1}{(k \operatorname{coth}(k)-1)}, k=\frac{d}{2} \sqrt{\frac{k_{\mathrm{p}}[\mathrm{M}]_{\mathrm{p}}+\frac{2 k_{\mathrm{t}}(\bar{n}-1)}{N_{\mathrm{A}} v}}{D_{\mathrm{p}}}}\end{array}$ \\
\hline
\end{tabular}

Radical desorption mechanism accounting for polymer and aqueous phase reactions: $k_{\mathrm{des}}=P \cdot f_{\mathrm{M}}, \quad f_{\mathrm{M}}=k_{\mathrm{fM}}[\mathrm{M}]_{\mathrm{p}}$

\begin{tabular}{|c|c|c|}
\hline & $\boldsymbol{P}:$ probability that a desorbed chain reacts in water & $\boldsymbol{k}_{\mathbf{0}}$ \\
\hline Hernandez \& Tauer (2008) [89] & $\begin{array}{l}P=\frac{P_{\mathrm{w}}\left(1-P_{\mathrm{p}}\right)}{1-\left(1-P_{\mathrm{w}}\right)\left(1-P_{\mathrm{p}}\right)} \\
P_{\mathrm{p}}=\frac{\sum_{i} k_{i, \mathrm{p}}}{k_{0}+\sum_{i} k_{i, \mathrm{p}}}, P_{\mathrm{w}}=\frac{\sum_{i} k_{\mathrm{i}, \mathrm{w}}}{\frac{k_{\mathrm{e}} N}{N_{\mathrm{A}}}+\sum_{i} k_{\mathrm{i}, \mathrm{w}}} \\
\text { Where } k_{i, \mathrm{p}} \text { and } k_{i, \mathrm{w}} \text { are rate coefficients for the } i^{\text {th }} \\
\text { competitive reaction in the polymer and aqueous phase } \\
\text { respectively, e.g. } \sum_{i} k_{i, \mathrm{w}}=k_{\mathrm{pw}}[\mathrm{M}]_{\mathrm{w}}+k_{\mathrm{tw}}\left[\mathrm{T}^{\circ}\right]_{\mathrm{W}}\end{array}$ & $k_{0}=\frac{60 D_{\mathrm{p}}}{d^{2}} \exp \left(-\frac{E_{\mathrm{des}}}{k_{\mathrm{B}} T}\right)$ \\
\hline Ghielmi et al. (2014) [91] & $\begin{array}{l}P=P_{\mathrm{d}}\left[1+\frac{\left(1-P_{\mathrm{w}}\right) P_{\mathrm{d}}}{1-\left(1-P_{\mathrm{w}}\right) P_{\mathrm{d}}} \frac{\bar{n} N_{i-1}}{n N_{i}}\right] \\
P_{\mathrm{d}}=\frac{k_{0}}{k_{0}+k_{\mathrm{p}}^{\prime}[\mathrm{M}]_{\mathrm{p}}}, P_{\mathrm{w}}=\frac{k_{\mathrm{tw}}\left[\mathrm{T}^{*}\right]_{\mathrm{w}}}{k_{\mathrm{tw}}\left[\mathrm{T}^{*}\right]_{\mathrm{w}}+k_{\mathrm{re}} \frac{N}{N_{\mathrm{A}}}}\end{array}$ & \\
\hline
\end{tabular}




\subsection{Surfactant partitioning}

The adsorption of surfactants on polymer surfaces is an important issue in various industrial processes, namely because of its direct bearing on the colloidal stability and rheological behaviour of polymer latexes.

Given that the adsorption of surfactants on the surface of polymer particles (or polymers in general for that matter) has such a strong impact on aspects such as latex stability, macroscopic viscosity and rheology, it is of great interest when modelling EP [52], [102]. Clearly, the surfactant will play a number of roles in determining the PSD in an emulsion polymerization process, and in particular in particle nucleation (micellar and homogeneous), secondary particle formation, particle coagulation, etc. Ideally, one would like to have reliable models and/or correlations, along with pertinent parameters in order to predict the location of the surfactant in the system of interest.

An adsorption isotherm can be used to describe surfactant partionning at equilibrium [103]. Different experimental approaches have been developed to measure the adsorption isotherms for different polymer-surfactant systems using conductivity, tensiometry or titration. For instance, Paxton[104] used surface tension titration curves to measure the adsorption of sodium dodecylbenzenesulfonate (SDBS) on PS and PMMA latexes. Using surface tension measurements of the aqueous phase after centrifuging their latexes, Brown \& Zhao [105] developed adsorption isotherms for the pair SDS and PS under different conditions. Zwetsloot \& Leyte[106] did not separate the particles from the aquous phase, and used conductivity to determine the adsorption isotherm of SDBS on PS. Stubbs et al. [107] criticized this approach, saying that the partitioning of the anionic surfactant can be hidden by the presence of initiator-derived anions (e.g., sodium or potassium) in the aqueous phase that can be more conductive. Using a different approach, Turner et al. [108] studied the adsorption of SDS on PS surfaces using neutron reflection and attenuated total reflection infrared spectroscopy. Serum replacement methods, followed by conductivity measurements of the stream leaving the replacement cell were used by Colombie et al. [109] to study the the adsorption of SDS on PS. Lin et al. [110] also investigated partitioning in the SDS/PS system using surface tension measurements, but using measurements of the latex surface tension. In yet another example of different techniques, Sefcik et al.[111] used ultratitration and analyzed the filtrate with ion chromatography (once again) of the system SDS-PS. In Pickering systems, Brunier et al. [112], [113] used different analytical methods to demonstrate the multilayer adsorption of clay on the surface of polystyrene particles such as transmission electron microscopy (TEM), quartz crystal microbalance and conductivity.

Among available isotherms, the Langmuir isotherm is the most widely used to describe the adsorption equilibrium of steric or electrostatic surfactants used in emulsion polymerization [114]. It was first 
developed to describe gas-solid adsorption assuming monolayer formation with no lateral interactions or steric hindrance between the adsorbed molecules. In specific areas, such as reactive surfactants, the adsorption may not be instantaneous to ensure equilibrium or the properties may evolve during the reaction.

In Pickering stabilization, other difficulties arise, such as the required longer dispersion time of the inorganic particles in water compared to surfactants, the lack of long term stability of the stabilizing colloids when dispersed in water, the absence of micelles, and the possible formation of multilayers on the polymer particles.[115] To model multilayer adsorption, the Brunauer-Emmett-Teller (BET) isotherm is the most widely used.[116] The concept of the theory is an extension of the Langmuir theory under the additional hypothesis that molecules can also physically adsorb by binding to already adsorbed molecules, resulting in the formation of multilayers with no limit regarding the number of layers. This model was first used to describe gas adsorption and then extended to liquid phase adsorption by substituting the partial pressure of the adsorbate by its concentration in the liquid phase. [117], [118] Recently, the BET isotherm was used to describe multilayer adsorption of clay platelets on polymer particles by Brunier et al. [112], [113].

In short, most quantitative investigations of surfactant partitioning seem to have been done in systems at equilibrium. In the absence of rapid nucleation or coagulation, this might be an acceptable approximation. However, if the surface area and/or surfactant concentrations are changing rapidly, then it remains to be seen what approach one can take with surfactant partitioning.

\subsection{Monomer partitioning}

In emulsion polymerization, the conversion from monomer to polymer occurs principally in the monomer-swollen polymer particles. Thus, the concentration of monomer in the polymer particles influences the rate of polymerization. In copolymerisations, monomer partitioning also affects the polymer composition. The monomer solubility and reaction in the aqueous phase also enhances homogeneous nucleation which influences the net reaction rate, as well as the final latex properties. Therefore, determining the monomer concentration in the different phases is important in order to evaluate particle formation and the final PSD. An old review on the theoretical considerations concerning the determining of the concentration of monomer in latex particles was done by Gardon.[119]

It is commonly believed that the monomer(s) is/are transferred from the monomer droplets (for liquid monomers) or from the monomer bubbles (for gas monomers) to the reaction site (polymer particles), most probably by diffusion through the aqueous phase (even though the assumption of monomer transfer through collision or shear-induced monomer transfer was also suggested [120]). Water and 
the polymer particles absorb a certain amount of monomer that is limited by thermodynamic equilibrium.

Essentially all models available in the literature assume thermodynamic equilibrium between the various phases present in the reactor (i.e., high mass transfer rate of monomer between the phases compared to the overall polymerization rate) (Table 7). Of course, this assumption will fail if, for instance, the stirring rate does not allow efficient monomer droplets breakup and the creation of a sufficient surface area for mass transfer. In particular, for the polymerisation of gaseous monomers in emulsion polymerization (such as ethylene, or fluorinated monomers such as tetrafluoroethylene or vinylidene fluoride), the reactor pressure becomes determinant for the concentration of monomer in the water and polymer phases and the rate of agitation can be critical in terms of ensuring a sufficiently high transport rate.

The assumption of homogeneously swollen particles under polymerization conditions was recently questioned by Tauer \& Hernandes[121], but this hypothesis is still implicit in every model. Based on the original Flory-Huggins[122] polymer solution theory, an equation determining the swelling of latex particles was developed by Morton et al.[123] under saturation homopolymerization, followed by Vanzo et al.[124] under unsaturation conditions, and by Guillot [125] for copolymerisation. These models state that the increase in surface energy on swelling compensates for the free energy gain of mixing, and takes into account the effect of the particles size on monomer partitioning. This model is still considered to provide the most complete description of the swelling of polymer particles with monomers, in the detriment of high number of involved parameters to be estimated. Ugelstad et al. (1983) contested the use of the Flory-Huggins model for evaluating the free energy of swelling of polymer, oligomer and polymer-oligomer particles. Maxwell et al.[126], [126]-[128] developed a semi-empirical simplified relationship for monomers of limited solubility in water. The equation involves the saturation swelling volume fraction of the polymers and no other parameter, and neglects the effect of the particle size on partitioning. Schoonbrood et al.[129] derived equations similar to that developed by Maxwell, from Morton's equation for partial and saturation swelling with $n$ monomers, depending only on the saturation concentrations of each monomer in the polymer particles and in the aqueous phase. A simpler model to determine the concentration of monomers in the different phases was proposed by Omi et al.[130] for monodisperse systems by employing constant partition coefficients. Armitage et al.[131] improved the algorithm for the calculation of the monomer partitioning in polydisperse emulsion copolymerization systems. In general, the constant partition coefficient algorithm is assumed to give the same results as Morton's model when used to determine the monomer partitioning in seeded and unseeded systems with high solids content, if the monomers 
are partially soluble in water, whereas, for unseeded low and medium solids content polymerizations involving completely water soluble monomers the Morton's equation is recommended.[132]

Table 7. Models for monomer partition between the different phases (copolymerisation case)

\begin{tabular}{|c|c|}
\hline Morton et al. (1954)[123] & $\begin{array}{l}\left(\frac{\Delta G}{\mathcal{R} T}\right)_{i}^{j}= \\
\ln \phi_{i}^{j}+\sum_{k=1}^{n}\left(1-m_{i k}\right) \phi_{k}^{j}+\sum_{k=1 \neq i}^{n} \chi_{i k}\left(\phi_{k}^{j}\right)^{2}+\sum_{k=1 \neq i}^{n-1} \sum_{l=k+1 \neq i}^{n} \phi_{k}^{j} \phi_{l}^{j}\left(\chi_{i k}+\right. \\
\left.\chi_{i l}-\chi_{i k} m_{i k}\right)+\frac{2 \gamma v_{i}}{r_{i} \mathcal{R} T}\end{array}$ \\
\hline $\begin{array}{l}\text { Maxwell et al. (1992-1993) } \\
\text { [122], [131] }\end{array}$ & $\begin{array}{l}\frac{\text { Under saturation, if } V_{\mathrm{A}}+V_{\mathrm{B}}>V^{\mathrm{p}}\left(\phi_{\mathrm{A}}^{\mathrm{p}}+\phi_{\mathrm{B}}^{\mathrm{p}}\right)+V^{\mathrm{w}}\left(\phi_{\mathrm{A}}^{\mathrm{w}}+\phi_{\mathrm{B}}^{\mathrm{w}}\right)}{V_{i}^{\mathrm{w}}=\frac{V^{\mathrm{w}}}{V^{\mathrm{d}}} V_{i}^{\mathrm{d}} \phi_{i, \text { sat }}^{\mathrm{w}}, i=\mathrm{A}, \mathrm{B}} \\
V_{\mathrm{A}}^{\mathrm{p}}=V_{\mathrm{A}}^{\mathrm{d}} \frac{V^{\mathrm{p}}}{V^{\mathrm{d}}}\left\{\left(\phi_{\mathrm{A}, \text { sat }}^{\mathrm{p}}-\phi_{\mathrm{B}, \mathrm{sat}}^{\mathrm{p}}\right) \frac{V_{\mathrm{A}}^{\mathrm{d}}}{V^{\mathrm{d}}}+\phi_{\mathrm{B}, \mathrm{sat}}^{\mathrm{p}}\right\} \\
V_{\mathrm{B}}^{\mathrm{p}}=V_{\mathrm{B}}^{\mathrm{d}} \frac{V^{\mathrm{p}}}{V^{\mathrm{d}}}\left\{\left(\phi_{\mathrm{B}, \text { sat }}^{\mathrm{p}}-\phi_{\mathrm{A}, \mathrm{sat}}^{\mathrm{p}}\right) \frac{V_{\mathrm{B}}^{\mathrm{d}}}{V^{\mathrm{d}}}+\phi_{\mathrm{A}, \mathrm{sat}}^{\mathrm{p}}\right\} \\
\text { Non saturated } \\
V_{\mathrm{A}}^{\mathrm{w}}=V^{\mathrm{w}} \phi_{\mathrm{A}, \mathrm{sat}}^{\prime \mathrm{w}}\left\{\frac{V_{\mathrm{A}}^{\mathrm{p}}}{V^{\mathrm{p}} \phi_{\mathrm{A}, \text { sat }}^{\prime \mathrm{p}}} \exp \left(\frac{V_{\mathrm{P}}^{\mathrm{p}}}{V^{\mathrm{p}}}-\phi_{\mathrm{P}, \text { sat }}^{\prime \mathrm{p}}\right)\right\} \\
V_{\mathrm{B}}^{\mathrm{w}}=V^{\mathrm{w}} \phi_{\mathrm{B}, \mathrm{sat}}^{\prime \mathrm{w}}\left\{\frac{V_{\mathrm{B}}^{\mathrm{p}}}{V^{\mathrm{p}} \phi_{\mathrm{B}, \mathrm{sat}}^{\prime \mathrm{p}}} \exp \left(\frac{V_{\mathrm{P}}^{\mathrm{p}}}{V^{\mathrm{p}}}-\phi_{\mathrm{P}, \text { sat }}^{\prime \mathrm{p}}\right)\right\}\end{array}$ \\
\hline Partition coefficient model & $k_{i}^{j}=\frac{\phi_{i}^{j}}{\phi_{i}^{\mathrm{w}}} ; i=A, B ; j=\mathrm{p}, \mathrm{d}$ \\
\hline
\end{tabular}

\subsection{Particle formation by nucleation}

Despite many decades of research, particle formation still remains a controversial and poorly understood issue. This is both due to the complexity of the phenomenon itself and to the experimental difficulties associated with its study.

\subsubsection{Mechanisms and rate of nucleation}

Although it has not always been so, most researchers now accept that the two most celebrated mechanisms of particle nucleation - micellar (or heterogeneous) and homogeneous - coexist in emulsion polymerization.[45], [134], [135][136] The relative importance of each depends on the specificities of the system and the conditions under which the reaction is carried out.

Droplet nucleation[137][138] is typically considered improbable in conventional EP and, hence, neglected in all current particle formation models. Nevertheless, a finite probability of nucleating monomer droplets exists, which may lead to the formation of coagulum.[139]

Table 8. Some of the various possible contributions to the nucleation rate (cf. Figure 3)

\begin{tabular}{ll}
\hline Homogeneous nucleation & $R_{\mathrm{hom}, \mathrm{I}}=k_{\mathrm{pw}}\left[\mathrm{IM}_{j_{\mathrm{cr}}-1}^{\cdot}\right]_{\mathrm{w}}[\mathrm{M}]_{\mathrm{w}}$ \\
& $R_{\mathrm{hom}, \mathrm{E}}=k_{\mathrm{pw}}\left[\mathrm{IM}_{\mathrm{Ecr}^{-1}}^{\cdot}\right]_{\mathrm{w}}[\mathrm{M}]_{\mathrm{W}}$ \\
\hline
\end{tabular}




\begin{tabular}{ll}
\hline Micellar nucleation & $R_{\mathrm{mic}, \mathrm{I}}=[\mathrm{MIC}] \sum_{i=z}^{j_{\mathrm{cr}}-1} k_{\mathrm{em}, \mathrm{I}(i)}\left[\mathrm{IM}_{i}^{*}\right]_{\mathrm{w}}$ \\
& $R_{\mathrm{mic}, \mathrm{E}}=[\mathrm{MIC}] \sum_{i=0}^{j_{\mathrm{Ecr}}-1} k_{\mathrm{em}, \mathrm{E}(i)}\left[\mathrm{EM}_{i}^{*}\right]_{\mathrm{w}}$ \\
\hline Total nucleation & $R_{\mathrm{nuc}}=\left(R_{\mathrm{hom}, \mathrm{I}}+R_{\mathrm{hom}, \mathrm{E}}\right)+\left(R_{\mathrm{mic}, \mathrm{I}}+R_{\mathrm{mic}, \mathrm{E}}\right)$ \\
\hline
\end{tabular}

Despite a certain consensus about the micellar and homogeneous nucleation mechanisms (cf. Table 8), different opinions persist. For instance, Tauer \& Kühn[140] proposed a new model for particle nucleation based on the classical nucleation theory and the Flory-Huggins theory of polymer solutions. The basic assumption is that water-born oligomers form stable nuclei under critical conditions. Among other things, the model can be used to analyze the influence of the monomer properties (e.g., solubility in water) on the nucleation time and $j$ cr. Good agreement between calculated and literature values for $j$ cr was found. Nevertheless, as presented, this simple model cannot account for relevant phenomena like coagulation, particle growth, secondary nucleation, etc. In a subsequent publication,[141] the same authors investigated the early stages of the emulsifier-free emulsion polymerization of styrene. They concluded that their results supported the view that nucleation occurs via cluster formation of water-born oligomers. The group later studied a system in which monomer was confined to a layer sitting on top of the water phase in a funnel-shaped reactor and found that sub-micron monomer droplets would spontaneously form just below the monomerwater interface both in the presence and absence of emulsifier.[142] The group[75] used the same reactor configuration to investigate the emulsifier-free polymerization of tert-butylstyrene, styrene and MMA. Monomer droplets (varying in size from $10^{-9}$ to $10^{-6} \mathrm{~m}$ in diameter) spontaneously formed at the monomer-water interface, regardless of monomer type. The authors proposed that the monomer droplets may constitute an additional site of particle nucleation and supported this claim using SEC-measurement data and TEM images.

Apart from these widely discussed aspects of the nucleation mechanism, there are a number of less popular topics that are also noteworthy. One particularly significant issue refers to the role of exited radicals on particle nucleation. As mentioned in Section 3.1.3, there is no agreement on this matter: some authors neglect it, while others assume that desorbed radicals can nucleate particles in exactly the same way as initiator-derived radicals. Proper account of the possibility of homogeneous and micellar nucleation by exited radicals requires a detailed reaction scheme as shown in Figure 3, where both types of radicals are distinguished. Ugelstad and co-workers[143], [144] proposed a scheme of this type, but only a few modeling studies[38] have actually made use of such an approach. Despite the lack of direct quantitative information, it seems plausible that this contribution could be significant, in particular, for systems where desorption is known to be relevant (e.g., VCM and VAc). 
In situ micellization[145] is sometimes pointed out as another possible nucleation mechanism when working with zero or small concentrations of surfactant. In this mechanism, micelles are formed from initiator-derived species presenting surface activity. Song \& Poehlein[146] state that in situ micellization can only be the dominating mechanism for sparingly soluble monomer systems; for more water soluble monomers, homogeneous nucleation dominates. According to Gilbert,[13] in situ micellization is expected to be rare at normal initiator concentrations, because under such conditions too much time would be required for the concentration of in situ surfactant to attain the corresponding CMC.

Finally, another interesting question is whether termination by coupling of two oligomers with DPs $i_{1}$ and $i_{2}$ such that $i_{1}+i_{2}>j$ cr can result in particle nucleation. This possibility has been mentioned by Hansen \& Ugelstad,[147] but these authors have neglected it on the basis that such chains would have two ionic groups and, thus, a higher value of $j$ cr. As a rule, this possibility is not taken into consideration.

Note that if the small particles (often called precursor or primary particles) formed by homogeneous and/or micellar nucleation are colloidally unstable, they will coagulate either among themselves or with other particles present in the system. This process of particle formation is sometimes named coagulative nucleation (as remarked by Fitch,[148] this is an unfortunate designation because of the contradiction in terms).

\subsubsection{Secondary Particle Formation}

Secondary particle formation (SPF) refers to the creation of a new population of particles in a system with pre-existing particles. In comparison to ab initio particle formation, SPF is far more complicated to quantify. This is because, in addition to all the factors relevant for ab initio systems, the number of new particles created also depends on the delicate balance between: (i) the rates of radical entry into pre-existing and new particles; (ii) the rates of coagulation between precursor particles (homocoagulation) and between precursor and old particles (heterocoagulation); and (iii) the rates of growth of new and old particles.

From a modeling point of view, it is convenient to distinguish between two situations:

- SPF is undesirable (e.g., growth of monodisperse latexes): it suffices to determine the range of conditions where it can be avoided.

- SPF is desirable (e.g., synthesis of bimodal latexes): it is necessary to determine the extent of SPF as a function of the operating conditions. 
In terms of modeling, the first situation can be seen as a particular case of the second. There is extensive literature mentioning SPF, but much less dealing with the quantitative aspects of this subject. The most relevant publications are reviewed below.

Hansen \& Ugelstad are among the first to investigate SPF both experimentally and theoretically. In an initial paper,[149] they analyzed the emulsifier-free polymerization of styrene. A series of batch runs with varying amounts of monodispersed seeds of different diameters were conducted, and the number of new particles determined by TEM. The experiments performed at $50^{\circ} \mathrm{C}$ showed unexpected maxima (sometimes even higher than in the experiments without seed) when the number of new

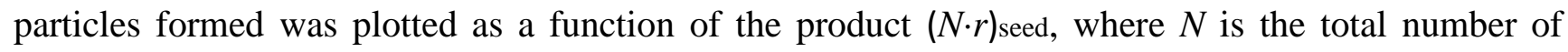
particles per unit volume and $r$ is the particle radius. On the other hand, the experiments at $60^{\circ} \mathrm{C}$, performed at lower ionic strength, gave a continuous decrease of the number of new particles with increasing $(N \cdot r)$ seed. The data were interpreted by means of a simple model, which was able to explain qualitatively the effect of $(N \cdot r)$ seed and seed surface charge density on the number of new particles. Coagulation of precursor particles, among themselves and with seed particles, was found to play an important role in determining the extent of SPF.

In a subsequent paper,[150] the same authors analyzed the effect of seed amount (for a single seed) and emulsifier concentration (above and below the $\mathrm{CMC}$ ) on the number of new particles formed. The data so obtained were used to draw conclusions about the role of micelles in particle nucleation. Regrettably, no attempt was made to interpret the data using the approach previously suggested.[149]

Morrison \& Gilbert[151] proposed a simple means to estimate the onset and extent of SPF in submicellar systems. Their treatment neglects coagulation and, thus, gives an upper bound to the number of particles formed. Model predictions were compared to experimental data obtained by the authors, showing reasonable agreement with respect to the onset of SPF. It was mentioned that increasing particle size and seed concentration lead to a decrease of SPF, but there was no reference as to whether the data correlated well with the product $(N \cdot r)$ seed. The maxima previously reported by Hansen \& Ugelstad[149] were attributed to in situ micellization. More recently, versions of this model have been used to explore conditions for growth of large particles[152] and core-shell VAc/Sty particles,[153] while avoiding SPF.

Cheong \& Kim[154] developed a model to investigate the effect of the surface charge density of the seed particles on SPF in the emulsifier-free seeded emulsion polymerization of MMA. The radical entry rate was assumed to depend on the electrostatic repulsion between oligoradicals and seed particles, which is, however, in contradiction with current knowledge.[155] Coagulation between precursor and seed particles was neglected. The simulation results could qualitatively explain the 
experimentally observed[63] effect of the seed charge density on polymerization rate and SPF, but no quantitative comparison was done.

Coen et al.[17] have employed the most sophisticated of all treatments described in this section, taking into account particle coagulation and PSD (further details in Section 3.5). The model was validated against the experimental data of Morrison \& Gilbert,[151] and improved accord was found in comparison with the results published by these authors. However, the predictions reported were obtained by assuming the seed particles to have a surface charge density corresponding to complete surface coverage with surfactant, when in reality the concentration of surfactant was very low: $[\mathrm{SDS}]=0.8 \mathrm{mM}$ (i.e., one-tenth of the CMC). Thus, the model failed in estimating particle coagulation rates, when this should be its major strength.

Jayasuriya \& Ottewill[156] following Chung-Li et al.[157] investigated the formation of new particles in the seeded emulsifier-free polymerization of styrene, and more particularly, conditions where SPF could be avoided. They found that the onset of SPF could be correlated to a minimum value of the

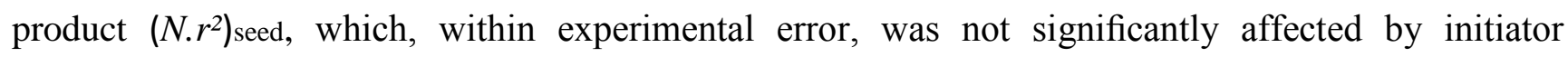
concentration or ionic strength.

Zeaiter et al.[158] extended the model of Coen et al.[40] to the semibatch EP of styrene, and used it to analyze the conditions for SPF. Comparison between calculated and experimental PSD typically showed poor agreement. Some simulations were done without leading to any particular conclusions.

Modeling nucleation, growth and particle coagulation in Pickering emulsion polymerization (surfactant free, stabilized by clay platelets) was considered by Brunier.[159] The authors tried to promote secondary particle nucleation using clay particles in Pickering EP, which could not be achieved and was attributed to the multilayer adsorption of clay platelets on the surface of polymer particles.[112]

\subsection{Particle Coagulation}

Quite frequently, coagulation is neglected when modeling particle formation without proper justification, just because of the added complexity it represents. However, there is substantial experimental evidence [160]-[164] supporting the role of coagulation in particle formation, including above the CMC. As a result, in our opinion, accounting for coagulation should be the rule, not the exception. The problem is that estimating the particle coagulation rates is not a simple matter, as explained below.

Two distinct mechanisms are responsible for particle coagulation in EP: (i) perikinetic aggregation, due to Brownian motion, which is diffusion-limited and (ii) orthokinetic aggregation, due to transport 
by fluid motion. Accounting for both coagulation mechanisms in a rigorous manner demands however a very complex mathematical treatment, by either considering precise estimations of the flow properties by computational fluid dynamics (CFD) or approximations of these properties (e.g., mean shear rate, mean energy dissipation rate, Peclet number).[165]-[167] Theoretical studies of particle coagulation suggest that hydrodynamics can play an important role when ionic strength is low and the double layer is thick (see Melis et al. for more details[168]). Forcolin et al.[169] found in their case that the contribution of fluid flow to the coagulation rate was limited, thereby justifying the use of a Brownian-only coagulation model. A number of other researchers neglect orthokinetic aggregation when modeling emulsion polymerization based on experimental results.[168]-[170] Perikinetic aggregation is sought to be the dominant mechanism at small particle sizes ( 50 nm).[171]

For modeling purposes, the coagulation between particles is assumed to occur as a result of binary collision events, although the assumption that all particles will coagulate through a binary collision mechanism is valid only when working with dilute systems. However, due to the complexity of formulating and solving the equations for multi-body collisions (never-mind experimental validation of the parameters), binary collision models have been used at all latex concentrations.[172]

What modelling the impact of coagulation on the PSD boils down to, is estimating the coagulation rate kernel $\beta$. This function will depend on numerous factors including the size of the particles, the state of their surface, the concentration and type of surfactant in the reactor, solids loading, the PSD, the intensity and distribution of shear in the reactor, and so forth. In the following section, perikinetic and orthokinetic coagulation mechanisms are discussed assuming that coagulation is exclusively due to binary particle interactions.

\subsubsection{Perikinetic Coagulation - the DLVO Approach}

Estimates of the rate of Brownian coagulation in EP are frequently obtained using the DLVO theory of colloid stability as a framework, but other empirical models have also been used (cf. Table 9).[38], [173], [174] In fact, the use of the DLVO theory to compute the coagulation rate coefficients is sometimes presented as a guarantee of quality for an EP model. The starting point of this approach is the Smoluchowski equation (which assumes laminar fluid motion and a collision efficiency of unity), to which the stability ratio of particles $(W)$ is added to account for the stabilizing surface charge density. Particle stability is dependent on the total particle potential energy of interaction, $V_{\mathrm{T}}$, which is the net sum of all attractive and repulsive contributions, including van der Waals' attraction and electrostatic, steric, depletion and solvation-based repulsion.[52]

Despite its widespread use, fundamental concerns arise regarding the use of DLVO theory in modeling EP. DLVO-based models do not provide accurate predictions of the aggregation rates of 
colloids when the potential barrier is located at surface distances below 1-2 nm, where non-DLVO forces dependent on the structure of the solution and particle surface become important.[175] It must also be noted that it is often difficult to obtain reliable estimates for a number of model input parameters such as the diffuse surface potential and surface charge density of the particles. Deviations of $10 \%$ in such parameters can result in differences of two orders of magnitude in the predicted stability ratio. Finally, there is substantial evidence that DLVO theory cannot explain a number of experimentally-observed trends and, therefore, may not correctly estimate the rate of particle aggregation under typical EP operating conditions.[175]-[178]

Table 9. Typical expressions used to compute the rate of Brownian (or perikinetic) coagulation

\begin{tabular}{|c|c|}
\hline Smoluchowski (1917) [179] & $\begin{array}{l}\beta\left(r, r^{\prime}\right)=4 \pi\left(r+r^{\prime}\right) \underbrace{\frac{k_{\mathrm{B}} T}{6 \pi \mu}\left(\frac{1}{r}+\frac{1}{r^{\prime}}\right)}_{D}=\frac{2 k_{\mathrm{B}} T}{3 \mu}\left(r+r^{\prime}\right)\left(\frac{1}{r}+\frac{1}{r^{\prime}}\right) \\
\beta\left(r, r^{\prime}\right)=\frac{2 k_{\mathrm{B}} T}{3 \mu}\left(r^{1 / d_{\mathrm{f}}}+r^{\prime 1 / d_{\mathrm{f}}}\right)\left(\frac{1}{r^{1 / d_{\mathrm{f}}}}+\frac{1}{r^{\prime 1 / d_{\mathrm{f}}}}\right)\end{array}$ \\
\hline \multicolumn{2}{|l|}{ Stability ratio (shear independent) } \\
\hline Fuchs (1934)[181] & $W\left(r, r^{\prime}\right)=\left(r+r^{\prime}\right) \int_{r+r^{\prime}}^{\infty} \exp \left(\frac{V_{\mathrm{T}}}{k_{\mathrm{B}} T}\right) \frac{d R}{R^{2}}$ \\
\hline Fuchs [182],[183] & $W\left(r, r^{\prime}\right) \approx \frac{r+r^{\prime}}{4 \kappa r r^{\prime}} \exp \left(\frac{V_{\mathrm{T}, \max }}{k_{\mathrm{B}} T}\right)$ \\
\hline DLVO[184] & $\beta\left(r, r^{\prime}\right)=\frac{2 k_{\mathrm{B}} T}{3 \mu W}\left(r+r^{\prime}\right)\left(\frac{1}{r}+\frac{1}{r^{\prime}}\right)$ \\
\hline Net potential & $V_{\mathrm{T}}=V_{\mathrm{A}}+V_{\mathrm{R}}$ \\
\hline Attractive potential[185] & $V_{\mathrm{A}}=-\frac{A}{6}\left[\frac{2 r r^{\prime}}{R^{2}-\left(r+r^{\prime}\right)^{2}}+\frac{2 r r^{\prime}}{R^{2}-\left(r-r^{\prime}\right)^{2}}+\ln \left(\frac{R^{2}-\left(r+r^{\prime}\right)^{2}}{R^{2}-\left(r-r^{\prime}\right)^{2}}\right)\right]$ \\
\hline Repulsive potential[186] & $V_{\mathrm{R}} \approx \frac{\epsilon r r \prime\left(\zeta^{2}+\left(\zeta^{\prime}\right)^{2}\right)}{4(r+r \prime)}\left[\frac{2 \zeta \zeta^{\prime}}{\zeta^{2}+\zeta^{\prime 2}} \ln \left(\frac{1+e^{-\kappa L}}{1-e^{-\kappa L}}\right)+\ln (1-\exp (-2 \kappa L))\right]$ \\
\hline Zeta potential [40] & $\zeta=\left(\frac{2 k_{\mathrm{B}} T}{v e}\right) \ln \left(\frac{\exp \left(\lambda_{4}\right)+1}{\exp \left(\lambda_{4}\right)-1}\right), \lambda_{4}=\delta_{\mathrm{s}} \kappa+\ln \left(\frac{\exp \left(\lambda_{5}\right)+1}{\exp \left(\lambda_{5}\right)-1}\right), \lambda_{5}=\frac{v e \Psi}{2 k_{\mathrm{B}} T}$ \\
\hline Surface potential & $\Psi= \begin{cases}\frac{4 \pi r o}{\varepsilon(1+\kappa r)} & , \text { if } \kappa r<1 \\
\frac{2 k_{\mathrm{B}} T}{e} \sinh ^{-1}\left(\frac{2 \pi e \sigma}{\varepsilon \kappa k_{\mathrm{B}} T}\right) & , \text { if } \kappa r>1\end{cases}$ \\
\hline Reciprocal Debye length & $\kappa=\sqrt{\frac{8 \pi N_{\mathrm{A}} e^{2} I_{\mathrm{s}}}{\varepsilon k_{\mathrm{B}} T}}, \varepsilon=4 \pi \varepsilon_{0} \varepsilon_{\mathrm{r}}, I_{\mathrm{s}}=\frac{1}{2} \sum C_{\mathrm{e}, i} v_{i}^{2}$ \\
\hline Total surface charge & $\sigma=\sigma_{\mathrm{S}}+\sigma_{\mathrm{I}}$ \\
\hline Surface charge due to surfactant & $\sigma_{\mathrm{S}}=\frac{v e}{A_{\mathrm{S}}}$ \\
\hline $\begin{array}{l}\text { Surface charge due to initiator- } \\
\text { derived radicals }\end{array}$ & $\sigma_{\mathrm{I}}=\frac{2\left([\mathrm{I}]_{0}-[\mathrm{I}]\right) v e N_{\mathrm{A}}}{A_{\mathrm{p}}}, A_{\mathrm{p}}=\int_{r_{\mathrm{nuc}}}^{\infty} 4 \pi r^{2} f(r) \mathrm{d} r$ \\
\hline Surface-to-surface distance & $L=R-\left(r+r^{\prime}\right)$ \\
\hline
\end{tabular}

Furthermore, DLVO theory assumes a dilute dispersion, such that the influence of the surrounding particles on the pair of interacting particles can be neglected. In concentrated systems, the surrounding particles cause an effective reduction of the total potential energy of the interacting particles, and hence a lower stability ratio.[187]-[189] This may have important implications in modeling particle 
coagulation in EP, particularly for high solid content where the concentration effect is likely to be relevant. Finally, in the development of DLVO-based models it is assumed that every particle in the system has the same surfactant coverage, while in reality the precursor particles formed from homogeneous nucleation may undergo coagulation at a rate faster than surfactant diffusion. For a complete overview of the failings of DLVO theory, as applicable to emulsion polymerization, again refer to Vale \& McKenna's review of PBEs in EP.[5]

Despite this, DLVO theory remains the most common basis for non-empirical modeling of particle coagulation and it is possible to fit certain model parameters to obtain coagulation rate coefficients that correctly describe experimental results. On the other hand, because of its theoretical limitations, certain authors[38], [173], [174] prefer to use empirical expressions for the coagulation rate coefficient or for the stability ratio. Sure, empirical methods are clearly not a definitive solution, but in many cases they are perhaps as 'scientific' as current DLVO theory applied to EP.

\subsubsection{Combined perikinetic and orthokinetic coagulation}

As mentioned above, most DLVO-based coagulation models have been formulated and experimentally validated under the assumption that shear-induced coagulation can be effectively ignored and omitted from the model, despite some evidence that mechanically-induced coagulation can occur under certain conditions. More complex treatments of particle coagulation, especially in larger reactors, where the local shear can be significant, should ideally integrate orthokinetic coagulation.

Another situation is frequently met, where only pure orthokinketic coagulation is considered, especially for big droplets/bubbles, where the electrostatic layer effect becomes negligible. A review by Meyer \& Deglon[190] that treats a wide number of applications, not just polymer colloids, suggests that the orthokinetic coagulation coefficient can be correlated with the shear rate. Nevertheless, they and other authors show that the semi-empirical coagulation models that have been validated experimentally require extensive parameter-fitting.[191], [192] Therefore, their applicability to a wider range of process conditions is limited.

The relative importance of the perikinetic or orthokinetic coagulation mechanisms depends on both the polymerization recipe and the mixing conditions; namely, on particle size, shear rate, and colloidal stability. In some cases, the coagulation rate coefficient for particles of a given size may include contributions from both orthorkinetic and perikinetic terms. However, the contributions of these two mechanisms to the overall coagulation rate are not necessarily additive.[193]-[195] Actually, considering these contributions as additive is equivalent to saying that particle stabilization (e.g., due to the presence of surfactant at their surface) is not efficient against orthokinetic 
coagulation. Thus, the additive-flux assumption is supposed to work well in the limit of completely screened electrostatic repulsion.[196] However, in relatively stable dispersions, there is a strong nonlinear coupling between convection and diffusion, which means that the overall coagulation rate coefficient is not equal to the sum of the two aggregation mechanisms. Thus, orthokinetic coagulation is slowed down due to the surfactant.

Table 10. Examples of expressions used to compute the rates of orthokinetic and combined (orthokinetic + perikinetic) coagulation

Some pure orthokinetic kernels

Smoluchowski (1917) (Laminar)

[179]

Saffman \& Turner (1956)

(Turbulent) [197]

Shear-dependent stability ratio

Blackley (1997) [198]

Spielman (1970) [199]

$$
\begin{gathered}
\beta\left(r, r^{\prime}\right)=\frac{4}{3} \dot{\gamma}\left(r+r^{\prime}\right)^{3} \\
\beta\left(r, r^{\prime}\right)=\sqrt{\frac{8 \pi}{15}} \underbrace{\sqrt{\frac{\epsilon}{v}}}_{\dot{\gamma}}\left(r+r^{\prime}\right)^{3}
\end{gathered}
$$

Combined - Additive:

Melis et al. (1999) [168], (using $W$

at zero shear)

$$
\begin{gathered}
W\left(r, r^{\prime}\right)=\left(r+r^{\prime}\right) \int_{r+r^{\prime}}^{\infty} \exp \left(\frac{V_{\mathrm{T}}-2 \dot{\gamma} \mu r r^{\prime}\left(r+r^{\prime}\right)^{2} / R}{k_{\mathrm{B}} T}\right) \frac{d R}{R^{2}} \\
W\left(r, r^{\prime}\right)=\left(r+r^{\prime}\right) \int_{r+r^{\prime}}^{\infty} \frac{\exp \left(\frac{V_{\mathrm{T}}}{k_{\mathrm{B}} T}\right)}{G} \frac{d R}{R^{2}}
\end{gathered}
$$

Moussa et al. (2013) [196]

Combined - Multiplicative:

Blackley (1997) [198], then used by

Elgebrandt et al. (2005) [193], (using

$W$ at zero shear)

Lattuada \& Morbidelli (2011) [194]

$$
\begin{gathered}
\beta\left(r, r^{\prime}\right)=\underbrace{\frac{4 k_{\mathrm{B}} T}{3 \mu W}\left(r+r^{\prime}\right)\left(\frac{1}{r}+\frac{1}{r^{\prime}}\right)}_{\beta_{\text {diff }}}+\underbrace{p \dot{\gamma}^{0.86}}_{\beta_{\text {conv }}} \\
\beta\left(r, r^{\prime}\right)=\frac{2 k_{\mathrm{B}} T}{3 \mu}\left(r^{1 / d_{\mathrm{f}}}+r^{\prime 1 / d_{\mathrm{f}}}\right)\left(\frac{1}{r^{1 / d_{\mathrm{f}}}}+\frac{1}{r^{\prime 1 / d_{\mathrm{f}}}}\right)+\frac{4}{3} \dot{\gamma}\left(r^{1 / d_{\mathrm{f}}}+r^{\prime 1 / d_{\mathrm{f}}}\right)^{3}
\end{gathered}
$$

$$
\begin{aligned}
& \beta\left(r, r^{\prime}\right)=\frac{2}{3} \frac{\dot{\gamma}}{W}\left(r+r^{\prime}\right)^{3} \\
& \beta\left(r, r^{\prime}\right)=\frac{\frac{2 k_{\mathrm{B}} T}{3 \mu}\left(r+r^{\prime}\right)\left(\frac{1}{r}+\frac{1}{r^{\prime}}\right)}{2 \int_{2}^{\infty} \frac{e^{\mathrm{H}(2+\delta-\xi)}\left(\int_{2+\delta}^{\xi}\left[-\mathrm{Pe} \cdot f(\xi)+\frac{1}{k_{\mathrm{B}} T} \frac{\mathrm{d} V_{\mathrm{int}}}{\mathrm{d} \xi}\right] \mathrm{d} \xi-\mathrm{Pe} \frac{p_{2}}{2+\delta}\right)-\mathrm{Pe} \cdot \mathrm{H}(\xi-2-\delta) \mathrm{d} \xi}{\xi^{2}}} \\
& \xi=\frac{2 R}{r+r^{\prime}}, \delta=p \sqrt{\frac{2}{\left(r+r^{\prime}\right) \mathrm{Pe}}}, f(\xi)=-\frac{\xi\left(1-G^{\prime}\right)}{3 \sqrt{3} G}, \mathrm{Pe}=\frac{3 \pi \mu r r^{\prime}\left(r+r^{\prime}\right)}{2 k_{\mathrm{B}} T}
\end{aligned}
$$

Lowry et al.[191], [192] used a semi-empirical coagulation model to study systems where both mechanisms are thought to be relevant, in an additive way. Melis et al.[168] investigated simultaneous shear-induced aggregation and DLVO-type interactions in an additive way. They conducted a theoretical investigation into the changes that arise in the magnitude of the coagulation rate coefficient as the ratio of fluid convection to particle diffusion changes. Under unstable conditions (i.e., low electrostatic forces), they suggested a semi-empirical expression (cf. Table 10), whereby the perikinetic and orthokinetic contributions were assumed to be additive. At low shear rates, $\beta=\beta_{\text {diff }}$ (i.e., the lower limit is independent of shear rate), while at high shear rates, $\beta$ varies nonlinearly with the shear rate (or Peclet number). However, this solution seemed to fit better systems that were rather unstable, giving a poor fit for more stable systems, where the transition between the two limits occurs 
over a much narrower range of shear rate. Thus, despite providing useful insight to the convectiondiffusion equation, attempts to develop an analytical expression that matched the numerical data over a full range of shear rates were generally unsuccessful.

Later, Lattuada \& Morbidelli[194] developed such an analytical expression. Through the use of a boundary layer approximation, they demonstrated that one can obtain a simplified model which matches the more thorough numerical simulations, even in the moderate shear rate range where the aggregation rate may sharply increase many orders of magnitude. Both mechanisms were taken into account in a combined way, so not simply added to each other. A combined kernel was also proposed by Blackley[198] and was used by Elgebrandt et al. [193]. In this kernel, the stability ratio is modified to account for both perikinetic and orthokinetic effects.

For the formation of non-spherical aggregates, Moussa et al.[196] considered both the perikinetic and orthokinetic kernel in an additive way and accounted for the particle shape through the fractal particle dimension.

The only thing that one can really conclude about this particular aspect of modeling the PSD of emulsion polymerization systems is that once one begins to include hydrodynamic effects on coagulation, the situation is even less clear than it is for perikinetic coagulation. Taking into account both perikinetic and orthokinetic coagulation in a combined way (not additive) is important in a number of cases, depending on the particles size, shear rate and electrostatic stabilization.

\section{Predictive Power of Current PSD Models}

Here, we present a critical review of the PBMs reported in the literature. The purpose is to assess the real capabilities of current models with respect to the prediction of particle formation and PSD evolution (cf. Table 11).

Table 11. Population balance models of EP by alphabetic order (1994-2015)

\begin{tabular}{lllll}
\hline Reference & System & Kinetics & Coagulation & Exp. validation \\
\hline Abad et al. [81] & VAc/Veova & PB & N & Y \\
Abad et al. [200] & VAc/Veova & PB & N & Y \\
Abedini \& Shahrokhi [201] & Sty & $0-1$ & Y & Y \\
Alamir et al. [202] & BA/MMA & PB & N & N \\
Alexopoulos et al. [165] & BA/MMA & PB & Y & Y \\
Araújo et al. [173]. & VAc/Veova & PB & Y & Y \\
Barazandegan et al. [203] & VAc & PB & N & N \\
Brunier et al. [159] & Sty & PB & Y & Y \\
Coen et al. [17] & Sty & $0-1$ & Y & Y \\
Coen et al.[25] & BA & $0-1 /$ PB & Y & Y \\
Crowley et al. [204] & Sty & $0-1$ & N & N \\
Dokucu et al. [205], [206] & VAc/BA & PB & Y & N \\
Edouard et al. [19] & Sty & PB & N & N \\
Feiz \& Navarchin [207] & Sty & $0-1$ & Y & Y
\end{tabular}


Forcolin et al. [169]

Fortuny et al. [10], [208]

Herrera \& Olayo [70], [209]

Hosseini et al. [210]

Hosseini et al. [23]

Immanuel et al. [211]

Immanuel et al. [212]

Jung \& Gomes [26]

Kammona et al. [213]

Kiparissides et al. [214]

Marinangelo et al. [215]

Meadows et al. [216]

Melis et al. [217]

Park et al. [218]

Pohn et al. [219]

Rajabi-Hamane \& Engell [220]

Sajjadi [221]

Saldívar et al. [4], [222]-[224]

Sood [225]

Sood [226]

Sweetman et al. [227]

Unzueta \& Forcada [174]

Vale \& McKenna [38]

Wulkow \& Richards [228]

Zeaiter et al. [158], [229]

$\begin{array}{llll}\text { VCM } & \text { PB } & \text { Y } & \text { N } \\ \text { MMA/BA } & \text { PB } & \text { Y } & \text { Y } \\ \text { Sty } & \text { PB } & \text { N } & \text { Y } \\ \text { Sty } & 0-1 & \text { N } & \text { Y } \\ \text { Sty } & \text { PB } & \text { N } & \text { Y } \\ \text { VAc/BA } & \text { PB } & \text { N } & \text { Y } \\ \text { VAc/BA } & \text { PB } & \text { Y } & \text { Y } \\ \text { Sty, BA } & 0-1 / \text { PB } & \text { Y } & \text { Y } \\ \text { Sty/2-EHA } & \text { PB } & \text { Y } & \text { Y } \\ \text { VCM } & \text { PB } & \text { Y } & \text { Y } \\ \text { Sty/BA } & \text { PB } & \text { N } & \text { N } \\ \text { Sty } & 0-1 & \text { N } & \text { N } \\ \text { VCM } & \text { PB } & \text { Y } & \text { N } \\ \text { VAc/BA } & \text { PB } & \text { Y } & \text { N } \\ \text { Sty } & 0-1 & \text { Y } & \text { N } \\ \text { Sty } & \text { PB } & \text { N } & \text { Y } \\ \text { Sty } & 0-1-2-3 & \text { N } & \text { Y } \\ \text { various binaries } & \text { PB } & \text { N } & \text { N } \\ \text { Sty } & \text { PB } & \text { N } & \text { Y } \\ \text { Sty } & \text { PB } & \text { N } & \text { N } \\ \text { VAc/BA } & \text { PB } & \text { Y } & \text { Y } \\ \text { MMA/BA } & \text { PB } & \text { Y } & \text { Y } \\ \text { VCM } & 0-1-2 & \text { Y } & \text { Y } \\ - & 0-1-2 & \text { N } & \text { Y } \\ \text { Sty } & 0-1 & \text { Y } & \end{array}$

Abad et al.[81] developed a model to describe the evolution of PSD in the emulsion copolymerization of VAc and Veova 10 in a continuous loop reactor. The RTD of the reactor was experimentally determined and it was found that, for the high recycle ratios used, the RTD was close to that of an ideal CSTR. Particle formation was modeled by a variation of the empirical approach proposed by Urretabizkaia et al.[230] and particle coagulation was neglected. The steady-state PSDs computed by the model were compared with experimental data obtained at 25 and $33 \%$ solids content, good agreement being found. It should not be forgotten, however, that with such reactors the shape of the PSD (broad) is, to a great extent, determined by the RTD.

In a subsequent paper, Abad et al.[200] modeled the same reactor in terms of two axial dispersion sections: the tube and the pump. No quantitative information was given about the RTD and no comparison was done with the work mentioned in the previous paragraph. The time evolution of the PSD predicted by the model agreed reasonably with the experimental distributions.

A few years later, the same polymerization process was modeled by Araújo et al.[224] using a different approach. Again, the reactor was modeled as an ideal CSTR, but particle coagulation was now included. A critical stability diameter was defined and used to divide the latex particles in two distinct populations. Particles with diameters below and above the critical value were designated, respectively, precursor and stable particles. Precursor particles can coagulate both with themselves 
(rate coefficient $\beta_{\mathrm{pp}}$ ) and with stable particles (rate coefficient $\beta_{\mathrm{ps}}$ ). Stable particles do not coagulate among themselves. Such a procedure may be seen as a discretization of the continuous kernel $\beta\left(r, r^{\prime}\right)$. The coagulation rate constants $\beta_{\mathrm{pp}}$ and $\beta_{\mathrm{ps}}$ were obtained by fitting the model to the experimental data. The model was able to qualitatively describe the main dynamic features of the reaction. The authors pointed out that the development of oscillatory patterns and PSD is intimately related to the existence of a population of precursor particles.

Coen et al.[17] were the first to develop a full PBM accounting for particle coagulation by means of the DLVO theory. The authors tested their model against experimental data on the $a b$ initio and seeded polymerization of styrene. With respect to ab initio systems, the model could adequately reproduce the effect of the surfactant (SDS) concentration on the final particle number, despite some mismatch around the $\mathrm{CMC}$. The effect of electrolyte $(\mathrm{NaCl})$ addition on the particle number was well described by the model for surfactant concentrations above the $\mathrm{CMC}$, but not below. At equal conversions, the general shape of the PSD was correctly predicted, but since the PSDs were essentially symmetrical this does not tell much about the model capabilities. Results on seeded experiments discussed above demonstrated the inability of the model in estimating the coagulation rate between particles.

More recently, Abedini \& Shahrokhi[231] modified Coen's model[17] to account for the effect of the aqueous phase ionic strength on the CMC using an empirical expression similar to the expression presented in Meadows et al.[216] The parameters of the CMC model were fitted to PSD data from two experimental runs, rather than CMC measurement data, as was done in Meadows' work. The model was shown to correctly predict the effects of temperature and initiator and surfactant concentrations on the evolution of conversion and the final PSD. The model predictions obtained with a fixed CMC value were not included for comparison.

In 2004, Coen et al.[25] proposed a method to extend their previous model[17] to systems where pseudo-bulk kinetics are important during the nucleation period. The authors defined a cross-over radius $r_{\mathrm{co}}$ and used it to divide the particle size domain in two regions: zero-one kinetics for $r<r_{\mathrm{co}}$, and pseudo-bulk kinetics for $r>r_{\text {co. }}$. To simplify the mathematics, the authors did not include coagulation above $r_{\mathrm{co}}$. This assumption seems questionable, however, there is no clear reason why the coagulation rate between a small and a big particle would be insignificant with respect to the coagulation rate between two small particles. The method to link the set of PBEs describing the 0-1 region with the PBE describing the PB region is not explained. This approach was applied to the $a b$ initio polymerization of BA. For the limited data presented, the evolution of conversion and the effects of initiator and surfactant (SDS) concentration on the final particle number were correctly predicted. No experimental or simulated PSDs were shown. 
Quite recently, Jung \& Gomes[26] adapted the concept of a cross-over radius to model the emulsion polymerization of styrene under batch operation and butyl acrylate under both batch and semibatch operation. The authors chose to neglect particle coagulation entirely due to the surfactant concentration being well above the $\mathrm{CMC}$; this simplification is questionable, as the concentration of aqueous phase surfactant will decrease during the course of a batch polymerization. The authors state that the two PBE systems are linked by smoothing the predictions over an $r_{\mathrm{co}}$ range (15-25 $\mathrm{nm}$ for BA; 50-60 nm for Sty), but the specifics of the smoothing operation were not presented. The level of experimental validation was limited to one set of batch conditions per monomer type. The evolution of conversion and the average particle diameter were correctly predicted for both the BA and Sty systems. For the BA system, the evolution of the MWD was correctly predicted, while the time evolution of the PSD curves was well-predicted at the first time step shown. The MWD and PSD curves were not shown for the Sty system. Although the stated objective of the publication was to develop semibatch process strategies using the model, the proposed strategy was not tested experimentally.

Feiz \& Navarchin[207] developed a model that focused on the adjustment of the surfactant ratio for a mixed ionic/non-ionic surfactant system in the batch ab initio emulsion polymerization of Sty. The DLVO framework was employed to model particle coagulation, with the total repulsive potential computed as a sum of the electrostatic and steric repulsive potentials. The CMC of the mixed surfactant system was modeled semi-empirically on the basis of thermodynamic theory for non-ideal mixtures and the adjustable interaction parameter was fit to $\mathrm{CMC}$ measurement data. The modelpredicted PSDs and conversion curves were in good agreement with the experimental data presented. $N$ vs. $t$ profiles obtained from simulation were presented, but no comparison with experimental data was made, nor were any transient PSD data presented.

Fortuny et al.[10], [208] modeled the nucleation stage during the batch emulsion polymerization of MMA and BA. Polymerization kinetics was independently validated by performing seed growth experiments (in the absence of SPF and coagulation). Good agreement was found between experimental and predicted values of instantaneous conversion and average particle size, for a wide range of conditions. Particle coagulation was quantified by a DLVO model with parameters validated in the absence of reaction.[232] The complete model (combining kinetics, coagulation, and nucleation) predicted the formation of a large number of moderately short-lived particles during the first instants of the reaction. The $N$ vs. $t$ profile computed by this model is completely different from those obtained with other PBMs, although in agreement with the findings of Fitch \& Tsai.[160]

Herrera \& Olayo[70], [209] developed a model for the polymerization of styrene above the CMC. Their objective was to demonstrate that a model without coagulation could correctly explain the 
experimental data obtained for this system. Reasonable accord was found for the effect of initiator and surfactant concentrations on monomer conversion. In contrast, agreement with experimental particle number and PSD data could only be achieved if, in the predicted PSD, particles with diameters below $20 \mathrm{~nm}$ were neglected. This incoherence was attributed to difficulties in experimentally detecting small particles. Nevertheless, the possibility that the mismatch can result from the fact that the model does not take coagulation into account should not be set aside.

Hosseini et al.[210] developed a seeded styrene emulsion polymerization model that included an additional term in the growth kernel to account for stochastic broadening. Particle coagulation and secondary particle nucleation were neglected. The stochastic broadening of the PSD over time was modeled using the Fokker-Planck equation. The dispersion coefficient parameter was estimated with a least squares fitting approach where the residual was the difference between the measured and predicted PSDs at a set of points in time. No information was given on the number of datum points used to compute the residuals. When the estimated stochastic correction was subsequently included in the simulation of an additional set of experimental conditions, there was good agreement between experimental and simulated PSDs. It must be noted however that only the amount of monomer added and the monomer flow rate were varied across experiments; the applicability of the approach to a wider range of processes (e.g., ab initio polymerization or multimodal PSDs) remains unknown.

Immanuel et al. developed two models for the semibatch emulsion copolymerization of VAc and BA stabilized by a nonionic poly(ethylene oxide) surfactant: a coagulation-free[211] and a coagulationinclusive[212] model. In the latter model, the steric repulsive potential due to the nonionic surfactant was described by a simple formula given by Israelachvili,[233] which accounts for osmotic and elastic contributions. Simulations were compared with experimental values of the solids content, number of particles, and PSD, obtained for different feed profiles of the monomers, surfactant, and initiator. The coagulation-inclusive model was able to provide better predictions, but only at a qualitative level. Quantitatively, the evolution of the number of particles and PSD showed significant mismatch. Recently, Immanuel et al.[234] compared the predictive performance of the coagulation-inclusive equations accounting for the total number of particles and total volume of the particle phase, under both semibatch and continuous operation. The model predictions were not directly compared against experimental data.

Kammona et al.[213] modeled the emulsion copolymerization of Sty and 2-EHA stabilized by a nonionic surfactant. A steric stabilization model previously developed by the same research group[235] was used. Experiments were conducted to analyze the effect of temperature, monomer composition, and initiator and emulsifier concentrations. Despite the large body of data, only a limited set of runs were used in validating the model. The comparisons presented agreed reasonably with 
experimental data. An example of comparison between experimental and predicted PSDs was given, showing good agreement.

Kiparissides et al.[214] developed a model to predict the effect of oxygen concentration on the emulsifier-free polymerization of vinyl chloride. Particle stability arises from the surface charge density generated by the sulfate groups, which is quantified by an empirical formula. The model performed well when validated against experimental data on conversion and average particle diameter obtained from a batch reactor operated at various initial oxygen and initiator concentrations. The Ushaped behavior of the average particle diameter with respect to the initial oxygen concentration was correctly explained by the model. This effect was attributed to the competition between the increase in radical production and the decrease in particle stability caused by the formation of $\mathrm{HCl}$. The authors also performed some simulation runs to analyze the influence of conversion and initiator concentration on the shape of the latex PSD, but no comparison between experimental and predicted PSDs was actually given.

Marinangelo et al.[215] modeled the emulsion copolymerization of styrene/BA under semibatch conditions, focusing on high solid content processes. Particle coagulation was neglected. The model specified the micelle and particle entry efficiencies as fitted parameters; the lack of particle coagulation necessitated the use of a very low micelle entry efficiency value $\left(<10^{-6}\right)$ in order to obtain a reasonable fit to experimental data. When a shot of emulsifier was added to the reactor for the purposes of inducing the nucleation of a second particle population, the model was able to qualitatively predict the formation of a second population mode. The model was able to qualitatively predict the effect of adding a shot of surfactant on the average particle diameter and number of particles. However, the PSDs predicted by the model did not match the experimental TEM data particularly well. The decision to completely neglect particle coagulation in the modeling of high solid content latexes remains highly questionable.

Sajjadi[221] modeled the semibatch emulsion polymerization of Sty under monomer-starved conditions using a PBE formulation that accounted for particles containing zero, one (both initiator-or monomer-derived), two or three growing radicals. Particle coagulation was neglected due to the high concentration of emulsifier. While the model was capable of predicting the PSDs at the end of the nucleation stage, the chain length at which the oligomeric radicals became surface active had to be adjusted from $z=2$ to $z=3$ during the growth stage in order to correctly predict the PSDs at the end of the polymerization. The physical basis for this adjustment, that the particle surface becomes more difficult to penetrate due to the high degree of instantaneous conversion during the growth stage, is plausible, but difficult to validate experimentally. This also contradicts the results of Hernandez \& Tauer[74] who suggest that the radical entry efficiency increases with the polymer volume fraction. 
Saldívar et al.[4] developed a comprehensive copolymerization model that has since then been tested with experimental data obtained for various binary systems. This model neglects particle coagulation. In a first paper, Saldívar \& Ray[222] validated the model against experimental data on the copolymerization of Sty and MMA in batch and continuous stirred tank reactors. The model was capable of predicting, with reasonable accuracy, the effect of temperature as well as initiator and surfactant concentrations on conversion, average particle diameter, and copolymer composition. In a later study,[223] the model was confronted with data for 4 binary systems: Sty/MMA, Sty/BA, Sty/BD, and Sty/AA. The experiments covered simultaneous variations of temperature, initiator and surfactant concentrations, monomer to water ratio, and monomer composition. The model was capable of explaining quantitatively the experimental evolution of conversion, but only qualitatively the evolution of average particle size. The latest work of this research group [223] focused on acrylic systems, namely: MMA/BA, MMA/BD, MMA/VAc, and BA/VAc. Similar conclusions were drawn with respect to model predicting power. It is worth noting that none of these works reported experimental or simulated PSDs.

Sood[226] developed a model for the ab initio batch emulsion polymerization of styrene, where the initial surfactant concentration was well-above the CMC. The model was validated using the experimental data of Harada et al.[236] emphasizing validation of the particle nucleation stage. Facilitated by the complete neglecting of particle coagulation, the PBEs were formulated with birth time as the internal coordinate, rather than particle volume or radius. The model was able to correctly predict the duration of the nucleation period and the number of particles formed during that same period, as well as the evolution of conversion over the course of polymerization for varying levels of initiator, surfactant and monomer concentration. However, the title of the paper is somewhat misrepresentative, as no information regarding the growth or shape of the PSD, total particle number and average particle diameter was reported. All of the kinetic parameters that are thought to depend on the PSD were neglected (radical desorption), eliminated through simplification (the radius-dependent term of the Morton monomer partitioning equation) or fit to experimental data (the rate of radical entry into particles). Therefore, it appears that the model ultimately made no attempt to model the PSD.

Unzueta \& Forcada[174] developed a model to predict the effect of mixed anionic/nonionic surfactant systems on the emulsion copolymerization of MMA and BA. Particle coagulation was taken into account by means of a simple size-independent kernel of the type $\beta=\beta_{0} / W$, with the stability ratio $W$ being an empirical function of the surface coverage of the particles. The results obtained with this semiempirical model were in reasonable accord with experimental data on the effect of surfactant 
concentration and surfactant mixture composition on the evolution of conversion, average particle diameter, and copolymer composition.

Vale \& McKenna[38] developed a model to understand the formation of particles and the evolution of the PSD in the emulsion polymerization of VCM. The computation of the coupled radical number and particle size distribution was carried out by means of the 0-1-2 PBEs, an approach that the authors argued was a requirement in order to correctly model particle formation. Particle coagulation was quantified by a simple empirical stability kernel. The kinetic part of the model was validated against batch seeded and unseeded experiments. When analyzing particle formation, it was found that plausible PSDs could only be obtained if coagulation was accounted for. After adjusting the parameters of the stability kernel, the model could correctly describe the experimental conversion and particle number profiles. However, as the coagulation sub-model is empirical, the model cannot really predict the effect of the surfactant concentration on particle number.

To help in appreciating the predictive power of the models reviewed here, it is convenient to define what we could call a PSD-benchmark scale:

1. monomodal system: average particle size;

2. monomodal system: average particle size and polydispersity index;

3. bimodal system: average particle size, polydispersity index, and relative amount of each of the two latex populations;

4. generic system: full PSD.

In this scale, higher levels correspond to more information on the particle size distribution and, thus, to better models. The present review shows that, with respect to prediction quality, current PBMs are positioned around the first level. In most cases, the prediction of the average particle size (or number of particles) of a monomodal latex is only qualitative, not quantitative. Predicted trends often conform to experimental ones, but the discrepancies between values are significant. This is true even in the case of well-studied systems like styrene emulsion polymerization.

Modeling nucleation, growth and particle coagulation in Pickering emulsion polymerization (surfactant free, stabilized by clay platelets) was considered by Brunier et al.[159] Due to the big particle size and high average number of radicals per particle, the PB model was found adapted. While the authors demonstrated multilayer adsorption of clay on the surface of polymer particles, only one layer was thought to effectively stabilize the polymer particles. The radical entry rate was found to depend on the surface of polymer particles.

The literature review also points out that systematic validation studies are more of an exception than a rule. The very minimum we can demand from a PSD model is that it be capable of predicting the 
evolution of conversion and number of particles as a function of the initial concentrations of initiator and surfactant (over a representative range) in a batch unseeded homopolymerization. However, such kind of elementary experimental programs are rarely carried out. As a result, the limitations of the models are not always apparent.

\section{Conclusions}

Emulsion polymerization is a very complex heterogeneous process involving a multitude of physical and chemical phenomena, many of which have not yet been completely elucidated: chemistry of the aqueous-phase species, radical entry and exit, mechanisms of particle nucleation, particle coagulation, etc. To a large part, this is the case because of limitations in our ability to measure a certain number of key properties such as free radical concentrations, or particle sizes in situ. These limitations are a major stumbling block when it comes to validating models and developing better theories of how things happen in the reactor. Another point worth stressing is that systematic validation studies are more of an exception than a rule.

Quantitatively describing the course of an emulsion polymerization, and particularly the formation of particles and the evolution of the PSD, can in principle be done through the use of population balance models. However, as we have discussed herein, the performance of such models still leaves significant room for improvement (although the first attempts date from the 70's). Progress in this area necessitates further research to unravel the abovementioned mechanistic issues, as well as solving a number of problems specific to PBMs of emulsion polymerization (see Figure 4). This includes, for instance (this is a non-exhaustive list):

- Assessing the validity of the underlying PBEs (common 0-1 and PB approximations may both be unsuitable), finding alternatives for the cases where they do not apply, and developing better numerical methods to solve the corresponding equations.

- Measurement of the PSD: The accurate measurement of the particle size and particle size distribution remains problematic. Some solutions exist, mostly off-line, and mostly useful after significant dilution of the original product. Nevertheless, if we are to measure the dynamic nature of particle formation and coagulation, new methods of in situ analysis will have to be developed to help quantify these events. 


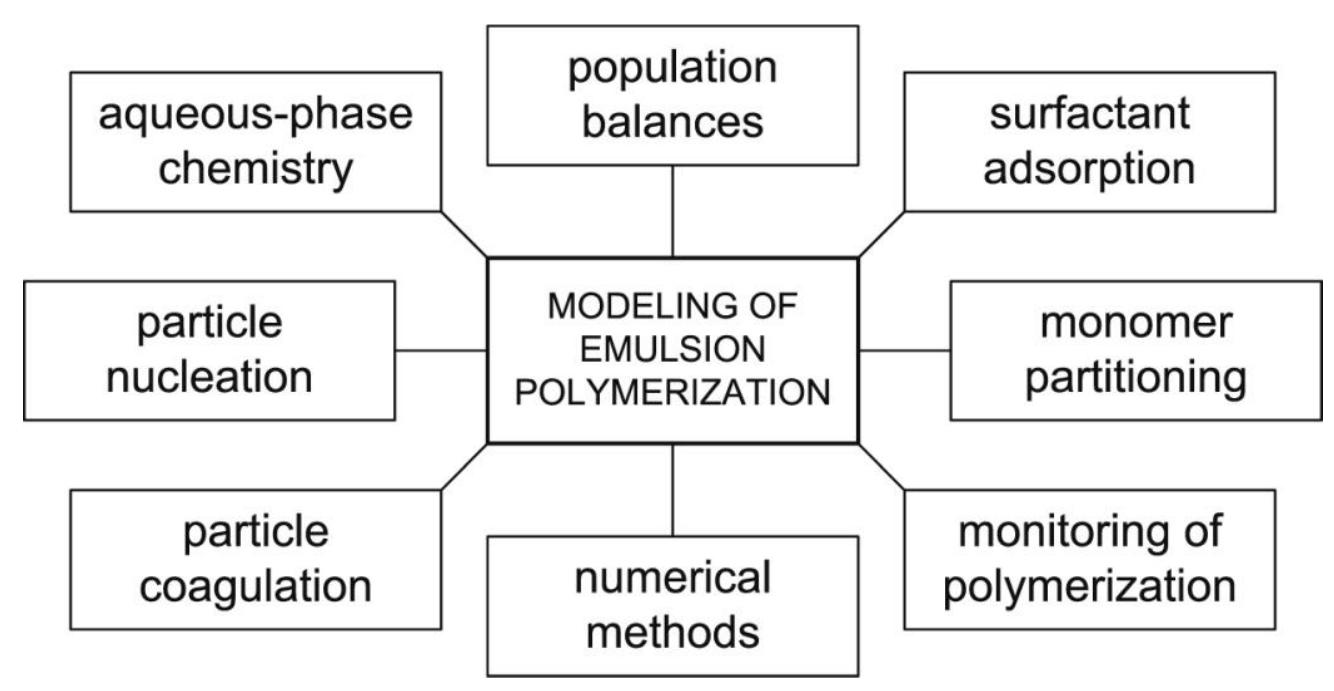

Figure 4. Main issues in the modeling of PSD.

- Water-phase Events: There is no universal agreement on the mechanistic details of the reactions that take place in the aqueous phase (aqueous-phase and phase-transfer events), including the potential importance of the side reactions of the initiator in the aqueous phase. The formation of water soluble oligomers and polymers will obviously play an important role in the development of the PSD. These species can act as in situ surfactants, and can also influence the latex viscosity. A better understanding of their formation and the role(s) played by these species is needed.

- Radical Entry: Our discussion shows that radical entry is not yet an entirely resolved issue, and in certain cases the lack of mechanistic information might remain concealed since the highly complex models used to describe these systems often rely upon fitted parameters.

- Particle Coagulation (Modeling): Modeling studies can occasionally present a somewhat misleading picture of the significance of particle coagulation. Coagulation is often neglected without proper justification because of the added complexity it represents. There is nonetheless experimental evidence supporting the role of coagulation in particle formation. As a result, accounting for coagulation should be the rule, not the exception. The problem is that estimating the particle coagulation rates is not a simple matter, as explained above.

- Particle Coagulation (Mechanism): Of course, in order to include coagulation in models of the PSD in EP, it is obviously necessary to have a mechanistic description thereof. Despite past efforts to overcome our limited knowledge of this aspect of EP, current understanding of particle formation and stability is based on simple theoretical models that describe colloidal interactions through various simple micellar, or more advanced DLVO-type models. The DLVO approach is faced with two fundamental problems: (1) the difficulty in obtaining reliable estimates for a number of input parameters; (2) the DLVO theory itself is possibly not 
applicable under emulsion polymerization conditions. Added to the perikinetic coagulation kernel, in several cases, orthokinetic coagulation cannot be neglected. The estimation of the orthokinetic coagulation impact is itself difficult and may require complicated fluid dynamic simulations. Moreover, the effect of both phenomena is most probably not additive.

- Secondary Particle Formation: In comparison to ab initio particle formation, SPF is significantly more complicated to quantify. In large part, this is because it simply adds a second level of complexity to an already complicated problem. Secondary particles will necessarily be of a size different from those already in the reactor and will therefore present different kinetic and stability problems.

- Monomer and surfactant partitioning: While most monomer partitioning models assume equilibrium, and thus instantaneous monomer distribution to compensate its consumption by the reaction, this is not the case in fast reaction systems or when mixing is not efficient. Surfactant partitioning might also be dependent on the reaction conditions and evolve with time, especially for non-conventional surfactants. The measurement of monomer and surfactant partitioning is also not a trivial task.

\section{Abbreviations}

AA acrylic acid

BA butyl acrylate

BD butadiene

CHDF capillary hydrodynamic fractionation

CSTR continuous stirred tank reactor

CTA chain transfer agent

DLS dynamic light scattering

DLVO Deryaguin-Landau-Verwey-Overbeek

DP degree of polymerization

2-EHA 2-ethyl hexyl acrylate

EP emulsion polymerization

HSC high solid content

MMA methyl methacrylate

MWD molecular weight disribution

PB pseudo-bulk

PBE population balance equation

PBM population balance model

PS polystyrene

PMMA polymethyl methacrylate

PSD particle size distribution

RTD residence time distribution

SDS sodium dodecyl sulfate

SLS static light scattering

SPF secondary particle formation

Sty styrene

TEM transmission electron microscopy

VAc vinyl acetate

VCM vinyl chloride monomer 


\section{Nomenclature}

$a$ : particle surface $\left(\mathrm{m}^{2}\right)$

$\boldsymbol{a}(\boldsymbol{f}, v, t)$ : vector of aggregation terms $\left(\operatorname{part~}^{-3} \mathrm{~m}^{-3} \mathrm{~s}^{-1}\right)$

$A$ : Hamaker constant

$A_{\mathrm{p}}$ : surface of the particle phase $\left(\mathrm{m}^{2}\right)$

$c$ : pseudo first order rate coefficient for termination in the particles $\left(\mathrm{s}^{-1}\right)$

$\mathrm{C}_{\mathrm{e}, i}$ : electrolyte concentration of ionic species $i\left(\mathrm{~mol} \mathrm{~m}^{-3}\right)$

CMC: critical micellar concentration $\left(\mathrm{mol} \mathrm{m}^{-3}\right)$

[CTA]: chain transfer agent concentration $\left(\mathrm{mol} \mathrm{m}^{-3}\right)$

$d$ : particle diameter $(\mathrm{m})$

$d_{\mathrm{f}}:$ the mass-based fractal dimension

$d_{i}$ : diameter of radical of size $i(\mathrm{~m})$

$D$ : mutual diffusion coefficient of two particles $\left(\mathrm{m}^{2} \mathrm{~s}^{-1}\right)$

$D_{\mathrm{h}}$ : diffusion rate coefficient of monomer (or oligoradicals) in the hairy layer $\left(\mathrm{m}^{2} \mathrm{~s}^{-1}\right)$

$D_{\mathrm{p}}$ : diffusion coefficient of monomer (or oligoradicals) in the polymer particle $\left(\mathrm{m}^{2} \mathrm{~s}^{-1}\right)$

$D_{\mathrm{w}}$ : diffusion coefficient of monomer (or oligoradicals) in the aqueous phase $\left(\mathrm{m}^{2} \mathrm{~s}^{-1}\right)$

$e$ : electron charge (C)

$E_{1}$ : heat of adsorption for the first layer $\left(\mathrm{J} \mathrm{mol}^{-1}\right)$

$E_{N}$ : heat for the second and higher layers $\left(\mathrm{J} \mathrm{mol}^{-1}\right)$

$E_{\text {des }}$ : net energy barrier for desorption $\left(\mathrm{J} \mathrm{mol}^{-1}\right)$

$\mathrm{EM}_{i}^{-}$: desorbed radical of length $i$

$\left[\mathrm{E}^{*}\right]_{\mathrm{W}}$ : total concentration of exited radicals $\left(\mathrm{mol} \mathrm{m}^{-3}\right)$

$\left[\mathrm{EM}_{i}^{*}\right]_{\mathrm{w}}$ : concentration of exited radicals after propagation in the aqueous phase with $i$ monomer units $\left(\mathrm{mol} \mathrm{m}^{-3}\right)$

$f(r, t)$ : number of particles density (part $\mathrm{dm}^{-1} \mathrm{~m}^{-3}$ )

$\mathbf{f}(v, t)$ : vector number density function (part $\mathrm{m}^{-1} \mathrm{~m}^{-3}$ )

$f^{\text {in }}(v, t)$ : inlet vector number density function (part $\left.\mathrm{m}^{-1} \mathrm{~m}^{-3}\right)$

$f_{1 \mathrm{~m}}(v, t), f_{1 \mathrm{p}}(v, t)$ : number density function for particles having monomeric or polymeric radicals respectively (part $\mathrm{m}^{-1}$ $\left.\mathrm{m}^{-3}\right)$

$f_{0}(v, t), f_{1}(v, t), f_{2}(v, t)$ : number density function for particles having no radicals, one or two radicals respectively (part $\left.\mathrm{m}^{-1} \mathrm{~m}^{-3}\right)$

$f_{\mathrm{M}}$ : frequency of transfer to monomer (or CTA) $\left(\mathrm{s}^{-1}\right)$

$f_{\mathrm{e}}$ : radical entry efficiency

$f_{\mathrm{I}}$ : initiation efficiency

$G, G^{\prime}$ : hydrodynamic functions

$\mathrm{H}:$ the Heaviside step function

$i$ : chain length

$I_{\mathrm{S}}$ : ionic strength $\left(\mathrm{mol} \mathrm{m}^{-3}\right)$

[I]: initiator concentration $\left(\mathrm{mol} \mathrm{m}^{-3}\right)$

$[\mathrm{I}]_{0}$ : initial initiator concentration at time $\left(\mathrm{mol} \mathrm{m}^{-3}\right)$

$\left[\mathrm{I}^{\circ}\right]$ : primary radicals concentration $\left(\mathrm{mol} \mathrm{m}^{-3}\right)$

$\left[\mathrm{IM}_{i}^{*}\right]_{\mathrm{W}}$ : concentration of initiator-derived radicals in aqueous phase with $i$ monomer unit $\left(\mathrm{mol} \mathrm{m}^{-3}\right)$

$j_{\text {cr }}$ : critical DP for particle formation by homogeneous nucleation for radicals generated by the initiator

$j_{\mathrm{Ecr}}$ : critical DP for particle formation by homogeneous nucleation for exited radicals

$k_{0}$ : rate of diffusion of a monomeric radical out of a particle $\left(\mathrm{s}^{-1}\right)$

$k_{\mathrm{B}}$ : Boltzmann constant $\left(\mathrm{J} \mathrm{K}^{-1}\right)$

$k_{\mathrm{d}}$ : rate coefficient for initiator decomposition $\left(\mathrm{s}^{-1}\right)$

$k_{\text {des }}:$ radical desorption rate coefficient $\left(\mathrm{s}^{-1}\right)$

$k_{\mathrm{e}}$ : rate coefficient for entry of initiator-derived radicals into particles $\left(\mathrm{m}^{3} \mathrm{~mol}^{-1} \mathrm{~s}^{-1}\right)$

$k_{\mathrm{e}, \mathrm{E}}:$ rate coefficient for entry of transfer-derived radicals into particles $\left(\mathrm{m}^{3} \mathrm{~mol}^{-1} \mathrm{~s}^{-1}\right)$

$k_{\mathrm{em}}$ : rate coefficient for entry of initiator-derived radicals into micelles $\left(\mathrm{m}^{3} \mathrm{~mol}^{-1} \mathrm{~s}^{-1}\right)$

$k_{\mathrm{em}, \mathrm{E}}:$ rate coefficient for entry of transfer-derived radicals into micelles $\left(\mathrm{m}^{3} \mathrm{~mol}^{-1} \mathrm{~s}^{-1}\right)$

$k_{\mathrm{fCTA}}$ : rate coefficient for transfer to chain transfer agent $\left(\mathrm{m}^{3} \mathrm{~mol}^{-1} \mathrm{~s}^{-1}\right)$

$k_{\mathrm{fM}}$ : rate coefficient for transfer to monomer $\left(\mathrm{m}^{3} \mathrm{~mol}^{-1} \mathrm{~s}^{-1}\right)$

$k_{i}^{j}$ : partition coefficient of monomer $i$ in phase $j$

$k_{\mathrm{p}}$ : rate coefficient for propagation in the polymer particles $\left(\mathrm{m}^{3} \mathrm{~mol}^{-1} \mathrm{~s}^{-1}\right)$

$k_{\mathrm{p}}^{\prime}$ : rate coefficient for propagation of chain-transfer-generated radicals $\left(\mathrm{m}^{3} \mathrm{~mol}^{-1} \mathrm{~s}^{-1}\right)$

$k_{\mathrm{pw}}$ : rate coefficient for propagation in the aqueous phase $\left(\mathrm{m}^{3} \mathrm{~mol}^{-1} \mathrm{~s}^{-1}\right)$

$k_{\mathrm{re}}$ : reentry coefficient of exited radical into particles $\left(\mathrm{m}^{3} \mathrm{~mol}^{-1} \mathrm{~s}^{-1}\right)$

$k_{\mathrm{tp}}$ : rate coefficient for radical termination in the polymer particles $\left(\mathrm{m}^{3} \mathrm{~mol}^{-1} \mathrm{~s}^{-1}\right)$ 
$k_{\mathrm{tw}}$ : rate coefficient for radical termination in the aqueous phase $\left(\mathrm{m}^{3} \mathrm{~mol}^{-1} \mathrm{~s}^{-1}\right)$

$K$ : coefficient of particle volume growth $\left(\mathrm{m}^{3} \mathrm{~s}^{-1}\right)$

$L$ : surface-to-surface distance between particles (or the particle and the radical) (m)

$m$ : partition coefficient of radicals between the polymer particles and the aqueous phase, usually approximated by $m=$ $[\mathrm{M}]_{\mathrm{p}} /[\mathrm{M}]_{\mathrm{w}}$,

$m_{i}$ : mass of radical of size $i(\mathrm{~kg})$

$m_{i k}$ : the ratio of the equivalent number of segments of components $i$ and $k$

$\left[\mathrm{M}_{i}^{*}\right]_{\mathrm{p}}$ : concentration of radicals of length $i$ in the polymer particles $\left(\mathrm{mol} \mathrm{m}^{-3}\right)$

$[\mathrm{M}]_{\mathrm{p}}$ : concentration of monomer in the polymer particles $\left(\mathrm{mol} \mathrm{m}^{-3}\right)$

$[\mathrm{M}]_{\mathrm{W}}$ : concentration of monomer in the aqueous phase $\left(\mathrm{mol} \mathrm{m}^{-3}\right)$

$M_{\mathrm{M}}$ : molecular weight of monomer $\left(\mathrm{kg} \mathrm{mol}^{-1}\right)$

[MIC]: concentration of micelles $\left(\mathrm{mol} \mathrm{m}^{-3}\right)$

$n(r)$ : number of radicals in a particle of size $r$

n: nucleation vector

$\bar{n}(r, t)$ : average number of radicals per particles of size $r$

$N$ : number of particles per unit volume (part $\mathrm{m}^{-3}$ )

$N_{\mathrm{A}}:$ Avogadro's number $\left(\mathrm{mol}^{-1}\right)$

$N_{i}$ : number of particles containing $i$ radicals per unit volume $\left(\mathrm{m}^{-3}\right)$

$P:$ probability that a desorbed chain reacts in water

Pe: Peclet number

$p, p^{\prime}$ : undetermined constants, adjustable parameters

$r:$ particle radius $(\mathrm{m})$

$r_{i}$ : the radius of phase $i(\mathrm{~m})$

$r_{\text {nuc }}$ : nucleation radius $(\mathrm{m})$

$R$ : center-to-center distance between particles (m)

$R_{\mathrm{i}}$ : rate of generation of initiator radicals in Harada et al. desorption model (molecule $\mathrm{m}^{-3} \mathrm{~s}^{-1}$ )

$R_{\text {nuc }}$ : nucleation rate $\left(\mathrm{mol} \mathrm{m}^{-3} \mathrm{~s}^{-1}\right)$

$R_{\text {hom, },}:$ homogeneous nucleation rate by initiator derived radicals $\left(\mathrm{mol} \mathrm{m}^{-3} \mathrm{~s}^{-1}\right)$

$R_{\text {hom, }}$ : homogeneous nucleation rate by exited radicals $\left(\mathrm{mol} \mathrm{m}^{-3} \mathrm{~s}^{-1}\right)$

$R_{\text {mic,I }}$ : micellar nucleation rate by initiator derived radicals $\left(\mathrm{mol} \mathrm{m}^{-3} \mathrm{~s}^{-1}\right)$

$R_{\text {mic, } \mathrm{E}}:$ micellar nucleation rate by exited radicals $\left(\mathrm{mol} \mathrm{m}^{-3} \mathrm{~s}^{-1}\right)$

$R_{\mathrm{p}}^{\mathrm{p}}$ : monomer propagation rate in the polymer particles $\left(\mathrm{mol} \mathrm{s}^{-1}\right)$

$R_{\mathrm{p}}^{\mathrm{W}}$ : monomer propagation rate in the aqueous phase $\left(\mathrm{mol} \mathrm{s}^{-1}\right)$

$s$ : maximum chain length of radicals in equilibrium with aqueous phase (that may desorb) in Nomura and Grady models

$\mathbf{s}(\boldsymbol{f}, v, t)$ : source function $\left(\right.$ part $\left.\mathrm{m}^{-3} \mathrm{~m}^{-1} \mathrm{~s}^{-1}\right)$

$T$ : temperature of the system $(\mathrm{K})$

$\left[\mathrm{T}^{*}\right]_{\mathrm{W}}$ : total concentration of oligomeric radicals in the aqueous phase $\left(\mathrm{mol} \mathrm{m}^{-3}\right)$

$V_{\mathrm{T}}, V_{\mathrm{T}, \max }$ : interaction energy and maximal interaction energy between a pair of particles ( $\mathrm{J}$ )

$V^{j}$ : volume of phase $j\left(j=\mathrm{w}, \mathrm{d}, \mathrm{p}\right.$, water, droplets, polymer particles) $\left(\mathrm{m}^{3}\right)$

$V_{i}^{j}$ : volume of species $i$ in phase $j\left(\mathrm{~m}^{3}\right)$

$V_{\mathrm{A}}:$ attractive potential energy $(\mathrm{J})$

$V_{\mathrm{R}}$ : repulsive potential energy $(\mathrm{J})$

$V_{\mathrm{T}}:$ total potential energy of interaction $(\mathrm{J})$

$\dot{V}^{\mathrm{w}}$ : flow rate $\left(\mathrm{m} \mathrm{s}^{-1}\right)$

$w_{\mathrm{p}}$ : weight fraction of polymer in the particles

$W$ : used to indicate to Fuchs' stability ratio between two particles as well as the electrostatic repulsion between the charged oligomeric radical and the charged particle surface in some radical entry models (-)

$x$ : ratio of the partial pressure of the adsorbate to its saturation partial pressure at the system temperature (replaced by its concentration in the liquid phase for liquids)

$z:$ minimal DP for radical entry

\section{Greek letters}

$\beta\left(r, r^{\prime}\right)$ : coagulation rate coefficient between particles of swollen radii $r$ and $r^{\prime}\left(\mathrm{m}^{3} \mathrm{~s}^{-1}\right)$

$\beta_{\text {diff }}\left(r, r^{\prime}\right)$ and $\beta_{\text {conv }}\left(r, r^{\prime}\right)$ : diffusive and convective coagulation rate coefficients respectively $\left(\mathrm{m}^{3} \mathrm{~s}^{-1}\right)$

$\gamma$ : interfacial tension $\left(\mathrm{N} \mathrm{m}^{-1}\right)$

$\dot{\gamma}:$ shear rate $\left(\mathrm{s}^{-1}\right)$

$\delta$ : Dirac function

$\delta_{1}$ : thickness of the hairy layer $(\mathrm{m})$

$\Delta G$ : free energy of mixing $\left(\mathrm{J} \mathrm{mol}^{-1}\right)$ 


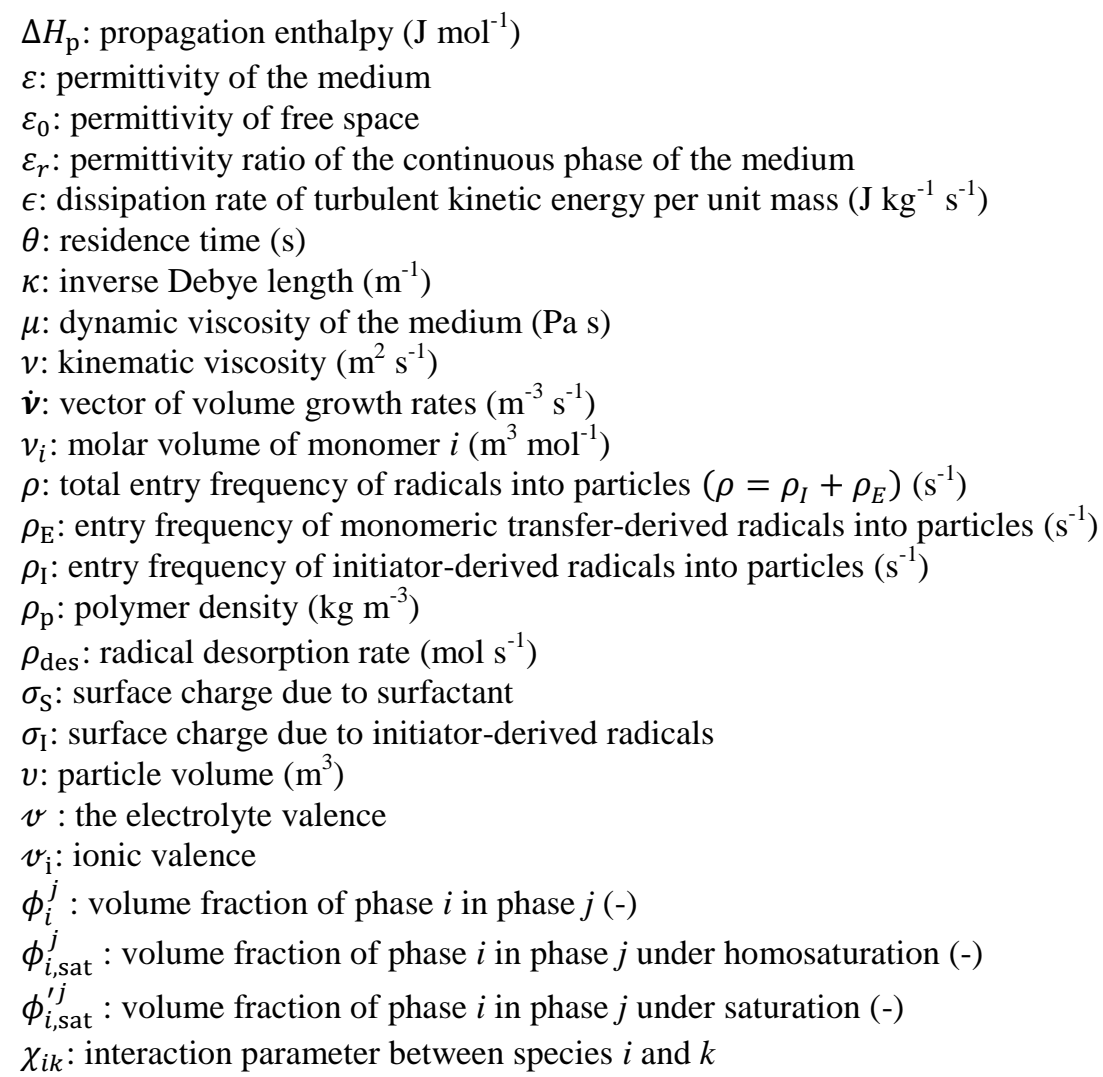

\section{References}

[1] A. Guyot, F. Chu, M. Schneider, C. Graillat, and T. F. McKenna, "High solid content latexes," Prog. Polym. Sci., vol. 27, no. 8, pp. 1573-1615, 2002.

[2] K. W. Min and W. H. Ray, "On the Mathematical Modeling of Emulsion Polymerization Reactors," Journal of Macromolecular Science, Part C - Reviews in Macromolecular Chemistry, pp. 177-255, 1974.

[3] M. Kroupa, M. Vonka, M. Soos, and J. Kosek, "Size and Structure of Clusters Formed by Shear Induced Coagulation: Modeling by Discrete Element Method," Langmuir, vol. 31, no. 28, pp. 7727-7737, Jul. 2015.

[4] E. Saldícar, P. Dafniotis, and W. Harmon Ray, "Mathematical Modeling of Emulsion Copolymerization Reactors. I. Model Formulation and Application to Reactors Operating with Micellar Nucleation,” J. Macromol. Sci. Part C Polym. Rev., vol. 38, no. 2, pp. 207-325, Jan. 1998.

[5] H. M. Vale and T. F. McKenna, "Modeling particle size distribution in emulsion polymerization reactors," Prog. Polym. Sci., vol. 30, no. 10, pp. 1019-1048, 2005.

[6] O. Elizalde, G. P. Leal, and J. R. Leiza, "Particle Size Distribution Measurements of PolymericDispersions: A Comparative Study," Part. Part. Syst. Charact., vol. 17, no. 5-6, pp. 236-243, Dec. 2000.

[7] M. Schneider and T. F. McKenna, "Comparative Study of Methods for the Measurement of," Part. Part. Syst. Charact., vol. 19, no. 1, pp. 28-37, Apr. 2002.

[8] J. M. Stubbs and D. C. Sundberg, "A round robin study for the characterization of latex particle morphology - multiple analytical techniques to probe specific structural features," Polymer, vol. 46, no. 4, pp. 1125-1138, Feb. 2005.

[9] "www.nanosight.com.".

[10] M. Fortuny, C. Graillat, T. F. McKenna, P. H. H. Araújo, and J. C. Pinto, "Modeling the nucleation stage during batch emulsion polymerization," AIChE J., vol. 51, no. 9, pp. 25212533, Sep. 2005. 
[11] H. M. Vale and T. F. McKenna, "Solution of Population Balance Equations for Emulsion Polymerization: Zero-One and Zero-One-Two Systems," Ind. Eng. Chem. Res., vol. 46, no. 2, pp. 643-654, Jan. 2007.

[12] B. S. Casey, B. R. Morrison, I. A. Maxwell, R. G. Gilbert, and D. H. Napper, "Free radical exit in emulsion polymerization. I. Theoretical model," J. Polym. Sci. Part Polym. Chem., vol. 32, no. 4, pp. 605-630, Mar. 1994.

[13] R. G. Gilbert, Emulsion polymerization, Academic Press san Diego. 1995.

[14] S. Maeder and R. G. Gilbert, "Measurement of Transfer Constant for Butyl Acrylate FreeRadical Polymerization," Macromolecules, vol. 31, no. 14, pp. 4410-4418, Jul. 1998.

[15] S. W. Prescott, "Chain-Length Dependence in Living/Controlled Free-Radical Polymerizations: Physical Manifestation and Monte Carlo Simulation of Reversible Transfer Agents," Macromolecules, vol. 36, no. 25, pp. 9608-9621, Dec. 2003.

[16] E. Giannetti, "Nucleation mechanisms and particle size distributions of polymer colloids," AIChE J., vol. 39, no. 7, pp. 1210-1227, Jul. 1993.

[17] E. M. Coen, R. G. Gilbert, B. R. Morrison, H. Leube, and S. Peach, "Modelling particle size distributions and secondary particle formation in emulsion polymerisation," Polymer, vol. 39, no. 26, pp. 7099-7112, 1998.

[18] Lovell and M. S. El-Aasser, Emulsion Polymerization and Emulsion Polymers, John Wiley and Sons. Chichester, 1997.

[19] D. Edouard, N. Sheibat-Othman, and H. Hammouri, "Observer design for particle size distribution in emulsion polymerization," AIChE J., vol. 51, no. 12, pp. 3167-3185, 2005.

[20] W. H. Stockmayer, "Note on the kinetics of emulsion polymerization," J. Polym. Sci., vol. 24, no. 106, pp. 314-317, 1957.

[21] G. W. Poehlein, in Emulsion Polymerization and Emulsion Polymers, Chichester: John Wiley and Sons, 1997, pp. 277-292.

[22] J. B. Rawlings and W. H. Ray, "The modeling of batch and continuous emulsion polymerization reactors. Part I: Model formulation and sensitivity to parameters," Polym. Eng. Sci., vol. 28, no. 5, pp. 237-256, Mar. 1988.

[23] A. Hosseini, A. Eldin Bouaswaig, and S. Engell, "Novel approaches to improve the particle size distribution prediction of a classical emulsion polymerization model," Chem. Eng. Sci., vol. 88, pp. 108-120, Jan. 2013.

[24] J. Ugelstad, P. C. Mork, P. Dahl, and P. Rangnes, "A kinetic investigation of the emulsion polymerization of vinyl chloride," J. Polym. Sci. Part C Polym. Symp., vol. 27, no. 1, pp. 4968, Jan. 1969.

[25] E. M. Coen, S. Peach, B. R. Morrison, and R. G. Gilbert, "First-principles calculation of particle formation in emulsion polymerization: pseudo-bulk systems," Polymer, vol. 45, no. 11, pp. 3595-3608, 2004.

[26] S. M. Jung and V. G. Gomes, "Transitional emulsion polymerisation: Zero-one to pseudobulk," Chem. Eng. Sci., vol. 66, no. 18, pp. 4251-4260, Sep. 2011.

[27] D. L. Marchisio, R. Dennis Vigil, and R. O. Fox, "Implementation of the quadrature method of moments in CFD codes for aggregation-breakage problems," Chem. Eng. Sci., vol. 58, no. 15, pp. 3337-3351, Aug. 2003.

[28] P. M. Bapat, L. L. Tavlarides, and G. W. Smith, "Monte carlo simulation of mass transfer in liquid-liquid dispersions," Chem. Eng. Sci., vol. 38, no. 12, pp. 2003-2013, 1983.

[29] A. W. Mahoney and D. Ramkrishna, "Efficient solution of population balance equations with discontinuities by finite elements," Chem. Eng. Sci., vol. 57, no. 7, pp. 1107-1119, Apr. 2002.

[30] M. Vanni, "Approximate Population Balance Equations for Aggregation-Breakage Processes," J. Colloid Interface Sci., vol. 221, no. 2, pp. 143-160, Jan. 2000.

[31] D. Meimaroglou and C. Kiparissides, "Monte Carlo simulation for the solution of the bi-variate dynamic population balance equation in batch particulate systems," Chem. Eng. Sci., vol. 62, no. 18-20, pp. 5295-5299, Sep. 2007. 
[32] S. Kumar and D. Ramkrishna, "On the solution of population balance equations by discretization-III. Nucleation, growth and aggregation of particles," Chem. Eng. Sci., vol. 52, no. 24, pp. 4659-4679, Dec. 1997.

[33] F. Filbet and P. Laurençot, "Numerical Simulation of the Smoluchowski Coagulation Equation," SIAM J. Sci. Comput., vol. 25, no. 6, pp. 2004-2028, Jan. 2004.

[34] S. Kumar and D. Ramkrishna, "On the solution of population balance equations by discretization-I. A fixed pivot technique," Chem. Eng. Sci., vol. 51, no. 8, pp. 1311-1332, Apr. 1996.

[35] S. Kumar and D. Ramkrishna, "On the solution of population balance equations by discretization-II. A moving pivot technique," Chem. Eng. Sci., vol. 51, no. 8, pp. 1333-1342, Apr. 1996.

[36] K. Tauer, S. Nozari, and A. M. Imroz Ali, "Experimental reconsideration of radical entry into latex particles," Macromolecules, vol. 38, no. 21, pp. 8611-8613, 2005.

[37] P. Daswani and A. van Herk, "Selective Adsorption of Aqueous Phase Co-Oligomers on Latex Particles Part 1: Influence of Different Initiator Systems," Macromol. Theory Simul., Aug. 2016.

[38] H. M. Vale and T. F. McKenna, "Particle Formation in Vinyl Chloride Emulsion Polymerization: Reaction Modeling," Ind. Eng. Chem. Res., vol. 48, no. 11, pp. 5193-5210, Jun. 2009.

[39] M. A. Dubé, J. B. P. Soares, A. Penlidis, and A. E. Hamielec, "Mathematical Modeling of Multicomponent Chain-Growth Polymerizations in Batch, Semibatch, and Continuous Reactors: A Review," Ind. Eng. Chem. Res., vol. 36, no. 4, pp. 966-1015, Apr. 1997.

[40] E. M. Coen, R. G. Gilbert, B. R. Morrison, H. Leube, and S. Peach, "Modelling particle size distributions and secondary particle formation in emulsion polymerization," Polymer, vol. 39, no. 26, pp. 7099-7112, décembre 1998.

[41] J. Gao and A. Penlidis, "Mathematical modeling and computer simulator/database for emulsion polymerizations," Prog. Polym. Sci., vol. 27, no. 3, pp. 403-535, Apr. 2002.

[42] B. P. Huo, J. D. Campbell, A. Penlidis, J. F. MacGregor, and A. E. Hamielec, "Effect of impurities on emulsion polymerization: Case II kinetics," J. Appl. Polym. Sci., vol. 35, no. 8, pp. 2009-2021, Jun. 1988.

[43] A. Penlidis, J. F. MacGregor, and A. E. Hamielec, "Effect of impurities on emulsion polymerization: Case I kinetics," J. Appl. Polym. Sci., vol. 35, no. 8, pp. 2023-2038, Jun. 1988.

[44] I. A. Maxwell, B. R. Morrison, D. H. Napper, and R. G. Gilbert, "The effect of chain transfer agent on the entry of free radicals in emulsion polymerization," Makromol. Chem., vol. 193, no. 2, pp. 303-313, février 1992.

[45] Z. Song and G. W. Poehlein, "Particle Formation in Emulsion Polymerization: Transient Particle Concentration," J. Macromol. Sci. Part - Chem., vol. 25, no. 4, pp. 403-443, Jan. 1988.

[46] J. Neelsen, P. Hecht, W. Jaeger, and G. Reinisch, "Zur Initiierung der Emulsionspolymerisation von Vinylchlorid mit Kaliumperoxidisulfat. 4. Zur Herkunft ionischer Gruppen am Emulsionspolyvinylchlorid," Acta Polym., vol. 38, no. 10, pp. 555-559, Oct. 1987.

[47] K. Tauer and R. Deckwer, "Polymer end groups in persulfate-initiated styrene emulsion polymerization," Acta Polym., vol. 49, no. 8, pp. 411-416, Aug. 1998.

[48] M. Goicoechea, M. J. Barandiaran, and J. M. Asua, "Entry of hydrophilic radicals into latex particles," Macromolecules, vol. 39, no. 15, pp. 5165-5166, 2006.

[49] K. Tauer, R. Deckwer, I. Kühn, and C. Schellenberg, "A comprehensive experimental study of surfactant-free emulsion polymerization of styrene," Colloid Polym. Sci., vol. 277, no. 7, pp. 607-626, Jul. 1999.

[50] N. M. Beylerian, L. R. Vardanyan, R. S. Harutyunyan, and R. L. Vardanyan, "Kinetics and Mechanism of Potassium Persulfate Decomposition in Aqueous Solutions Studied by a Gasometric Method," Macromol. Chem. Phys., vol. 203, no. 1, pp. 212-218, Jan. 2002. 
[51] I. M. Kolthoff and I. K. Miller, "The Chemistry of Persulfate. I. The Kinetics and Mechanism of the Decomposition of the Persulfate Ion in Aqueous Medium "," J. Am. Chem. Soc., vol. 73, no. 7, pp. 3055-3059, Jul. 1951.

[52] J. M. Asua, Ed., Polymeric Dispersions: Principles and Applications. Dordrecht: Springer Netherlands, 1997.

[53] J. M. Asua, Ed., Polymer reaction engineering. Oxford; Ames, Iowa: Blackwell Pub, 2007.

[54] I. A. Maxwell, B. R. Morrison, D. H. Napper, and R. G. Gilbert, "Entry of free radicals into latex particles in emulsion polymerization," Macromolecules, vol. 24, no. 7, pp. 1629-1640, 1991.

[55] J. M. Asua and J. C. De La Cal, "Entry and exit rate coefficients in emulsion polymerization of styrene," J. Appl. Polym. Sci., vol. 42, no. 7, pp. 1869-1877, avril 1991.

[56] W. V. Smith and R. H. Ewart, "Kinetics of emulsion polymerization," J. Chem. Phys., vol. 16, no. 6 , pp. 592-599, 1948.

[57] I. A. Penboss, R. G. Gilbert, and D. H. Napper, "Entry rate coefficients in emulsion polymerization systems," J. Chem. Soc. Faraday Trans. 1 Phys. Chem. Condens. Phases, vol. 82, no. 7, pp. 2247-2268, 1986.

[58] V. I. Yeliseyeva and A. V. Zuikov, "Emulsion polymerization of polar monomers," Polym. Sci. USSR, vol. 19, no. 11, pp. 3021-3031, 1977.

[59] J. M. H. Kusters, D. H. Napper, R. G. Gilbert, and A. L. German, "Kinetics of particle growth in emulsion polymerization systems with surface-active initiators," Macromolecules, vol. 25, no. 25, pp. 7043-7050, Dec. 1992.

[60] Colombié Damien, E. D. Sudol, and M. S. El-Aasser, "Effect of a Mixed Anionic-Nonionic System of Surfactants on the Entry and Exit of Free Radicals into Polystyrene Particles," Macromolecules, vol. 33, no. 12, pp. 4347-4353, Jun. 2000.

[61] X. Wang, B. Boya, E. D. Sudol, and M. S. El-Aasser, "Effect of a Reactive Surfactant and Its Polymeric Counterpart on the Kinetics of Seeded Emulsion Polymerization of Styrene," Macromolecules, vol. 34, no. 26, pp. 8907-8912, Dec. 2001.

[62] E. M. Coen, R. A. Lyons, and R. G. Gilbert, "Effects of Poly(acrylic acid) Electrosteric Stabilizer on Entry and Exit in Emulsion Polymerization," Macromolecules, vol. 29, no. 15, pp. 5128-5135, Jan. 1996.

[63] I.-W. Cheong and J.-H. Kim, "Effects of surface charge density on emulsion kinetics and secondary particle formation in emulsifier-free seeded emulsion polymerization of methyl methacrylate," Colloid Polym. Sci., vol. 275, no. 8, pp. 736-743, Aug. 1997.

[64] L. Vorwerg and R. G. Gilbert, "Electrosteric Stabilization with Poly(Acrylic) Acid in Emulsion Polymerization: Effect on Kinetics and Secondary Particle Formation," Macromolecules, vol. 33, no. 18, pp. 6693-6703, Sep. 2000.

[65] L. Leemans, R. Jérôme, and P. Teyssié, "Diffusive Radical Entry as the Rate-Determining Step in Amphiphilic Block Polyelectrolyte Mediated Emulsion Polymerization," Macromolecules, vol. 31, no. 17 , pp. 5565-5571, août 1998.

[66] I. A. Maxwell, B. R. Morrison, D. H. Napper, and R. G. Gilbert, "Entry of free radicals into latex particles in emulsion polymerization," Macromolecules, vol. 24, no. 7, pp. 1629-1640, 1991.

[67] R. S. Kshirsagar and G. W. Poehlein, "Radical entry into particles during emulsion polymerization of vinyl acetate," J. Appl. Polym. Sci., vol. 54, no. 7, pp. 909-921, Nov. 1994.

[68] J. Ugelstad and F. K. Hansen, "Kinetics and Mechanism of Emulsion Polymerization," Rubber Chem. Technol., vol. 49, no. 3, pp. 536-609, 1976.

[69] F. K. Hansen and J. Ugelstad, "Particle nucleation in emulsion polymerization. I. A theory for homogeneous nucleation," J. Polym. Sci. Polym. Chem. Ed., vol. 16, no. 8, pp. 1953-1979, 1978.

[70] J. Herrera-Ordóñez and R. Olayo, "On the kinetics of styrene emulsion polymerization above CMC. I. A mathematical model," J. Polym. Sci. Part Polym. Chem., vol. 38, no. 12, pp. 22012218, juin 2000. 
[71] M. Nomura, H. Tobita, and K. Suzuki, "Emulsion Polymerization: Kinetic and Mechanistic Aspects," in Polymer Particles, M. Okubo, Ed. Springer Berlin Heidelberg, 2005, pp. 1-128.

[72] H. F. Hernandez and K. Tauer, "Brownian dynamics simulation studies on radical capture in emulsion polymerization," in Macromolecular symposia, 2007, vol. 259, pp. 274-283.

[73] J. L. Gardon, "Emulsion polymerization. I. Recalculation and extension of the Smith-Ewart theory," J. Polym. Sci. [A1], vol. 6, no. 3, pp. 623-641, 1968.

[74] H. F. Hernández and K. Tauer, "Brownian Dynamics Simulation of the Capture of Primary Radicals in Dispersions of Colloidal Polymer Particles," Ind. Eng. Chem. Res., vol. 46, no. 13, pp. 4480-4485, juin 2007.

[75] K. Tauer and P. Nazaran, "Mechanism and Modeling of Emulsion Polymerization: New Ideas and Concepts - 1. Particle Nucleation," Macromol. Symp., vol. 288, no. 1, pp. 1-8, Feb. 2010.

[76] V. Liotta, C. Georgakis, E. D. Sudol, and M. S. El-Aasser, "Manipulation of Competitive Growth for Particle Size Control in Emulsion Polymerization," Ind. Eng. Chem. Res., vol. 36, no. 8, pp. 3252-3263, août 1997.

[77] L. L. de Arbina, M. J. Barandiaran, L. M. Gugliotta, and J. M. Asua, "Emulsion polymerization: particle growth kinetics," Polymer, vol. 37, no. 26, pp. 5907-5916, 1996.

[78] S. C. Thickett and R. G. Gilbert, "Emulsion polymerization: State of the art in kinetics and mechanisms," Polymer, vol. 48, no. 24, pp. 6965-6991, Nov. 2007.

[79] H. F. Hernandez and K. Tauer, "Radical Desorption Kinetics in Emulsion Polymerization, 2 Brownian Dynamics Simulation of Radical Desorption in Non-Homogeneous Particles," Macromol. Theory Simul., vol. 19, no. 5, pp. 249-257, Apr. 2010.

[80] H. F. Hernandez and K. Tauer, "Radical Desorption Kinetics in Emulsion Polymerization. 1. Theory and Simulation," Ind. Eng. Chem. Res., vol. 47, no. 24, pp. 9795-9811, décembre 2008.

[81] C. Abad, J. C. De La Cal, and J. M. Asua, "Emulsion copolymerization in continuous loop reactors," Chem. Eng. Sci., vol. 49, no. 24, pp. 5025-5037, Dec. 1994.

[82] J. Forcada and J. M. Asúa, "Modeling of unseeded emulsion copolymerization of styrene and methyl methacrylate," J. Polym. Sci. Part Polym. Chem., vol. 28, no. 5, pp. 987-1009, Apr. 1990.

[83] B. S. Casey, B. R. Morrison, and R. G. Gilbert, "The role of aqueous-phase kinetics in emulsion polymerizations," Prog. Polym. Sci., vol. 18, no. 6, pp. 1041-1096, 1993.

[84] S. C. Thickett and R. G. Gilbert, "Rate-Controlling Events for Radical Exit in Electrosterically Stabilized Emulsion Polymerization Systems," Macromolecules, vol. 39, no. 6, pp. 2081-2091, Mar. 2006.

[85] S. C. Thickett, B. Morrison, and R. G. Gilbert, "Particle Size Distributions in Electrosterically Stabilized Emulsion Polymerization Systems: Testing the 'Mid-Chain-Radical' Hypothesis," Macromolecules, vol. 41, no. 10, pp. 3521-3529, May 2008.

[86] S. C. Thickett, M. Gaborieau, and R. G. Gilbert, "Extended Mechanistic Description of Particle Growth in Electrosterically Stabilized Emulsion Polymerization Systems," Macromolecules, vol. 40, no. 13, pp. 4710-4720, Jun. 2007.

[87] R. G. Gilbert, Emulsion polymerization, Academic Press san Diego. 1995.

[88] E. M. Coen, R. G. Gilbert, B. R. Morrison, H. Leube, and S. Peach, "Modelling particle size distributions and secondary particle formation in emulsion polymerisation," Polymer, vol. 39, no. 26, pp. 7099-7112, 1998.

[89] H. F. Hernandez and K. Tauer, "Radical Desorption Kinetics in Emulsion Polymerization. 1. Theory and Simulation," Ind. Eng. Chem. Res., vol. 47, no. 24, pp. 9795-9811, décembre 2008.

[90] J. M. Asua, E. D. Sudol, and M. S. El-Aasser, "Radical desorption in emulsion polymerization," J. Polym. Sci. Part Polym. Chem., vol. 27, no. 12, pp. 3903-3913, 1989.

[91] A. Ghielmi, D. Cuccato, and G. Storti, "Particle State Dependent Radical Desorption and Its Effect on the Kinetics of Emulsion Polymerization," Ind. Eng. Chem. Res., vol. 53, no. 22, pp. 9049-9057, Jun. 2014. 
[92] K. H. S. Chang, M. H. Litt, and M. Nomura, "The Reinvestigation of Vinyl Acetate Emulsion Polymerization (I) - The Rate of Polymerization," in Emulsion Polymerization of Vinyl Acetate, M. S. El-Aasser and J. W. Vanderhoff, Eds. Springer Netherlands, 1981, pp. 89-136.

[93] B. R. Morrison et al., "Free radical exit in emulsion polymerization. II. Model discrimination via experiment," J. Polym. Sci. Part Polym. Chem., vol. 32, no. 4, pp. 631-649, Mar. 1994.

[94] M. Harada, M. Nomura, W. Eguchi, and S. Nagata, "Studies of the Effect of Polymer Particles on Emulsion Polymerization," J. Chem. Eng. Jpn., vol. 4, no. 1, pp. 54-60, 1971.

[95] N. Friis and L. Nyhagen, "A kinetic study of the emulsion polymerization of vinyl acetate," $J$. Appl. Polym. Sci., vol. 17, no. 8, pp. 2311-2327, 1973.

[96] M. Nomura and M. Harada, "Rate coefficient for radical desorption in emulsion polymerization," J. Appl. Polym. Sci., vol. 26, no. 1, pp. 17-26, Jan. 1981.

[97] M. Nomura, "Desorption and Reabsorption," Emuls. Polym., p. 191, 1982.

[98] R. N. Mead and G. W. Poehlein, "Free-radical transport from latex particles," J. Appl. Polym. Sci., vol. 38, no. 1, pp. 105-122, 1989.

[99] I. Lacik, B. S. Casey, D. F. Sangster, R. G. Gilbert, and D. H. Napper, "Desorbed free radicals in emulsion polymerizations: effect of aqueous-phase spin trap," Macromolecules, vol. 25, no. 16, pp. 4065-4072, 1992.

[100] M. C. Grady, "Preparation of \{omega\}-unsaturated Oligo(methyl Methacrylate) Macromer and Its Application in Emulsion Polymerization: Key Learnings about Radical Desorption," 1996.

[101] J. M. Asua, "A New Model for Radical Desorption in Emulsion Polymerization," Macromolecules, vol. 36, no. 16, pp. 6245-6251, août 2003.

[102] C. A. Finch, "Polymer latices: Science and technology. Second edition. Vol. 1, Fundamental principles. Vol. 2, Types of latices. Vol. 3, Applications of latices. D. C. Blackley. Chapman \&amp; Hall, London, 1997. pp. Vol. 1: xvii+557; Vol. 2: xvii+592; Vol. 3: xxi+653, price $£ 370.00$ (set). ISBN: Vol. 1, 041262870 8. Vol. 2, 041262880 5. Vol. 3, 041262890 2,” Polym. Int., vol. 47, no. 1, pp. 85-85, Sep. 1998.

[103] B.-Y. Zhu and T. Gu, "Surfactant adsorption at solid-liquid interfaces," Adv. Colloid Interface Sci., vol. 37, no. 1-2, pp. 1-32, Nov. 1991.

[104] T. R. Paxton, "Adsorption of emulsifier on polystyrene and poly(methyl methacrylate) latex particles," J. Colloid Interface Sci., vol. 31, no. 1, pp. 19-30, Sep. 1969.

[105] W. Brown and J. Zhao, "Adsorption of sodium dodecyl sulfate on polystyrene latex particles using dynamic light scattering and zeta potential measurements," Macromolecules, vol. 26, no. 11, pp. 2711-2715, May 1993.

[106] J. P. H. Zwetsloot and J. C. Leyte, "The Determination of the Adsorption of an Ionic Surfactant on Latex from Conductivity Measurements," J. Colloid Interface Sci., vol. 175, no. 1, pp. 1-5, Oct. 1995.

[107] J. M. Stubbs, Y. G. Durant, and D. C. Sundberg, "Competitive Adsorption of Sodium Dodecyl Sulfate on Two Polymer Surfaces within Latex Blends," Langmuir, vol. 15, no. 9, pp. 32503255, Apr. 1999.

[108] S. F. Turner et al., "Adsorption of Sodium Dodecyl Sulfate to a Polystyrene/Water Interface Studied by Neutron Reflection and Attenuated Total Reflection Infrared Spectroscopy," Langmuir, vol. 15, no. 4, pp. 1017-1023, Feb. 1999.

[109] D. Colombié, K. Landfester, E. D. Sudol, and M. S. El-Aasser, "Competitive Adsorption of the Anionic Surfactant SLS and the Nonionic Surfactant Triton X-405 on Polystyrene Latex Particles," Langmuir, vol. 16, no. 21, pp. 7905-7913, Oct. 2000.

[110] S.-Y. Lin, C. Dong, T.-J. Hsu, and C.-T. Hsu, "Determination of adsorption of an ionic surfactant on latex from surface tension measurements," Colloids Surf. Physicochem. Eng. Asp., vol. 196, no. 2-3, pp. 189-198, Jan. 2002.

[111] J. Sefcik, M. Verduyn, G. Storti, and M. Morbidelli, "Charging of Latex Particles Stabilized by Sulfate Surfactant," Langmuir, vol. 19, no. 11, pp. 4778-4783, May 2003. 
[112] B. Brunier, N. Sheibat-Othman, Y. Chevalier, and E. Bourgeat-Lami, "Partitioning of Laponite Clay Platelets in Pickering Emulsion Polymerization," Langmuir, vol. 32, no. 1, pp. 112-124, Jan. 2016.

[113] B. Brunier, N. Sheibat-Othman, M. Chniguir, Y. Chevalier, and E. Bourgeat-Lami, "Investigation of Four Different Laponite Clays as Stabilizers in Pickering Emulsion Polymerization," Langmuir, vol. 32, no. 24, pp. 6046-6057, Jun. 2016.

[114] I. Langmuir, "THE CONSTITUTION AND FUNDAMENTAL PROPERTIES OF SOLIDS AND LIQUIDS. PART I. SOLIDS.," J. Am. Chem. Soc., vol. 38, no. 11, pp. 2221-2295, Nov. 1916.

[115] Y. Xu, B. Higgins, and W. J. Brittain, "Bottom-up synthesis of PS-CNF nanocomposites," Polymer, vol. 46, pp. 799-810, Jan. 2005.

[116] S. Brunauer, P. H. Emmett, and E. Teller, "Adsorption of Gases in Multimolecular Layers," J. Am. Chem. Soc., vol. 60, no. 2, pp. 309-319, février 1938.

[117] A. Ebadi, J. S. S. Mohammadzadeh, and A. Khudiev, "What is the correct form of BET isotherm for modeling liquid phase adsorption?," Adsorption, vol. 15, pp. 65-73, Feb. 2009.

[118] C. A. Prestidge, T. Barnes, and S. Simovic, "Polymer and particle adsorption at the PDMS droplet-water interface," Adv. Colloid Interface Sci., vol. 108, pp. 105-118, 2004.

[119] J. L. Gardon, "Emulsion polymerization. VI. Concentration of monomers in latex particles," $J$. Polym. Sci. [A1], vol. 6, no. 10, pp. 2859-2879, Oct. 1968.

[120] T. G. T. Jansen, J. Meuldijk, P. A. Lovell, and A. M. van Herk, "On the miniemulsion polymerization of very hydrophobic monomers initiated by a completely water-insoluble initiator: thermodynamics, kinetics, and mechanism," J. Polym. Sci. Part Polym. Chem., vol. 54, no. 17, pp. 2731-2745, Sep. 2016.

[121] K. Tauer and H. F. Hernandez, "Molecular Aspects of Radical Polymerizations-The Propagation Frequency," Macromol. Rapid Commun., vol. 31, no. 5, pp. 419-442, Mar. 2010.

[122] P. J. Flory, Principles of Polymer Chemistry. Ithaca, United States: Cornell University Press, 1953.

[123] M. Morton, S. Kaizerman, and M. W. Altier, "Swelling of latex particles," J. Colloid Sci., vol. 9, no. 4, pp. 300-312, Aug. 1954.

[124] E. Vanzo, R. H. Marchessault, and V. Stannett, "The solubility and swelling of latex particles," J. Colloid Sci., vol. 20, no. 1, pp. 62-71, 1965.

[125] J. Guillot, "Kinetics and thermodynamic aspects of emulsion copolymerization. Acrylonitrilestyrene copolymerization," Acta Polymerica, pp. 593-600, 1981.

[126] I. A. Maxwell, L. F. J. Noel, H. A. S. Schoonbrood, and A. L. German, "Thermodynamics of swelling of latex particles with two monomers: A sensitivity analysis," Makromol. Chem. Theory Simul., vol. 2, no. 2, pp. 269-274, Mar. 1993.

[127] I. A. Maxwell, J. kurja, H. J. gerard, Van Doremael, and A. L. German, "Partial swelling of latex particles with monomers," Die Makromolekulare Chemie, pp. 2049-2063, 1992.

[128] L. F. J. Noel, I. A. Maxwell, and A. L. German, "Partial swelling of latex particles by two monomers," Macromolecules, vol. 26, no. 11, pp. 2911-2918, May 1993.

[129] H. A. S. Schoonbrood, M. A. T. Van Den Boom, A. L. German, and J. Hutovic, "Multimonomer partitioning in latex systems with moderately water-soluble monomers," $J$. Polym. Sci. Part Polym. Chem., vol. 32, no. 12, pp. 2311-2325, Sep. 1994.

[130] S. Omi, Kushibiki, Negishi, and Iso, "A generalized computer modeling of semi batch, ncomponent emulsion copolymerization system and its applications," Tokyo, pp. 34-49, 1985.

[131] P. D. Armitage, J. C. De La Cal, and J. M. Asua, "Improved methods for solving monomer partitioning in emulsion copolymer systems," J. Appl. Polym. Sci., vol. 51, no. 12, pp. 19851990, 1994.

[132] L. M. Gugliotta, G. Arzamendi, and J. M. Asua, "Choice of monomer partition model in mathematical modeling of emulsion copolymerization systems," J. Appl. Polym. Sci., vol. 55, no. 7, pp. 1017-1039, 1995. 
[133] I. A. Maxwell, J. kurja, H. J. gerard, Van Doremael, and A. L. German, "Thermodynamics of swelling of latex particles with two monomers," Die Makromolekulare Chemie, pp. 2065-2080, 1992.

[134] F. K. Hansen, "The function of surfactant micelles in latex particle nucleation," Chem. Eng. Sci., vol. 48, no. 2, pp. 437-444, 1993.

[135] Z. Song and G. W. Poehlein, "Particle Formation in Emulsion Polymerization: Particle Number at Steady State," J. Macromol. Sci. Part-Chem., vol. 25, no. 12, pp. 1587-1632, Jan. 1988.

[136] B. R. Morrison, I. A. Maxwell, R. G. Gilbert, and D. H. Napper, in ACS Symposium Series; American Chemical Society, 1992, pp. 28-44.

[137] J. Ugelstad, M. S. El-Aasser, and J. W. Vanderhoff, "Emulsion polymerization: Initiation of polymerization in monomer droplets," J. Polym. Sci. Polym. Lett. Ed., vol. 11, no. 8, pp. 503513, Aug. 1973.

[138] F. K. Hansen and J. Ugelstad, "The effect of desorption in micellar particle nucleation in emulsion polymerization," Die Makromolekulare Chemie, pp. 2423-2434, 1979.

[139] D. R. Bassett and A. E. Hamielec, Eds., Emulsion Polymers and Emulsion Polymerization, vol. 165. WASHINGTON, D. C.: AMERICAN CHEMICAL SOCIETY, 1981.

[140] K. Tauer and I. Kühn, "Modeling particle formation in emulsion polymerization: an approach by means of the classical nucleation theory," Macromolecules, vol. 28, no. 7, pp. 2236-2239, 1995.

[141] I. Kühn and K. Tauer, "Nucleation in emulsion polymerization: a new experimental study. 1. Surfactant-free emulsion polymerization of styrene," Macromolecules, vol. 28, no. 24, pp. 8122-8128, 1995.

[142] K. Tauer, H. Hernandez, S. Kozempel, O. Lazareva, and P. Nazaran, "Towards a consistent mechanism of emulsion polymerization - new experimental details," Colloid Polym. Sci., vol. 286, no. 5, pp. 499-515, May 2008.

[143] F. K. Hansen and J. Ugelstad, Emulsion polymerization, Academic Press. Piirma, 1982.

[144] J. Ugelstad, P. C. Mork, F. K. Hansen, K. H. Kaggerud, and T. Ellingsen, "Kinetics and mechanism of vinyl chloride polymerization," Pure Appl. Chem., vol. 53, no. 2, Jan. 1981.

[145] A. R. Goodall, M. C. Wilkinson, and J. Hearn, "Mechanism of emulsion polymerization of styrene in soap-free systems," J. Polym. Sci. Polym. Chem. Ed., vol. 15, no. 9, pp. 2193-2218, Sep. 1977.

[146] Z. Song and G. W. Poehlein, "Particle formation in emulsifier-free aqueous-phase polymerization of styrene," J. Colloid Interface Sci., vol. 128, no. 2, pp. 501-510, 1989.

[147] F. K. Hansen and J. Ugelstad, "Particle nucleation in emulsion polymerization. I. A theory for homogeneous nucleation," J. Polym. Sci. Polym. Chem. Ed., vol. 16, no. 8, pp. 1953-1979, 1978.

[148] R. M. Fitch, Polymer colloids: A comprehensive introduction, Academic Press. London, 1997.

[149] F. K. Hansen and J. Ugelstad, "Particle nucleation in emulsion polymerization. II. Nucleation in emulsifier-free systems investigated by seed polymerization," J. Polym. Sci. Polym. Chem. Ed., vol. 17, no. 10, pp. 3033-3045, Oct. 1979.

[150] F. K. Hansen and J. Ugelstad, "Particle nucleation in emulsion polymerization. III. Nucleation in systems with anionic emulsifier investigated by seeded and unseeded polymerization," $J$. Polym. Sci. Polym. Chem. Ed., vol. 17, no. 10, pp. 3047-3067, Oct. 1979.

[151] B. R. Morrison and R. G. Gilbert, "Conditions for secondary particle formation in emulsion polymerization systems," Macromol. Symp., vol. 92, no. 1, pp. 13-30, Apr. 1995.

[152] S. W. Prescott, C. M. Fellows, and R. G. Gilbert, "Maximum Achievable Particle Size in Emulsion Polymerization: Modeling of Large Particle Sizes," Macromol. Theory Simul., vol. 11, no. 2, pp. 163-170, 0212002.

[153] C. J. Ferguson, G. T. Russell, and R. G. Gilbert, "Modelling secondary particle formation in emulsion polymerisation: application to making core-shell morphologies," Polymer, vol. 43, no. 17, pp. 4557-4570, Aug. 2002. 
[154] I.-W. Cheong and J.-H. Kim, "Simulation of secondary particle formation in seeded emulsion polymerization: The effect of surface charge density," Macromol. Theory Simul., vol. 7, no. 1, pp. 49-57, Jan. 1998.

[155] M. Adams, M. Trau, R. Gilbert, D. Napper, and D. Sangster, "The Entry of Free Radicals Into Polystyrene Latex Particles," Aust. J. Chem., vol. 41, no. 12, pp. 1799-1813, Jan. 1988.

[156] Jayasuriya and Ottewill, in Polymer colloids: science and technology of latex systems, Washington: ACS Symposium series (801); Americal Chemical Society, 2002.

[157] Y. Chung-li, J. W. goodwin, and R. H. Ottewill, "Studies on the preparation and characterisation of monodisperse polystyrene latices," in Kolloidchemie heute II, vol. 60, H. W. Kohlschütter, F. H. Müller, and A. Weiss, Eds. Darmstadt: Steinkopff, 1976, pp. 163-175.

[158] J. Zeaiter, J. A. Romagnoli, and V. G. Gomes, International Journal of Chemical Reactor Engineering, p. A2, 2004.

[159] B. Brunier, "Modeling of Pickering Emulsion Polymerization," University Claude Bernard Lyon 1, Lyon, France, 2016.

[160] R. M. Fitch and C. H. Tsai, "Particle Formation in Polymer Colloids, III: Prediction of the Number of Particles by a Homogeneous Nucleation Theory," in Polymer Colloids, R. M. Fitch, Ed. Springer US, 1971, pp. 73-102.

[161] R. M. Fitch and R. C. Watson, "Coagulation kinetics in polymer colloids determined by light scattering," J. Colloid Interface Sci., vol. 68, no. 1, pp. 14-20, 1979.

[162] A. R. Goodall, M. C. Wilkinson, and J. Hearn, "Characterization of Particles During Growth in Emulsifier-Free Emulsion Polymerization of Styrene," in Polymer Colloids II, R. M. Fitch, Ed. Boston, MA: Springer US, 1980, pp. 629-650.

[163] J. W. Goodwin, J. Hearn, C. C. Ho, and R. H. Ottewill, "Studies on the preparation and characterisation of monodisperse polystyrene laticee: III. Preparation without added surface active agents," Colloid Polym. Sci., vol. 252, no. 6, pp. 464-471, Jun. 1974.

[164] H. Schlueter, "Particle formation and catalyzed agglomeration in emulsion polymerization," Macromolecules, vol. 23, no. 6, pp. 1618-1625, Nov. 1990.

[165] A. H. Alexopoulos, P. Pladis, and C. Kiparissides, "Nonhomogeneous Mixing Population Balance Model for the Prediction of Particle Size Distribution in Large Scale Emulsion Polymerization Reactors," Ind. Eng. Chem. Res., vol. 52, no. 35, pp. 12285-12296, Sep. 2013.

[166] S. Fathi Roudsari, R. Dhib, and F. Ein-Mozaffari, "Using a Novel CFD Model to Assess the Effect of Mixing Parameters on Emulsion Polymerization: A Novel CFD Model for Emulsion Polymerization," Macromol. React. Eng., vol. 10, no. 2, pp. 108-122, Apr. 2016.

[167] J. Pohn, M. Cunningham, and T. F. L. McKenna, "Scale-Up of Emulsion Polymerization Reactors Part II - Simulations and Interpretations: Scale-Up of Emulsion Polymerization Reactors Part II ...," Macromol. React. Eng., vol. 7, no. 8, pp. 393-408, Aug. 2013.

[168] S. Melis, M. Verduyn, G. Storti, M. Morbidelli, and J. Baldyga, "Effect of fluid motion on the aggregation of small particles subject to interaction forces," AIChE J., vol. 45, no. 7, pp. 13831393, 1999.

[169] S. Forcolin, A. M. Marconi, A. Ghielmi, A. Butté, G. Storti, and M. Morbidelli, "Coagulation phenomena in emulsion polymerisation of vinyl chloride," Plast. Rubber Compos., vol. 28, no. 3, pp. 109-115, Mar. 1999.

[170] S. Melis, M. Kemmere, J. Meuldijk, G. Storti, and M. Morbidelli, "A model for the coagulation of polyvinyl acetate particles in emulsion," Chem. Eng. Sci., vol. 55, no. 16, pp. 3101-3111, 2000.

[171] M. F. Kemmere, J. Meuldijk, A. A. H. Drinkenburg, and A. L. German, "Aspects of coagulation during emulsion polymerization of styrene and vinyl acetate," J. Appl. Polym. Sci., vol. 69, no. 12, pp. 2409-2421, Sep. 1998.

[172] H. M. Vale and T. F. McKenna, "Population Balance Modeling of Emulsion Polymerization Reactors: Applications to Vinyl Chloride Polymerization," University Claude Bernard Lyon 1, Lyon, France, 2007. 
[173] P. H. H. Araújo, J. C. de la Cal, J. M. Asua, and J. C. Pinto, "Modeling Particle Size Distribution (PSD) in Emulsion Copolymerization Reactions in a Continuous Loop Reactor," Macromol. Theory Simul., vol. 10, no. 8, pp. 769-779, Oct. 2001.

[174] E. Unzueta and J. Forcada, "Modeling the effect of mixed emulsifier systems in emulsion copolymerization," J. Appl. Polym. Sci., vol. 66, no. 3, pp. 445-458, Oct. 1997.

[175] F. Bezzo and S. Macchietto, "A general methodology for hybrid multizonal/CFD models," Comput. Chem. Eng., vol. 28, no. 4, pp. 513-525, Apr. 2004.

[176] F. Bezzo, S. Macchietto, and C. C. Pantelides, "A general methodology for hybrid multizonal/CFD models," Comput. Chem. Eng., vol. 28, no. 4, pp. 501-511, Apr. 2004.

[177] F. Bezzo, S. Macchietto, and C. C. Pantelides, "General hybrid multizonal/CFD approach for bioreactor modeling," AIChE J., vol. 49, no. 8, pp. 2133-2148, Aug. 2003.

[178] J. B. Joshi et al., "CFD simulation of stirred tanks: Comparison of turbulence models (Part II: Axial flow impellers, multiple impellers and multiphase dispersions)," Can. J. Chem. Eng., vol. 89, no. 4, pp. 754-816, Aug. 2011.

[179] M. Smoluchowski, Zeitschrift fuer Physikalische Chemie, pp. 129-168, 1917.

[180] M. Elimelech, J. gregory, X. Jia, and R. A. Williams, Particle Deposition and Aggregation Measurement, Modelling and Simulation, Butterworth-Heinemann. 1995.

[181] N. Fuchs, "Über die Stabilität und Aufladung der Aerosole," Z. Für Phys., vol. 89, no. 11-12, pp. 736-743, Nov. 1934.

[182] E. J. W. Verwey and J. T. G. Overbeek, Theory of the Stability of Lyophobic Colloids. Elsevier, 1948.

[183] M. S. El-Aasser, "Emulsion Polymerization," in An Introduction to Polymer Colloids, F. Candau and R. H. Ottewill, Eds. Dordrecht: Springer Netherlands, 1990, pp. 1-34.

[184] V. Derjaguin and D. Landau, Acta Physicochim., p. 633, 1941.

[185] H. C. Hamaker, "The London — van der Waals attraction between spherical particles," Physica, vol. 4, no. 10, pp. 1058-1072, Oct. 1937.

[186] R. Hogg, T. W. Healy, and D. W. Fuerstenau, "Mutual coagulation of colloidal dispersions," Trans. Faraday Soc., vol. 62, no. 0, pp. 1638-1651, Jan. 1966.

[187] J.-P. Hsu, W.-L. Hsu, and K.-L. Liu, "Diffusiophoresis of a Charge-Regulated Sphere along the Axis of an Uncharged Cylindrical Pore," Langmuir, vol. 26, no. 11, pp. 8648-8658, Jun. 2010.

[188] M. Hütter, "Coagulation rates in concentrated colloidal suspensions studied by Brownian dynamics simulation," Phys. Chem. Chem. Phys., vol. 1, no. 18, pp. 4429-4436, 1999.

[189] A. K. SenGupta and K. D. Papadopoulos, "Stability of Concentrated Colloids: The Controlling Parameters," J. Colloid Interface Sci., vol. 203, no. 2, pp. 345-353, Jul. 1998.

[190] C. J. Meyer and D. A. Deglon, "Particle collision modeling - A review," Miner. Eng., vol. 24, no. 8, pp. 719-730, Jul. 2011.

[191] V. Lowry, M. . El-Aasser, J. . Vanderhoff, A. Klein, and C. . Silebi, "Kinetics of agitationinduced coagulation of high-solid latexes," J. Colloid Interface Sci., vol. 112, no. 2, pp. 521529, Aug. 1986.

[192] V. Lowry, M. S. El-Aasser, J. W. Vanderhoff, and A. Klein, "Mechanical coagulation in emulsion polymerizations," J. Appl. Polym. Sci., vol. 29, no. 12, pp. 3925-3935, Dec. 1984.

[193] R. C. Elgebrandt, J. A. Romagnoli, D. F. Fletcher, V. G. Gomes, and R. G. Gilbert, "Analysis of shear-induced coagulation in an emulsion polymerisation reactor using computational fluid dynamics," Chem. Eng. Sci., vol. 60, no. 7, pp. 2005-2015, Apr. 2005.

[194] M. Lattuada and M. Morbidelli, "Effect of repulsive interactions on the rate of doublet formation of colloidal nanoparticles in the presence of convective transport," $J$. Colloid Interface Sci., vol. 355, no. 1, pp. 42-53, Mar. 2011.

[195] S.-H. Xu, Z.-W. Sun, X. Li, and J. T. Wang, "Coupling effect of Brownian motion and laminar shear flow on colloid coagulation: a Brownian dynamics simulation study," Chin. Phys. B, vol. 21, no. 5, p. 54702, May 2012. 
[196] A. S. Moussa, M. Lattuada, B. Ó. Conchúir, A. Zaccone, M. Morbidelli, and M. Soos, "FlowInduced Aggregation and Breakup of Particle Clusters Controlled by Surface Nanoroughness," Langmuir, vol. 29, no. 47, pp. 14386-14395, Nov. 2013.

[197] P. G. Saffman and J. S. Turner, "On the collision of drops in turbulent clouds," J. Fluid Mech., vol. 1, no. 1, p. 16, May 1956.

[198] D. C. Blackley, Polymer Latices science and technology second edition - volume 1 fundamental principles. London: Chapman \& Hall, 1997.

[199] L. A. Spielman, "Viscous interactions in Brownian coagulation," J. Colloid Interface Sci., vol. 33, no. 4, pp. 562-571, Aug. 1970.

[200] C. Abaé, J. C. De La Cal, and J. M. Asua, "Modelling nucleation and particle growth in emulsion copolymerization in continuous loop reactors," Macromol. Symp., vol. 92, no. 1, pp. 195-204, Apr. 1995.

[201] H. Abedini and M. Shahrokhi, "Simulation and Experimental Evaluation of Initiator and Surfactant Concentrations and Temperature Effects on Styrene Conversion and Polymer Particle Size Distribution in Batch Emulsion Polymerization," Iranian Polymer Journal, pp. 599-614, 2010.

[202] M. Alamir, N. Sheibat-Othman, and S. Othman, "Measurement Based Modeling and Control of Bimodal Particle Size Distribution in Batch Emulsion Polymerization," AIChE J., vol. 56, no. 8, pp. 2122-2136, 2010.

[203] M. Barazandegan, M. Shahrokhi, H. Abedini, and E. Vafa, "Simulation and control of monomer conversion in a continuous emulsion polymerization reactor," IFAC-Pap., vol. 48, no. 8, pp. 315-320, 2015.

[204] T. J. Crowley, E. S. Meadows, E. Kostoulas, and F. J. Doyle III, "Control of particle size distribution described by a population balance model of semibatch emulsion polymerization," $J$. Process Control, vol. 10, no. 5, pp. 419-432, Oct. 2000.

[205] M. T. Dokucu, M.-J. Park, and F. J. Doyle, "Multi-rate model predictive control of particle size distribution in a semibatch emulsion copolymerization reactor," J. Process Control, vol. 18, no. 1, pp. 105-120, Jan. 2008.

[206] M. T. Dokucu, M.-J. Park, and F. J. Doyle, "Reduced-order methodologies for feedback control of particle size distribution in semi-batch emulsion copolymerization," Chem. Eng. Sci., vol. 63, no. 5, pp. 1230-1245, Mar. 2008.

[207] S. Feiz and A. H. Navarchian, "Emulsion polymerization of styrene: Simulation the effects of mixed ionic and non-ionic surfactant system in the presence of coagulation," Chem. Eng. Sci., vol. 69, no. 1, pp. 431-439, Feb. 2012.

[208] M. Fortuny Heredia, "Modelisation de procedes pour la synthese de latex multipopules," Thèse de doctorat, Universite Claude Bernard, Lyon, France, 2002.

[209] J. Herrera-Ordóñez and R. Olayo, "On the kinetics of styrene emulsion polymerization above CMC. II. Comparison with experimental results," J. Polym. Sci. Part Polym. Chem., vol. 38, no. 12, pp. 2219-2231, 2000.

[210] A. Hosseini, A. Eldin Bouaswaig, and S. Engell, "Comparison of classical population balance models of emulsion polymerization with experimental results and a stochastic extension," Chem. Eng. Sci., vol. 72, pp. 179-194, Apr. 2012.

[211] C. D. Immanuel, C. F. Cordeiro, S. S. Sundaram, E. S. Meadows, T. J. Crowley, and F. J. Doyle III, "Modeling of particle size distribution in emulsion co-polymerization: comparison with experimental data and parametric sensitivity studies," Comput. Chem. Eng., vol. 26, no. 7, pp. 1133-1152, 2002.

[212] C. D. Immanuel, F. J. Doyle, C. F. Cordeiro, and S. S. Sundaram, "Population balance PSD model for emulsion polymerization with steric stabilizers," AIChE J., vol. 49, no. 6, pp. 13921404, 2003.

[213] O. Kammona, P. Pladis, C. E. Frantzikinakis, and C. Kiparissides, "A Comprehensive Experimental and Theoretical Investigation of the Styrene/2-Ethylhexyl Acrylate Emulsion Copolymerization,” Macromol. Chem. Phys., vol. 204, no. 7, pp. 983-999, May 2003. 
[214] C. Kiparissides, D. S. Achilias, and C. E. Frantzikinakis, "The Effect of Oxygen on the Kinetics and Particle Size Distribution in Vinyl Chloride Emulsion Polymerization," Ind. Eng. Chem. Res., vol. 41, no. 13, pp. 3097-3109, Jun. 2002.

[215] G. Marinangelo, W. H. Hirota, and R. Giudici, "Semi-batch emulsion copolymerization of styrene and butyl acrylate for production of high solids content latexes: Experiments and mathematical model," Chem. Eng. Sci., vol. 66, no. 23, pp. 5875-5890, Dec. 2011.

[216] E. S. Meadows, T. J. Crowley, C. D. Immanuel, and F. J. Doyle, "Nonisothermal Modeling and Sensitivity Studies for Batch and Semibatch Emulsion Polymerization of Styrene," Ind. Eng. Chem. Res., vol. 42, no. 3, pp. 555-567, Feb. 2003.

[217] S. Melis, A. Ghielmi, G. Storti, and M. Morbidelli, "Aggregation Phenomena in Emulsion Polymerization of Vinyl Chloride," ENTROPIE, pp. 65-72, 1998.

[218] M.-J. Park, M. T. Dokucu, and F. J. Doyle, "Modeling and Sensitivity Analysis of Particle Size Distribution and Chain Length Distribution in a Semibatch Emulsion Copolymerization Reactor," Macromol. Theory Simul., vol. 14, no. 8, pp. 474-490, Oct. 2005.

[219] J. Pohn, M. Heniche, L. Fradette, M. Cunningham, and T. McKenna, "Development of a Computational Framework to Model the Scale-up of High-Solid-Content Polymer Latex Reactors," Chem. Eng. Technol., vol. 33, no. 11, pp. 1917-1930, Nov. 2010.

[220] M. Rajabi-Hamane and S. Engell, "Time optimal production of a specified particle size distribution in emulsion polymerization," Chem. Eng. Sci., vol. 62, no. 18, pp. 5282-5289, 2007.

[221] S. Sajjadi, "Population balance modeling of particle size distribution in monomer-starved semibatch emulsion polymerization," AIChE J., vol. 55, no. 12, pp. 3191-3205, 2009.

[222] E. Saldívar and W. H. Ray, "Mathematical Modeling of Emulsion Copolymerization Reactors: Experimental Validation and Application to Complex Systems," Ind. Eng. Chem. Res., vol. 36, no. 4, pp. 1322-1336, Apr. 1997.

[223] E. Saldívar, O. Araujo, R. Giudici, and C. Guerrero-Sánchez, "Modeling and experimental studies of emulsion copolymerization systems. III. Acrylics: Emulsion Copolymerization Systems. III," J. Appl. Polym. Sci., vol. 84, no. 7, pp. 1320-1338, May 2002.

[224] E. Saldivar, O. Araujo, R. Giudici, and C. Lopez-Barron, "Modeling and experimental studies of emulsion copolymerization systems. II. Styrenics," J. Appl. Polym. Sci., vol. 79, no. 13, pp. 2380-2397, Mar. 2001.

[225] A. Sood, "Particle size distribution control in emulsion polymerization," J. Appl. Polym. Sci., vol. 92, no. 5, pp. 2884-2902, 2004.

[226] A. Sood, "Modeling of the particle size distribution in emulsion polymerization," J. Appl. Polym. Sci., vol. 109, no. 3, pp. 1403-1419, Aug. 2008.

[227] S. J. Sweetman, C. D. Immanuel, T. Malik, S. Emmett, and N. Williams, "Population Balance Model for Emulsion Polymerisation Under Pseudo-Bulk Conditions: Combined Particle Size Distribution and Molecular Weight Distribution," in Macromolecular Symposia, 2006, vol. 243, pp. $159-178$.

[228] M. Wulkow and J. R. Richards, "Evaluation of the Chain Length Distribution in Free-Radical Emulsion Polymerization-The Compartmentalization Problem," Ind. Eng. Chem. Res., vol. 53, no. 18, pp. 7275-7295, May 2014.

[229] J. Zeaiter, A. Bakhtazad, J. A. Romagnoli, G. W. Barton, and V. G. Gomes, "The role of wavenet models in emulsion polymerisation," Powder Technol., vol. 124, no. 3, pp. 212-218, 2002.

[230] A. Urretabizkaia, G. Arzamendi, and J. M. Asua, "Modeling semicontinuous emulsion terpolymerization," Chem. Eng. Sci., vol. 47, no. 9, pp. 2579-2584, 1992.

[231] H. Abedini and M. Shahrokhi, "Inferential closed-loop control of particle size distribution for styrene emulsion polymerization," Chem. Eng. Sci., vol. 63, no. 9, pp. 2378-2390, 2008.

[232] M. Fortuny, C. Graillat, and T. F. McKenna, "Coagulation of Anionically Stabilized Polymer Particles," Ind. Eng. Chem. Res., vol. 43, no. 23, pp. 7210-7219, Nov. 2004.

[233] J. Israelachvili, Intermolecular and surface forces. San Diego: Academic Press, 1992. 
[234] C. D. Immanuel, M. A. Pinto, J. R. Richards, and J. P. Congalidis, "Population balance model versus lumped model for emulsion polymerisation: Semi-batch and continuous operation," Chem. Eng. Res. Des., vol. 86, no. 7, pp. 692-702, Jul. 2008.

[235] N. Lazaridis, A. H. Alexopoulos, E. G. Chatzi, and C. Kiparissides, "Steric stabilization in emulsion polymerization using oligomeric nonionic surfactants," Chem. Eng. Sci., vol. 54, no. 15-16, pp. 3251-3261, juillet 1999.

[236] M. Harada, M. Nomura, H. Kojima, W. Eguchi, and S. Nagata, "Rate of emulsion polymerization of styrene," J. Appl. Polym. Sci., vol. 16, no. 4, pp. 811-833, 1972. 